Academic Dissertation

To be publicly discussed with the permission

of the Faculty of Medicine of the University of Helsinki

in Lecture Hall 1 of Töölö Hospital on June $3^{\text {th }}, 2016$ at 12:00 noon

University of Helsinki 2016

VERLAG JANOS STEKOVICS (Wettin-Löbejün OT Dößel) 
Professor emeritus Juha Hernesniemi, M.D., Ph.D.

Helsinki, Finland

Associate Professor Martin Lehecka, M.D., Ph.D.

Department of Neurosurgery

Helsinki University Central Hospital

Helsinki, Finland

\section{Posterior Cerebral Artery}

Reviewed by:

\section{Aneurysms}

Professor Sami Tetri, M.D., Ph.D.

Department of Neurosurgery

University of Oulu

Oulu, Finland

Associated Professor Sakari Savolainen, M.D., Ph.D.

Department of Neurosurgery

University of Eastern Finland

Kuopio, Finland

To be discussed with:

Professor Dr. med. habil. Andreas Raabe

Department of Neurosurgery

Inselspital, University of Bern

Bern, Switzerland 
2. Literature Review

2.1 Intracranial Aneurysms

2.1.1 Incidence and Prevalence

2.1.2 Diagnosis and Imaging of Intracranial Aneurysms

2.1.3 Risk Factors

2.1.4 Morphology

2.1.5 Histology and Aneurysm Wall Degeneration

2.1.6 Genetics

2.2 Aneurysmal Subarachnoid Hemorrhage

2.2.1 Incidence of Aneurysmal Subarachnoid Hemorrhage

2.2.2 Fatality of Aneurysmal Subarachnoid Hemorrhage

2.3 Microsurgical Anatomy and PCA Aneurysms

2.3.1 Microsurgical PCA Anatomy

2.3.2 Symptoms Associated to PCA Aneurysms

2.3.3 Characteristics of PCA Aneurysms

2.4 Historical Aspects

2.5 Treatment Strategies for PCA Aneurysms

2.5.1 Direct Microsurgical Treatment of PCA Aneurysms

2.5.1.1 Frontolateral Approach to PCA Aneurysms

2.5.1.2 Subtemporal Approach to PCA Aneurysms

2.5.1.3 Posterior Approaches to PCA Aneurysms

2.5.1.4 Revascularization Procedures Applied to PCA Aneurysms

2.5.2 Endovascular Treatment of PCA Aneurysms

2.5.3 Outcome after Posterior Cerebral Artery Aneurysm Treatment 2.5.3.1 Radiological Outcome

Department of Neurosurgery Stroke Center

Bergmannstrost Hospital Halle

Merseburger Straße 165

06112 Halle (Saale)

Germany

3. Aims of the study

4. Patients, Materials and Methods

4.1 Publication I - Characteristics of PCA Aneurysms

4.1.1 Patients

4.1.2 Imaging

4.2 Publication II - Treatment and Outcome of PCA Aneurysms 
4.2.1 Analysis

4.2.2 Patients

4.3 Publication III - Subtemporal Approach to PCA Aneurysms

4.3.1 Patients

4.3.2 Analysis

4.4 Publication IV - Lateral Supraorbital Approach to PCA Aneurysm

4.4.1 Patient History and Imaging

5. Results

5.1 Characteristics of PCA Aneurysms

5.2 Outcome after PCA Aneurysm Treatment

5.2.1 Historical Series (1954-1979)

5.2.2 Distribution of 135 PCA Aneurysms

5.2.3 Clinical Presentation

5.2.4 Microsurgical Treatment

5.2.5 Endovascular Treatment

5.2.6 Conservative Treatment

5.2.7 One-Year Outcome

5.2.8 Complications and Poor Outcome Analyses

5.3 Subtemporal Approach to PCA Aneurysms

5.4 Lateral Supraorbital Approach to PCA Aneurysms

6. Discussion

6.1 Characteristics of PCA Aneurysms

6.2 Treatment Strategies for PCA Aneurysms

6.3 Complications

6.4 Future Aspects of PCA Aneurysm Treatment

7. Conclusion

Acknowledgement

References

Original Publications

Publication

Characteristics of Posterior Cerebral Artery Aneurysms:

An Angiographic Analysis of 93 Aneurysms in 81 Patients

Publication II

Posterior Cerebral Artery Aneurysms -

Treatment and Outcome Analyzes of 121 Patients

Publication III

Subtemporal Approach to Posterior Cerebral Artery Aneurysms

Publikation IV

Lateral supraorbital approach to ipsilateral PCA-P1 and ICA-PCoA aneurysms

\section{List of Original Publications}

Goehre $F$, Jahromi BR, Hernesniemi JA, Elsharkawy $A$, Kivisaari $R$, von und zu Fraunberg $M$, Jääskeläinen JE, Lehto H, Lehecka M: Characteristics of Posterior Cerebral Artery Aneurysms: An Angiographic Analysis of 93 Aneurysms in 81 Patients. Neurosurgery. 75(2):134-143, 2014

Goehre F, Jahromi BR, Lehecka M, Lehto H, Kivisaari $\mathrm{R}$, Andrade-Barazarte $\mathrm{H}$, Ibrahim $\mathrm{T}$, Párraga $\mathrm{RG}$ Ludtka C, Meisel HJ, Koivisto T, von und zu Fraunberg $M$, Niemelä $M$, Jääskeläinen JE, Hernesniemi JA: Posterior Cerebral Artery Aneurysms - Treatment and Outcome Analyzes of 121 Patients. (World Neurosurgery - in press)

Goehre F, Lehecka M, Jahromi BR, Lehto H, Kivisaari $R$, Hijazy $F$, Nayeb $L$, Sugimoto $T$, Morishige $M$, Elsharkawy $A$, von und zu Fraunberg $M$, Jääskeläinen JE, Hernesniemi JA: Subtemporal Approach to Posterior Cerebral Artery Aneurysms. World Neurosurgery. 83(5):842-851, 2015.

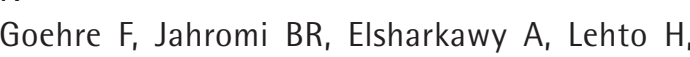
Shekhtman 0, Andrade-Barazarte $H_{1}$ Munoz $F_{\text {, }}$ Hijazy $F$, Mekhkamov M, Hernesniemi JA: Lateral supraorbital approach to ipsilateral PCA-P1 and ICA-PCoA aneurysms. Surgical Neurology International. 6:91, 2015 
BA Basilar artery

CT Computed tomography

CTA Computed tomography angiography

DSA Digital subtraction angiography

ECA External carotid artery

ELANA Excimer laser-assisted nonocclusive anastomosis

HEtH Hunt and Hess

$\mathrm{ICH} \quad$ Intracerebral hematoma

IVH Intraventricular hematoma

LSO Lateral supraorbital approach

MRI Magnetic resonance imaging

MRA Magnetic resonance angiography

MTT Mean transit time

PCoA Posterior communicating artery

P1 P1 segment of posterior cerebral artery

$\mathrm{P} 1 / 2 \quad \mathrm{P} 1 / \mathrm{P} 2$ junction of posterior cerebral artery

P2 P2 segment of posterior cerebral artery

$\mathrm{P} 2 \mathrm{~A} \quad$ Anterior $\mathrm{P} 2$ segment of posterior cerebral artery

P2P Posterior P2 segment of posterior cerebral artery

P3 P3 segment of posterior cerebral artery

P4 P4 segment of posterior cerebral artery

PCA Posterior cerebral artery

PdistAs Aneurysms of P3 and P4 segment of posterior cerebral artery

SAH Subarachnoid hemorrhage

SCA Superior cerebellar artery

SCTTA Supracerebellar transtentorial approach

SDH Subdural hematoma

SV Saphenous vein

\section{Objective:}

Aneurysms of the posterior cerebral artery are rare vascular lesions. The overall incidence is less than $1 \%$, representing around $7 \%$ of posterior circulation aneurysms. Due to this low incidence, most of the institutional series on PCA aneurysms are small and contain less than 25 patients. Only one other series comparable in scope to ours has been previously published. The presented study analyzes and describes the characteristic features of PCA aneurysms as well as investigates the relevant treatment strategies and their outcomes. A particular focus is in the description and analysis of PCA aneurysms treated from a subtemporal approach and the presentation of an associated aneurysm treatment from a lateral supraorbital approach.

Patients and Methods:

We reviewed 121 patients diagnosed with 135 PCA aneurysms, all of whom were treated between 1980 and 2012 at two Finnish neurosurgical units (Department of Neurosurgery at the University of Eastern Finland, Kuopio and Department of Neurosurgery at the University of Helsinki). Additionally, twelve historical (pre-1980) cases were presented. Detailed analyses of cerebral angiographies were conducted for 93 PCA aneurysms in 81 patients. A further subgroup analysis of 34 patients diagnosed with 37 PCA aneurysms treated via subtemporal approach was also performed.

Results:

Of the 121 patients with 135 PCA aneurysms, 52 $(39 \%)$ aneurysms were ruptured and $83(61 \%)$ unruptured. The following distribution along the PCA segments was observed: $P 1$ segment $(n=53), P 1 / 2$ junction ( $n=39), P 2$ segment $(n=28)$, and P3 segment ( $n=15)$; no P4 segment aneurysms were found. Saccular aneurysms were more common than fusiform PCA aneurysms (76\% vs. 24\%). The detailed angiographic analysis showed that the me- dian aneurysm size was $7 \mathrm{~mm}$ for ruptured PCA aneurysms and $4 \mathrm{~mm}$ for unruptured aneurysms. Saccular aneurysms ( $n=69,74 \%)$ had a characteristic dome projection for each location: P1 segment upward (67\%); P1/P2 junction, anterior/upward (80\%); P2 segment, lateral (67\%); and P3 segment, posterior (50\%). The following treatment results at 1-year follow-up were achieved for patients with unruptured PCA aneurysms $(n=19 ; 12$ good outcomes, 63\%; 6 moderate, 31\%; 1 poor, 5\%), ruptured PCA aneurysms ( $\mathrm{n}=27 ; 10 \mathrm{good}, 37 \% ; 9$ moderate, 33\%; 8 poor, 30\%), and patients with complex neurovascular pathologies and PCA aneurysms ( $n=96 ; 42$ good, 43\%; 40 moderate 42\%; 14 poor, 15\%). Analyzing the subtemporal approach we found that most complications were not related to the subtemporal approach itself but to the specific nature of the PCA aneurysms treated and the chosen strategy. The most common (12 out of $34 ; 35 \%$ ) serious complication in this series was an ipsilateral PCA infarction after parent vessel occlusion.

\section{Conclusion:}

PCA aneurysms are infrequent vascular lesions that are often associated with other vascular pathologies. Most ruptured PCA aneurysms are smaller than $10 \mathrm{~mm}$ and distally located. The saccular PCA aneurysms have a typical dome orientation at each PCA segment. Microsurgery and endovascular treatment are effective options for the occlusion of PCA aneurysms. As a result, individual treatment strategies are required. Despite commonly adequate vessel collateralization of the distal PCA territory, preservation or reconstruction of the parent vessel is crucial for favorable treatment outcomes. The subtemporal approach is favorable for the treatment of PCA aneurysms in proximity to the tentorium. Frontolateral approaches allow the treatment of proximal PCA aneurysms and ipsilateral anterior circulation aneurysms inside the Circle of Willis. 


\section{Introduction}

Subarachnoid hemorrhage caused by the rupture of an intracranial aneurysm is a life-threatening event and results in fatality in approximately $40 \%$ of all cases [Nieuwkamp 2009, Steiner 2013]. Metaanalyses show that around 2\% of the population carries an intracranial aneurysm [Nieuwkamp 2009, Steiner 2013]. Different risk factors for aneurysm rupture have been identified such as female gender smoking, older age, hypertension, aneurysmal size and location, and genetic predisposition [Feigin 2005, Juvela 1993, Juvela 2000, Juvela 2003, Linn 1996, Raaymakers 1998, Rinkel 1998].

Aneurysms of the posterior cerebral artery (PCA) are rare and have an overall incidence of less than $1 \%$, representing roughly $7 \%$ of all the aneurysms of the posterior circulation [Drake 1996, Honda 2004, Locksley 1966]. Different, closely related classifications of the PCA segments and affecting aneurysms have been published [Saeki 1977, Seoane 1997]. The most frequently used classification is that of Zeal and Rhoton [Zeal 1978], who divided the artery into four main segments (P1 to P4). We consider aneurysms of the $\mathrm{P} 1$ segment and the $P 1 / 2$ junction as proximal PCA aneurysms belonging to the Circle of Willis and aneurysms of the P2, P3, and P4 segment as distal PCA aneurysms.

\section{Literature Review}

The microsurgical treatment of PCA aneurysms is technical and demanding. During the last three decades, endovascular techniques have evolved rapidly [Ciceri 2001, Hallacq 2002, Molyneux 2002 , Wiebers 2003, van Rooij 2006] and PCA aneurysms that are located close to the brainstem are treated using endovascular techniques at many institutions [Lavine 2007, Cicerini 2001, Halaqc 2002, Rooi] 2006]. Due to their low incidence, most of the institutional series on PCA aneurysms are small and analyze fewer than 25 cases. The largest collection of PCA aneurysms was reported by Drake et al. (1996) and focuses on the surgical treatment and outcome of 125 PCA aneurysms [Drake 1996].

The present study is based on the retrospective analysis of 121 patients with 135 PCA aneurysms along with 12 historical cases, treated at the Department of Neurosurgery at the University of Helsinki between 1954 and 1979. The aim of this study is to provide new information about the special anatomical features of PCA aneurysms and to analyze the applied treatment strategies for the further development of PCA aneurysm management.

\subsection{Intracranial Aneurysms}

\subsubsection{Incidence and Prevalence}

Intracranial aneurysms are present in 2-4\% of the general population [Jellinger 1979, Hausepian 1958, Vernooij 2007, Vlack 2011]. Posterior circuation aneurysms are infrequent with an incidence of 7-10\% and PCA aneurysms are particularly rare with an incidence of 0.5-2.3\% [Ciceri 2001, Drake 1979, Drake 1996, Hallacq 2002, Locksley 1966, Orita 1994, Seoane 1997, Sakata 1993, Terasaka 2000, Yasargil 1984, Zeal 1978]. Multiple aneurysms were found in 18-44\% of all intracranial aneurysm carriers [Inagawa1990/1990, Wilson 1989]. The general incidence of subarachnoid hemorrhage is 6-10/100,000 per year [Anderson 2000, Linn 1996]. Older studies show that in Finland and Japan the incidence rate is much higher at 16-20/100,000 per year [Fogelholm 1993, Inagawa 2001, Ohkuma 2002, Sivenius 2004, Stegmayr 2004]. In recent years the incidence of SAH has decreased dramatically and, at least in Southern Finland, appears to be the same as the frequency reported for western countries. The decline may be due to dietary habits and a dramatic decrease in smoking.

2.1.2 Diagnosis and Imaging of Intracranial Aneurysms

Symptoms

Key symptoms of a ruptured aneurysm are a sudden and severe headache, loss of consciousness, confusion, seizures, nausea, vomiting, cranial nerve disturbance, double vision, light sensitivity and neck stiffness.

Unruptured aneurysms are usually asymptomatic; however, symptomatic unruptured aneurysms can present the following symptoms: pain above and behind the eye, a dilated pupil, a drooping eyelid, visual disturbance, double vision, numbness, weakness or paralysis of one side of the face.

Imaging

Nowadays SAH is usually diagnosed by computed tomography (CT) during the first 6 hours after the incident or lumbar puncture [Backes 2012, Perry 2011]. Computed tomography and magnetic resonance imaging can indicate major vascular lesions on predilection sites. For detailed analysis of the cause of bleeding, further angiographies by computed tomography angiography (CTA) (Fig. 1), magnetic resonance angiography (MRA) or digital subtraction angiography (DSA) is required [Chen 2009, Papke 2007, Villablanca 2005, Wang 2013].

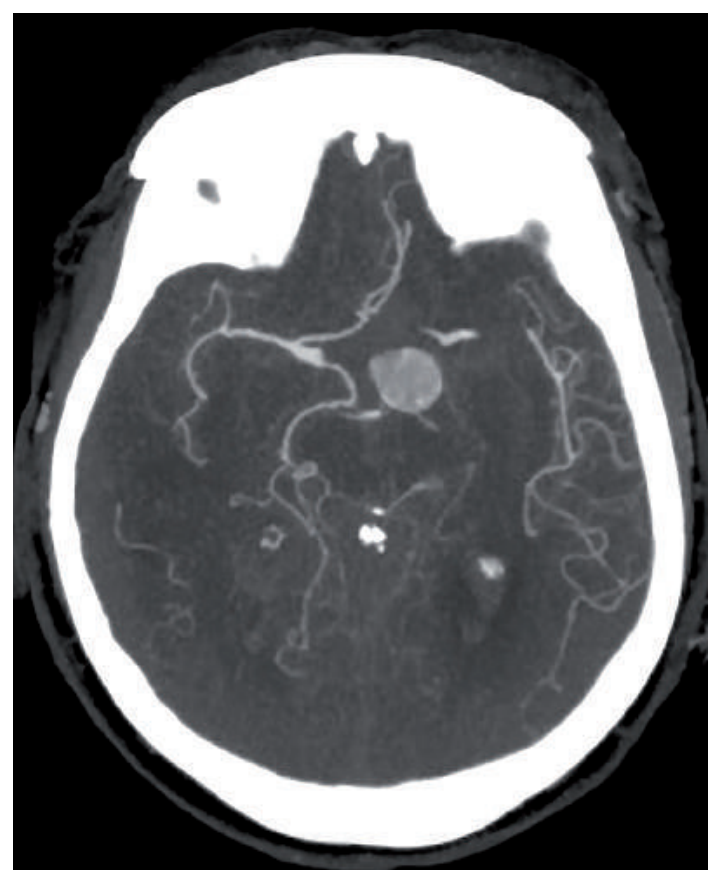

Figure 1. Axial CTA of a ruptured left saccular PCA-P1/2 junction aneurysm. 
The annual rupture rate for previously diagnosed unruptured aneurysms is around 1\% [Juvela 2013] There are modifiable risk factors such as smoking drug abuse and heavy alcohol consumption [Juvela 2001, Korja 2014]. Non-modifiable risk factors include female gender, older age, arteriosclerosis, head injury and infectious disease [Feigin 2005, Juvela 2001, van Gijn 2007]. Treatable risk factors include hypertension and postmenopausal decreased estrogen levels [Feigin 2005, Juvela 2001, van Gijn 2007].

Congenital factors are various inherited connective tissue disorders, polycystic kidney disease coarctation of the aorta and cerebral arteriovenous malformations [Chapman 1992, Connolly 2003, Debette 2014, Meisel 2000]. Risk factors for aneurysm rupture are current smoking, aneurysm size above $7 \mathrm{~mm}$, hypertension, alcohol abuse and aneurysm growth in follow up examinations [Bonita 1986, Knekt 1991, Korja 2014, Lindekleiv 2012, Taylor 1995].

\subsubsection{Morphology}

Aneurysms are basically divided into saccular and fusiform aneurysms. Most intracranial aneurysms are saccular, having a shape reminiscent of a sac pouch or berry. They mostly originate in close relation to arterial bifurcations or major perforating branches from the parent vessel. Fusiform aneurysms are spindle shaped dilations of the artery wall; dilations greater than $1.5 \mathrm{~mm}$ from the norma vessel lumen are considered to be aneurysms [Flemming 2004]. Fusiform aneurysms are uncommon compared to saccular aneurysms [Anson 1996 Dashti 2007]. Fusiform aneurysms can be further subclassified into dissecting (acute and chronic) and atherosclerotic aneurysms based on pathological mechanisms. The vessel course and the lengths of the affected segment allow for an aneurysm description of either dolichoectatic or serpentine. Dolichoectatic aneurysms present a combination of dilatation, elongation and tortuosity of the af fected segment; serpentine aneurysms contain thrombotic material. Large $(15-25 \mathrm{~mm})$ and giant $(>25 \mathrm{~mm}$ ) aneurysms are very rare, representing only around 5\% of all aneurysms [Lonjon 2015].

\subsubsection{Histology and Aneurysm Wall} Degeneration

The wall of an intracranial vessel consist of three layers: an inner layer of endothelial and smooth muscle cells (tunica interna, intima), a middle laye with smooth muscle cells (tunica media, media) and an outer layer of connective tissue (tunica externa, adventitia). The internal elastic lamina, located between the tunica interna and tunica media further stabilizes the artery wall.

Frösen et al. (2004) have analysed the wal structures of intracranial aneurysms and described four wall types of intracranial aneurysms: Type $A$ an endothelialized wall with linearly organized smooth muscle cells; Type $B$, a thickened wall with disorganized smooth muscle cells; Type $C_{\text {, a hypo- }}$ cellular wall; and Type $D$, a thin thrombosis-lined hypocellular wall. Wall types $C$ and $D$ are predominant in ruptured saccular aneurysms. In general, the walls of ruptured saccular aneurysms feature apoptosis, de-endothelialization, luminal thrombosis, smooth muscle cell proliferation and T-cell and macrophage infiltration [Frösen 2004].

Endothelial defects, blood clotting and intraluminal thrombus formation are associated with aneurysm wall degeneration and subsequen aneurysm rupture [Frösen 2004, Kataoka 1999]. Endothelium or tunica media injuries or defects lead to consequential pathological changes in the selfrepair of these layers [Newby 2000]. In response to the respective loads, self-remodeling results in partial wall stabilization [Frösen 2012, Sawabe 2010] However, these are not always effective [Bäck 2010 Bruno 1998, Frösen 2004, Kataoka 1999, Migniatt 1993]. Apoptosis processes are substantially involved in the degeneration of the wall [Chou 2008, Guo 2007, Miller 2011, Sakaki 1997]. Inflammatory cellular responses play an important role in aneurysm wall degeneration [Chyatte 1999, Crompton 1966, Frösen 2004, Kataoka 1999]. Oxidized LDL accumulates in the aneurysm wall of most rup- tured saccular aneurysms. Saccular aneurysm wall remodelling is associated with changes in growth factor receptor expression. Protein kinases and complementary activation by multiple activators are involved in the degeneration of the aneurysm wall and the consecutive growth and rupture of intracranial aneurysms [Laaksamo 2008, Tulamo 2006/2010/2010].

In fusiform acute dissecting aneurysms, an internal elastic membrane defect is what leads to an intramural haematoma. In the chronic phase of these aneurysms, there is an intramural thrombus formation and neovascularization, resulting in new haemorrhages within the affected vessel wall [Nakatomi 2000]. The aneurysm wall is a heterogeneous and dynamic system with a continuous remodelling process.

\subsubsection{Genetics}

Intracranial aneurysms are associated with heritable connective tissue diseases like autosomal dominant polycystic kidney disease, Ehlers-Danlos syndrome type IV and neurofibromatosis type I [Chapman 1992, Debette 2014]. The risk of having an intracranial aneurysm is higher in families having two or more members already affected by an intracranial aneurysm. This is also associated with an increased risk of SAH [Ronkainen 1993/1999]. The "Nordic Twin Study" shows that genetic factors play only a minimal role in the etiology of aneurysmal SAH [Korja 2010]. The association of gene loci $8 q$ and $9 \mathrm{q}$ with intracranial aneurysms has been previously described [Helgadottir 2008, Yasuno 2008, Bilguvar 2008]. However, these gene loci are also associated with other cardiovascular pathologies in general. Based on family history, association with heritable connective tissue diseases and personal risk factors, an active screening with non-invasive vascular imaging (MRA) is justified for this population.
2.2 Aneurysmal Subarachnoid Hemorrhage

2.2.1 Incidence of Aneurysmal Subarachnoid Hemorrhage

Subarachnoid hemorrhage causes 5-10\% of all strokes [Johnston 1998, Kosierkiewicz 1994]. The incidence of subarachnoid hemorrhage is around 6-10 persons per 100,000 annually [Anderson 2000 Linn 1996]. Subarachnoid hemorrhage can be caused by aneurysm rupture ( $80 \%$ of cases), AVM rupture $(5 \%)$ or an unknown cause $(15 \%)$ [Ronkainen 1992, Schievink 1997]. The general mortality associated with subarachnoid hemorrhage is $30-40 \%$, followed by a high percentage of patients (around 20\%) who subsequently require assistance for daily living [Nieuwkamp 2009, Steiner 2013] The occurrence rate in younger, working age individuals is high and results in a significant loss of productive life years [Johnston 1998, Rivero-Arias 2009]

2.2.2 Fatality of Aneurysmal Subarachnoid Hemorrhage

Mortality

Unselected historical analyzes provide crucial information about the natural history of aneurysmal SAH fatalities [Pakarinen 1967]. The first day mortality rate is very high at $32 \%$, and rises steadily over time to $46 \%$ within the first week, 56\% within the first month and 60\% after 6 months [Pakarinen 1967].

Even today, the mortality rate is very high at around $40 \%$ despite modern diagnostic and treatment methods [Nieuwkamp 2009, Steiner 2013]. One reason is fatality resulting from the initia bleeding [Fogelholm 1993]. About 12-15\% of patients in western countries are unable to reach medical treatment before their resulting death [Huang 2002, Pobereskin 2001].

\section{Rebleeding}

A second hemorrhage occurs in 4-12\% of patients during the first 24 hours [Inagawa 1987, Juvela 1989, Kassell 1983, Pakarinen 1967, Starke 2011]. 
The first 6 hours are especially critical [Starke 2011] During the next four weeks the daily rebleeding risk remains at $1-2 \%$. The rebleeding risk during the first year decreases to $3 \%$ annually.

\section{Vasospasm}

Cerebral vasospasm is defined as delayed reactive contraction of the affected vessels, which reduces the distal blood flow. The incidence is high at $50-75 \%$ and around 50\% of these patients are clinically symptomatic [Inagawa 1990, Kassell 1985]. Around 15\% of patients with SAH are affected by permanent neurologic deficits from cerebral vasospasm [Haley 1992, Longstreth 1993] and a fatal outcome is also possible. The critical time period is between the $4^{\text {th }}$ and $12^{\text {th }}$ day after the initial bleeding [Weir 1978]. Vasospasm can be detected by transcranial Doppler ultrasound (TCD) CTA, DSA and CT perfusion imaging. In particular, the initial amount of SAH in the cisterns allows prediction of vasospasm [Fisher 1980]. An active treatment can reduce the rate of ischemic complications related to cerebral vasospasm. Nimodipine has been shown to improve neurologic outcome and decrease the incidence of cerebral vasospasm [Dorhout Mees 2007]. Classically, the "triple H therapy" of hypervolemia, induced hypertension and slight hemodilution is used as the treatment basis after occlusion of the ruptured aneurysm [Lee 2006].

\section{Hydrocephalus}

Treatment requiring hydrocephalus occurs in around $10-30 \%$ of patients following SAH [de Oliveir 2007. Erixon 2014]. The subarachnoid blood clot can disturb CSF circulation and resorption. This can lead to an acute hydrocephalus, which is a leading cause of intracranial hypertension in the early phase after aneurysm rupture. The acute hydrocephalus can be detected in the primary $\mathrm{CT}$ scans and should be treated immediately.

\section{Medical Complications}

ECG abnormalities following SAH are common and include: prolonged $\mathrm{O}-\mathrm{T}$ interval, inverted t-waves and increased $\mathrm{U}$ waves. Cardial dysrhythmia may cause some of the sudden deaths following SAH. Acute SAH can cause a neurogenic pulmonary edema with an increased risk for pneumonia [Weir 1978]. Hyponatremia and natriuresis are other common problems following SAH. Hyponatremia should be corrected by fluid replacement, not by fluid restriction, due to decreased plasma volume.

2.3 Microsurgical Anatomy and PCA Aneurysms

\subsubsection{Microsurgical PCA Anatomy}

The posterior cerebral artery is the terminal branch of the basilar artery and supplies the posterior aspects of the hippocampus, thalamus, midbrain choroid plexus and a part of the lateral cerebra surface [Adamczyk 2014, Erdem 1993, Kocaeli 2013, Margolis 1972, Milisavljevic 1986, Percheron 1973 Zeal 1978]. During embryological development, the posterior cerebral artery arises from the interna carotid artery (ICA) [Padget 1948, Zeal 1978]. Several different closely related classifications of the PCA have been proposed [Saeki 1977, Seoane 1997]. The most frequently used is that of Zeal and Rhoton [Zeal 1978] who divided the artery into four main segments (Fig. 2)

The $\mathrm{P} 1$ segment is localized between the origin of the PCA at the bifurcation of the basilar artery and the posterior communication artery ( $\mathrm{PCOA})$ The cerebral peduncle forms the medial border of the P1 segment (Fig. 3, 4); the oculumotor nerve runs laterally and inferiorly to the P1. The feta configuration consists of a dominant PCoA and has been observed in $16-22 \%$ of brains in cadaveric studies [Padget 1948, Párraga 2011, Saeki 1977 , Zeal 1978]. The average length of the $P 1$ is $7.7 \mathrm{~mm}$ (range 4-20 mm) according to Párraga et al. [Párraga 2011]. Thalamoperforating branches originate mostly from the medial third of the P1 segment and also posteriorly from the lateral third with an average of 3 branches (range 1-10 branches) [Párraga 2011]. Additionally, the shor and long circumflex arteries usually arise from the P1 segment.

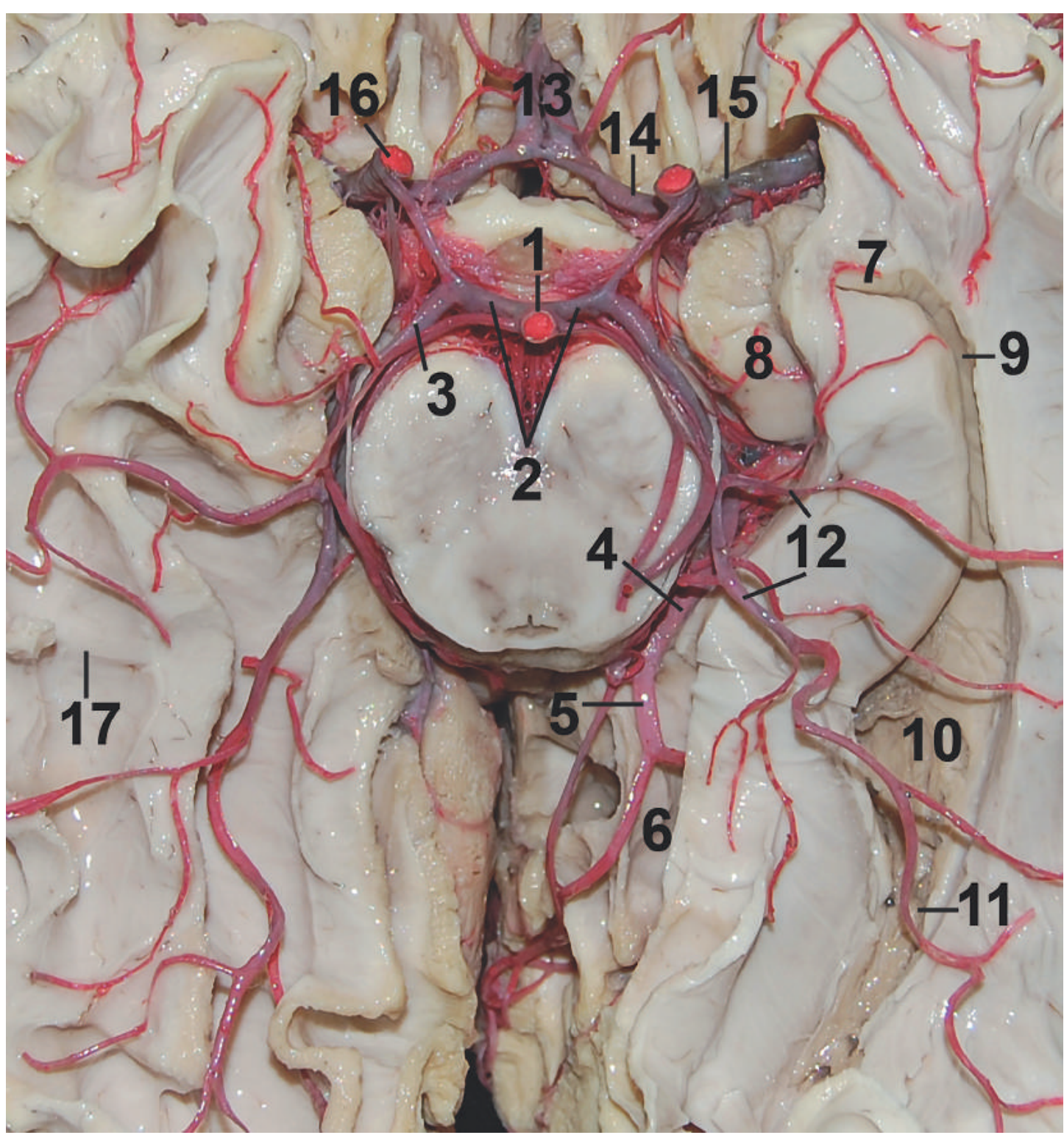

Figure 2. Dissection of the basal surface of the brain in Klingler's technique under preservation of the PCA. The brainstem is sectioned at the level of the pontonethe is section at the lise disclose the inferior longituding pasiculus, hippocampus, calne bavis, atrium, 2A segment; 4, PCA-P2P segment; 5, PCA-P3 segment; 6, Calcarine fissure with calcarine artery, PCA-P4 segment 7, Amygdala; 8, Hippocampus head; 9, Temporal horn; 10, Ventricular atrium; 11, Occipital horn; 12, Temporal arteries; 13, ACA-A2 segment; 14, ACA-A1 segment; 15, MCA-M1 segment; 16, ICA; 17, Arcuate fibers)

Iprovided by Dr. Richard Gonzalo Parraga with personal approval, Reprinted from Publication: Párraga RG, Ribas GC, Andrade $\mathrm{SE}$, de Oliveira E: Microsurgical anatomy of the posterior cerebral artery in three-dimensional images. World Neurosurg. 2011;75:233-257, with permission from Elsevier]. 


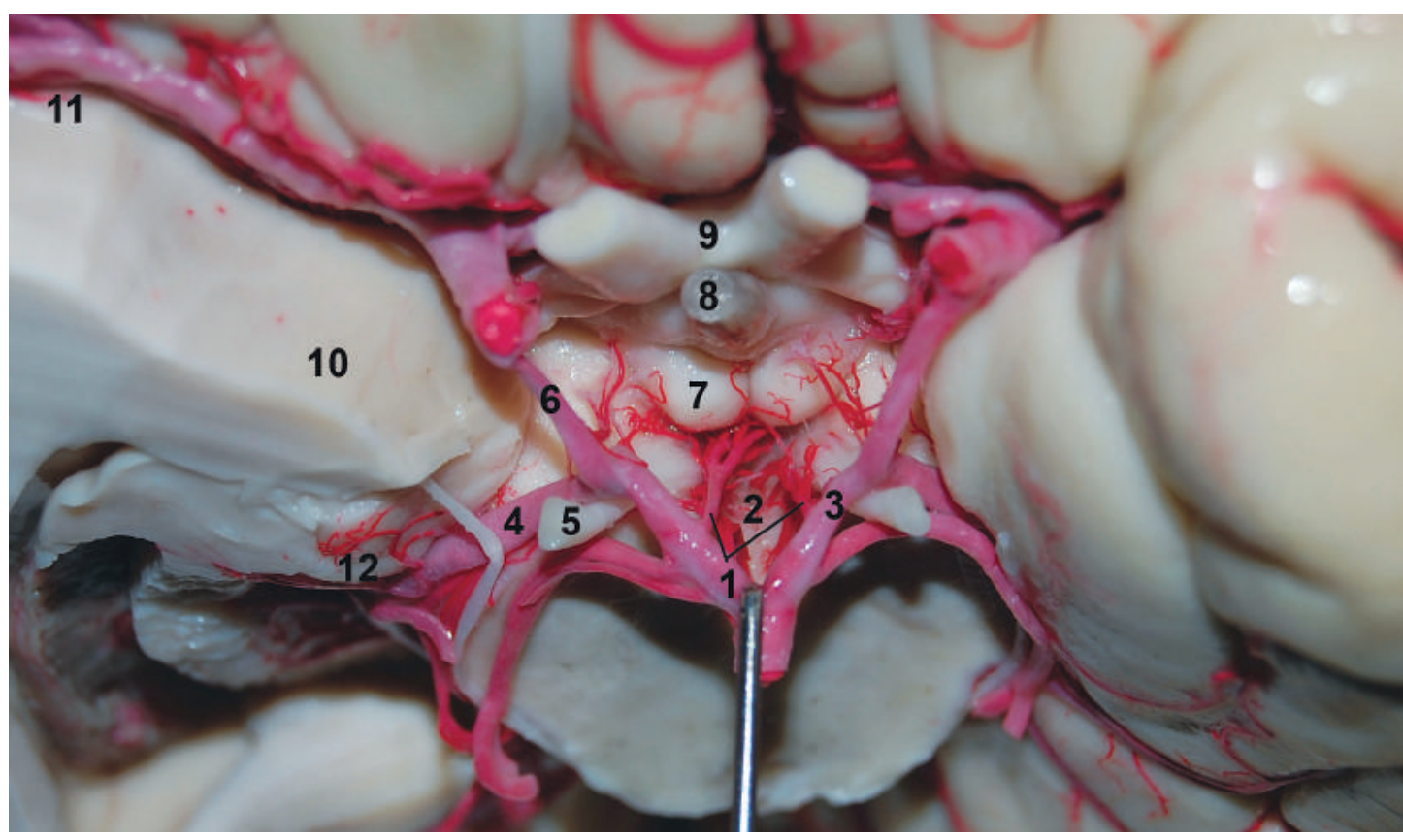

Figure 3. Anteroinferior view of the brain with dissection of the temporal lobe exposing the amygdala. The basila bifurcation is retracted with a dissector to showcase the thalamoperforating arteries originating along the superior surface of the right P1 segment and posterior surface of the left P1 segment, then traveling posteriorly toward the posterio perforated substance. The mamillary perforating branches arise along the middle third of the posterior communicating artery. (1, Thalamoperforating arteries; 2, Posterior perforated substance; 3, PCA-P1 segment; 4, PCA-P2A segment; 5, Oculomotor nerve; 6, Posterior communicating artery; 7, Mamillary body; 8, Pituitary stalk; 9, Optic chiasm; 10, Amygdala; 11, Limen insulae; 12, Hippocampus head)

[provided by Dr. Richard Gonzalo Párraga with personal approval, Reprinted from Publication: Párraga RG, Ribas GC, Andrade $\mathrm{SE}$, de Oliveira E: Microsurgical anatomy of the posterior cerebral artery in three-dimensional images. World Neurosurg 2011;75:233-257, with permission from Elsevier].

The P2 section consists of the segment extending from the PCoA to the point where it leaves the midbrain and runs through the peduncular and ambient cisterns (Fig. 5). Zeal and Rhoton further subdivided this segment into the anterior (P2A) and posterior (P2P) subsegments. The anterior subsegment begins at the PCoA and ends at the most lateral aspect of the cerebral peduncle [Párraga 2011]. The average length of the P2A subsegment is $23.6 \mathrm{~mm}$ (range $18-30 \mathrm{~mm}$ ) with an average diameter of $1.7 \mathrm{~mm}$ (range 1-3 $\mathrm{mm}$ ) [Párraga 2011]. The posterior subsegment (P2P) begins where the PCA resumes its course along the posterior edge of the lateral surface of the midbrain. The average length of the P2P subsegment is $1.4 \mathrm{~mm}$ (range 9-25 $\mathrm{mm}$ ) with a diameter of $1.4 \mathrm{~mm}$ (range 0.8-2 mm) [Párraga 2011]. Perforators from this segment include the peduncle perforating arteries and thalamogeniculate arteries. The medial posterior choroidal arteries arise mainly from the P2A segment, as does the first cortical branch. The lateral posterior choroidal arteries arise from the P2P subsegment In addition, the inferior temporal arteries also arise from the $\mathrm{P} 2$ segment.

The PCA segment between the inferior temporal arteries and the origin of the parieto-occipital and calcarine arteries constitutes the P3 segment. The perforators arising from this segment are the infe-

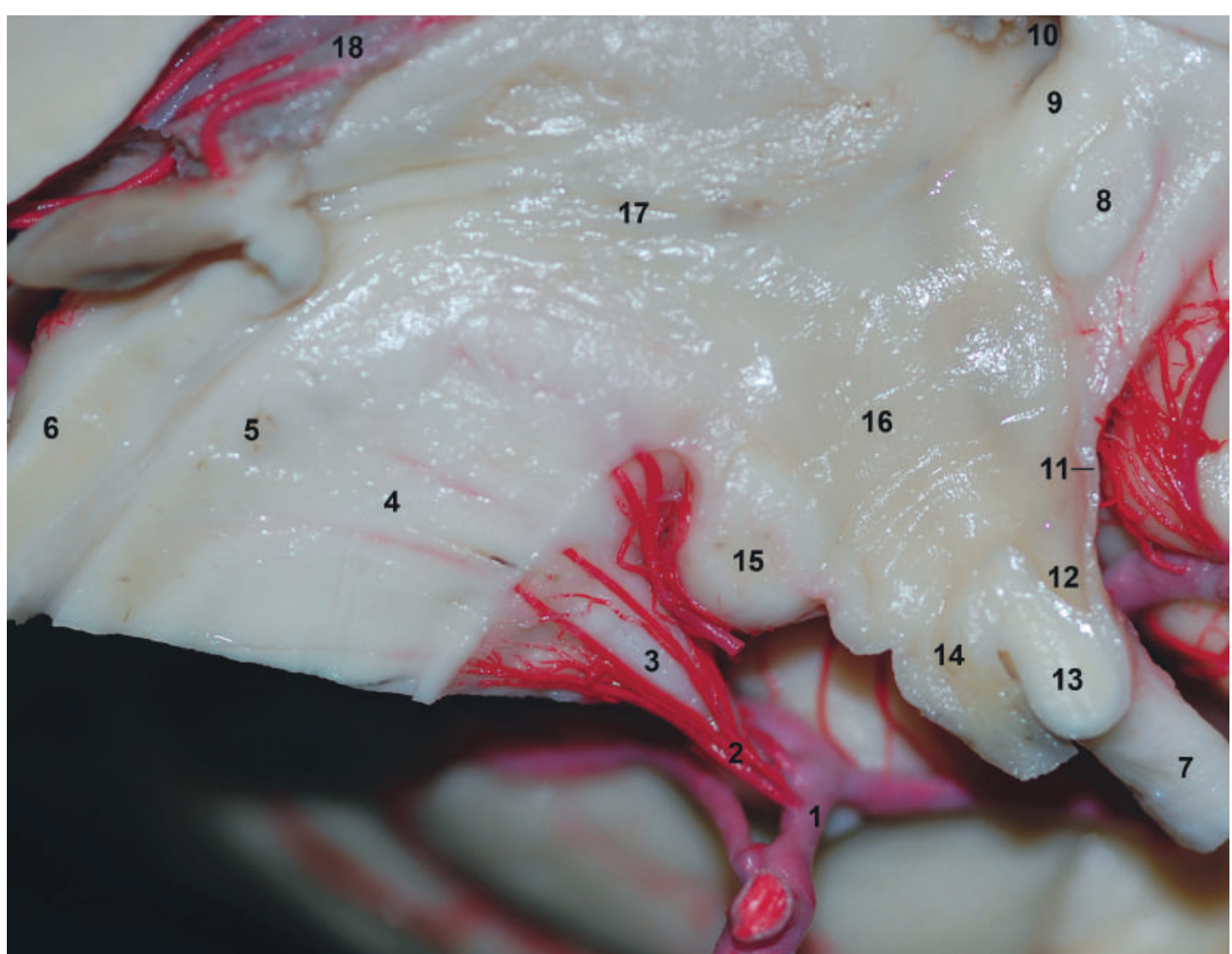

Figure 4. A view of the medial surface of the left hemisphere with magnification of the third ventricle and thalamoperforating arteries traveling toward the mesencephalic periaqueductal gray substance. (1, PCA-P1 segment; 2, Thalamoperforating arteries; 3, Oculomotor nerve; 4, Mesencephalic tegmentum; 5, Periaqueductal gray substance; 6, Quadrigeminal plate; 7, Optic nerve; 8, Anterior commissure; 9, Fornix column; 10, Foramen of Monro; 11, Lamina terminalis; 12, Chiasmatic recess; 13, Optic chiasm; 14, Infundibular recess; 15, Mamillary body; 16, Third ventricle; 17, Hypothalamic sulcus; 18, Velum interpositum cistern

[provided by Dr. Richard Gonzalo Párraga with personal approval, Reprinted from Publication: Párraga RG, Ribas GC, Andrade SE, de Oliveira E: Microsurgical anatomy of the posterior cerebral artery in three-dimensional images. World Neurosurg. 2011;75:233-257, with permission from Elsevier].

rior temporal branches and the posterior pericallosal artery. This segment has an average length of $19.8 \mathrm{~mm}$ (range $9-30 \mathrm{~mm}$ ) and an average diameter of $1.1 \mathrm{~mm}$ (range 0.5-1.5 mm) [Párraga 2011]. The point where the left and right posterior cerebral arteries are closest is known as the "collicular point". This distance has been estimated to range from 2-35 mm [Margolis 1972, Párraga 2011, Zeal 1978]. The majority of the cortical PCA branches at the lateral cerebral surface typically have a diameter of 0.4-0.6 mm [Zeal 1978].

The P4 segment consists of the terminal cortical branches such as the parietooccipital arteries, the calcarine arteries and the cortical branches. The P4 vessels supply the cuneus, the posterior aspect of the lingual gyrus and the occipital pole, including the primary visual cortex. The parietooccipital artery is one of the major terminal branches and lies in or 


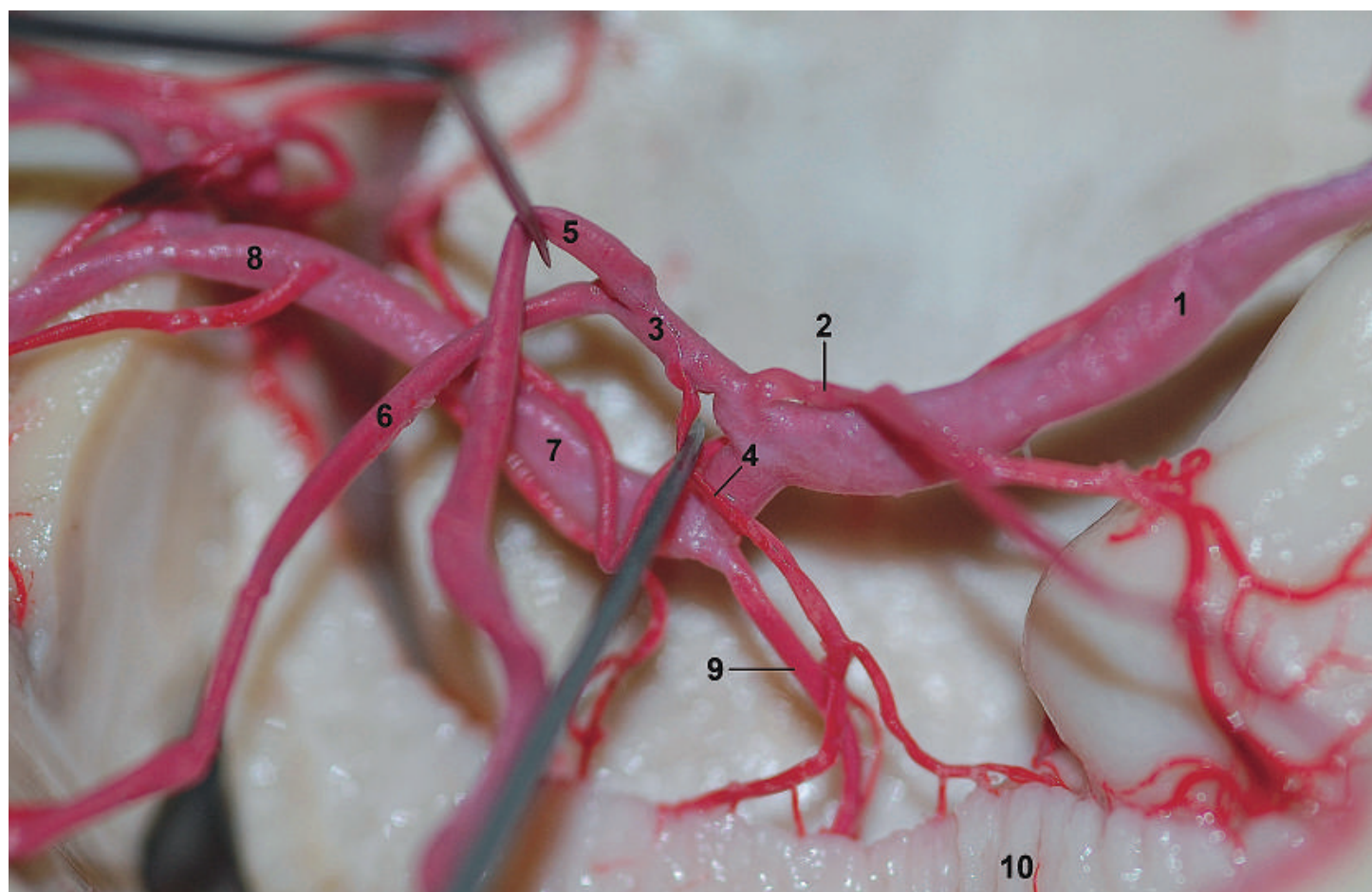

Figure 5. Inferior view showing the common temporal artery originated at the transition between the $P 2 A$ and $P 2 P$ segments. The hippocampal artery originates from the common temporal artery: the posterolateral choroidal artery from the P2P segment. (1, P2A segment; 2, anterior temporal artery; 3, common temporal artery; 4, hippocampal artery; 5, media temporal artery; 6 , posterior temporal artery; 7, P2P segment; 8, P3 segment; 9, posterolateral choroidal artery; 10, dentate gyrus)

Iprovided by Dr. Richard Gonzalo Párraga with personal approval, Reprinted from Publication: Párraga RG, Ribas GC, Andrade $\mathrm{SE}$, de Oliveira E: Microsurgical anatomy of the posterior cerebral artery in three-dimensional images. World Neurosurg. 2011;75:233-257, with permission from Elsevier].

along the parietooccipital sulcus. The posterior pericallosal artery usually originates from the parietooccipital artery that anastomoses with the anterior pericallosal artery. A second terminal branch is the calcarine artery and runs in or along the calcarine sulcus to supply the cuneus and the lingual gyrus, as well as the visual cortex.

Important collaterals to the PCA territory come from the anterior pericallosal artery (ACA), the supracerebellar artery (SCA), anterior choroidal artery (ICA) and superior temporal branches (MCA).

2.3.2 Symptoms Associated to PCA Aneurysms

Most patients with PCA aneurysms are symptomatic of SAH following aneurysm rupture. The distribution pattern can be different between proximal (Fig. 6A) and distal (Fig. 6B) PCA aneurysms. PCA aneurysms are often associated with other intracranial vascular lesions such as: moyamoya, arterial occlusions, multiple aneurysms and AVM [Drake 1996, Honda 2004 Sawada 1998]. Therefore, many PCA aneurysms were detected by vascular imaging for these lesions. Symptoms of ischemia are relatively often associated with thrombosed large and giant aneurysms
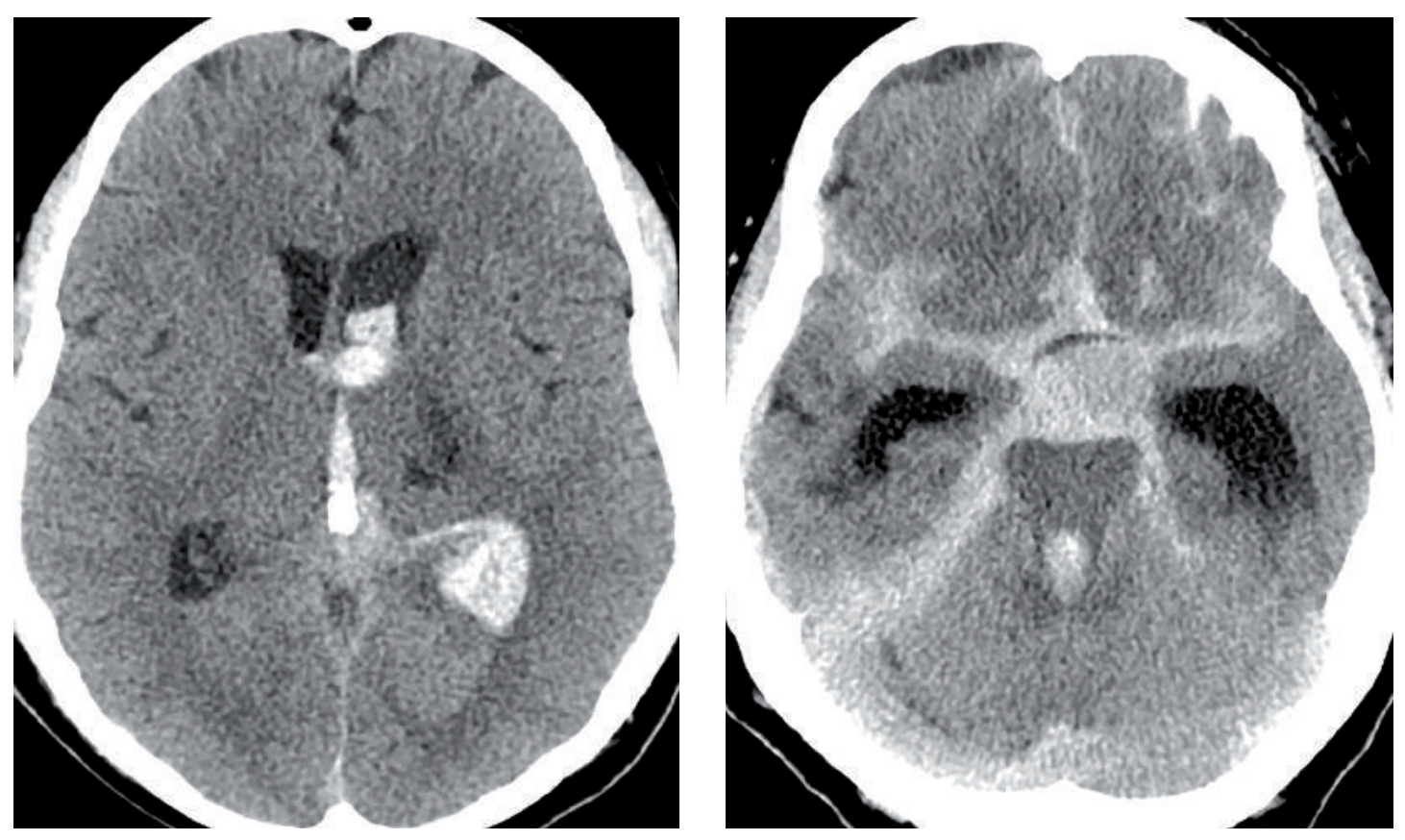

Figure 6. SAH caused by a left PCA-P3 (A) and a PCA-P1/2 junction aneurysm rupture (B).

[Drake 1996]. Due to the close anatomical relationship, affection of the oculomotor nerve is also a common sign, especially for proximal PCA aneurysms. Symptoms of visual disturbance, memory disturbance, seizures and temporal pain have been described for PCA aneurysms with mass effect [Drake 1996, Honda 2004].

2.3.3 Characteristics of PCA Aneurysms

Previously reported series have a high proportion of large and giant PCA aneurysms. Additionally, fusiform PCA aneurysms were commonly observed [Drake 1996]. In general, the proportion of proximal PCA aneurysms is predominant [Drake 1996, Yonekawa 2011]. 
Following the development of cerebral angiography by Moniz in 1933, Krayenbühl was able to angiographically diagnose the first posterior circulation aneurysm in 1941, located at the basilar artery [Krayenbühl 1941, Moniz 1933]. The first direct treatment for an angiographically diagnosed aneurysm was carried out by the team of DeSaussure in 1956 [DeSaussure 1958]. However, the microsurgical treatment of posterior circulation aneurysms was significantly influenced by Charles Drake, who summarized his experience together
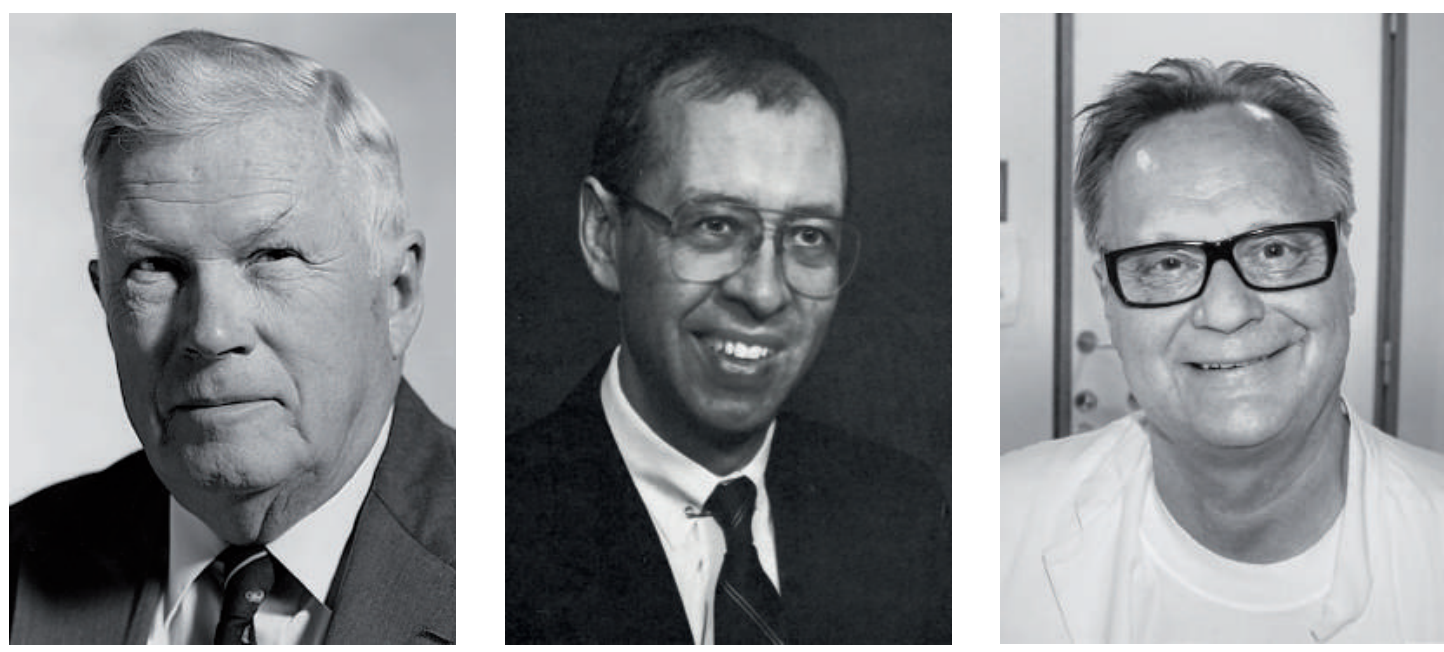

Figure 7. Charles G. Drake

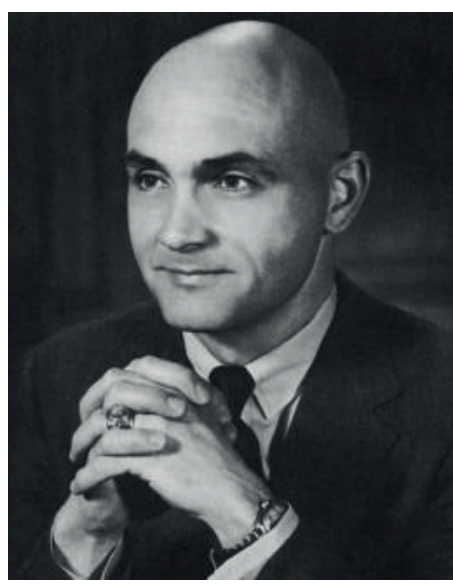

Thoralf M. Sundt Jr. . 7) [Drake 1988/1996, Kassell 1999].

Furthermore, we must remember that J. Ausman and T. Sundt, Jr. contributed to the developmen of revascularization procedures applied to the posterior circulation (Fig. 8) [Ausman 1976/1981/1981 Kelly 1989, Sundt 1978/1981/1982]. They described posterior circulation, bridging procedures between SCA and PCA as well as even presenting high flow augmentation in the form of an ICA-SV-PCA bypass in 1982 [Sundt 1981/1982]

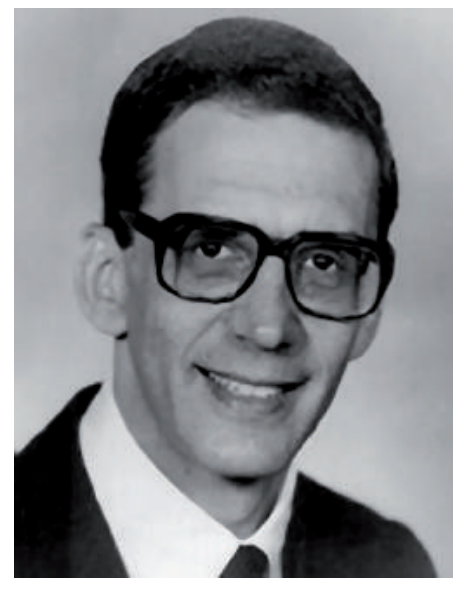

Figure 8. James I. Ausman
Nowadays various open microsurgical and endovascular methods are available for the occlusion of PCA aneurysms. Clip occlusion, wrapping, proximal occlusion, trapping, trapping after bypass bridging and aneurysmorrhaphy of these aneurysms is possible by open microsurgery. Using endovascular techniques such as direct coil occlusion, balloon assisted coiling and stent assisted coiling, proximal occlusion, aneurysm coiling with parent vessel occlusion and combinations with bypass procedures are well described. Due to the low incidence of PCA aneurysms, it is an accurate assessment that comparative trials are not feasible.

\subsection{Direct Microsurgical Treatment of PCA} Aneurysm

The PCA aneurysm configuration and exact location in relation to skull base structures is particularly important when choosing the microsurgical approach. Each of approaches described hereafter are demanding due to the deep anatomical location of the PCA and the narrowed surgical corridor.

Irrespective of the approach selected, the following key points are always important:

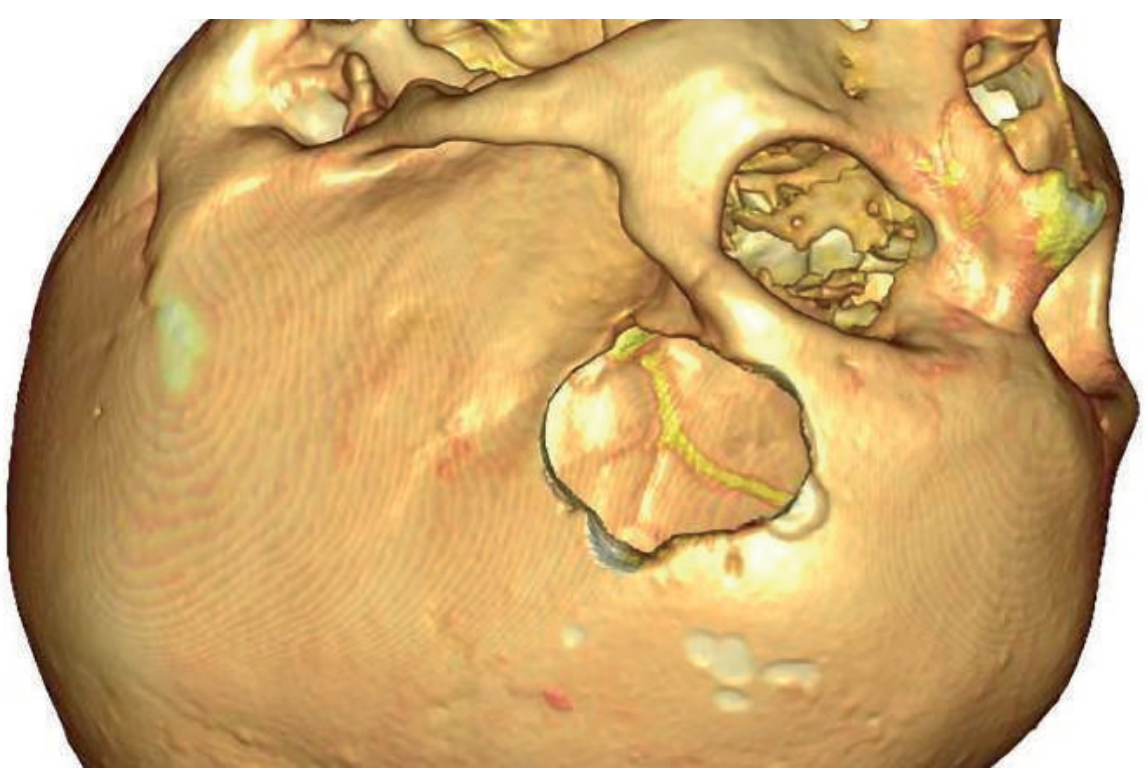

Figure 9. 3D CT of LSO for a left-sided approach.
- avoidance of injury to the temporal lobe from retraction,

- prevention of injury to the venous system

- prevention of injury to the brainstem perforators,

- securement of a sufficient perfusion of the PCA territory while preventing PCA infarctions.

2.5.1.1 Frontolateral Approach to PCA Aneurysms

Several frontolateral approaches are described for the treatment of the proximal PCA aneurysms such as the pterional approach [Yasargil 1976, Yonekawa 1999, Yonekawa 2011], lateral supraorbital or extended lateral supraorbital approach [Goehre 2015, Hernesniemi 2005] anterior temporal approach [Goehre 2016, Sundt 1990] and orbitozygomatic approach [Gerber 1993, Hakuba 1986]. For the treatment of multiple intracranial aneurysms in particular, these frontolateral approaches provide access to the intracranial ICA, the ACA-A1 segment, the ACOA complex and proximal ACA-A2 segments, the MCA$M 1$, the MCA-bifurcation and the M2 segments.

Positioning, Skin Incision, \&t Craniotomy

The patient is placed in the supine position with 

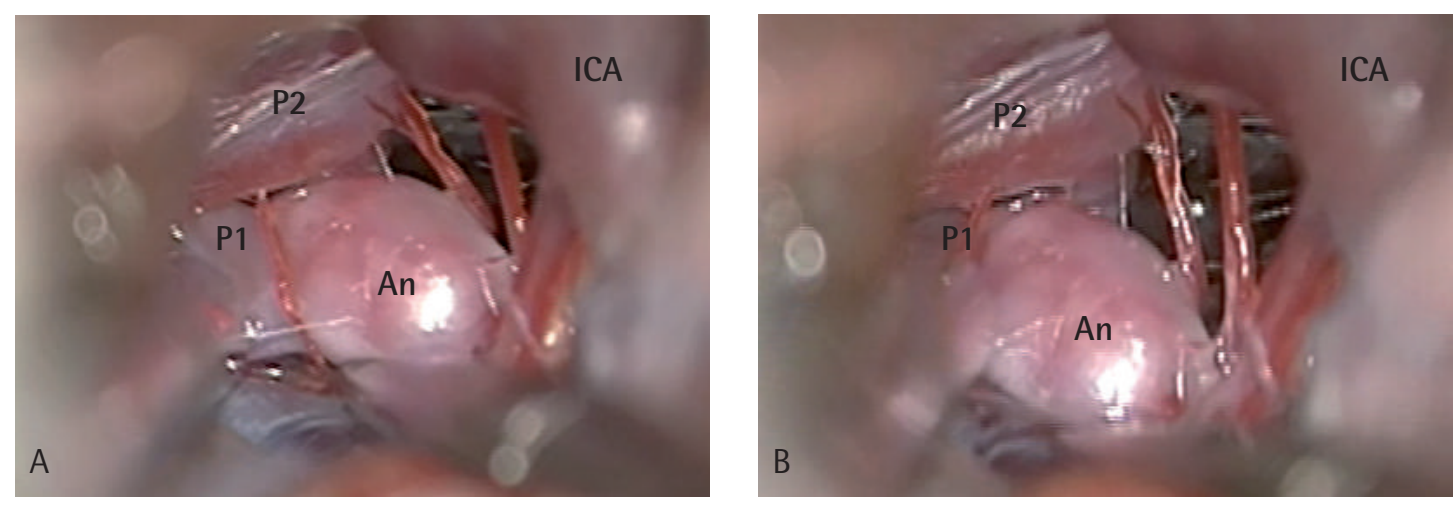

Figure 10. Mobilization of small perforators $(A, B)$ during dissection of a PCA-P1 aneurysm from a left lateral supraorbital approach.
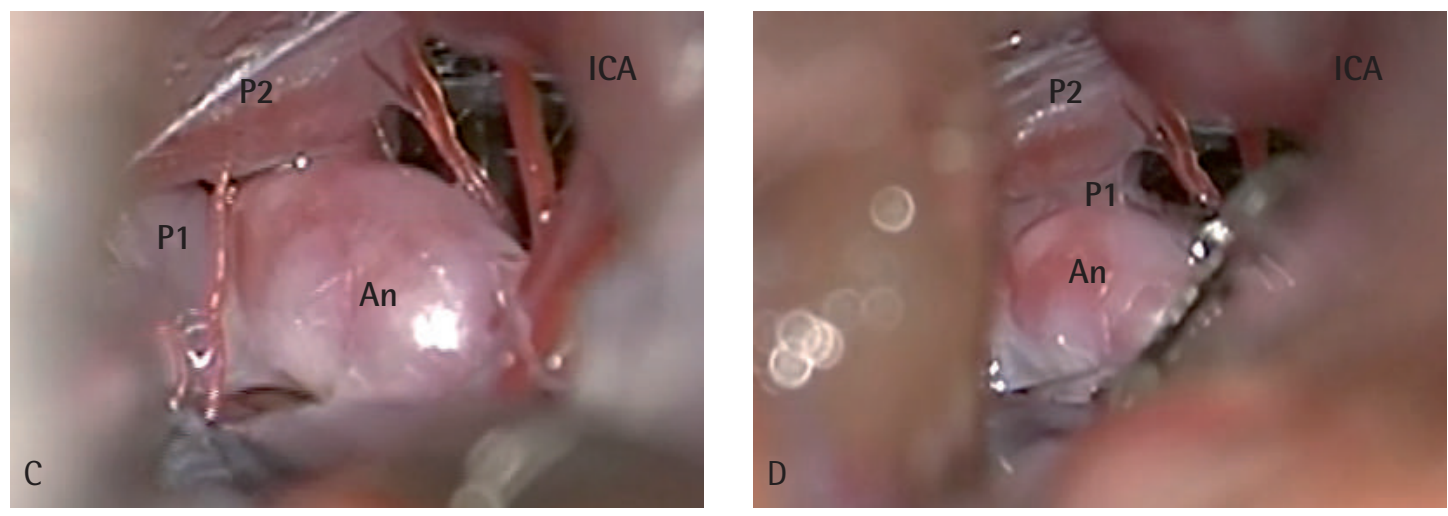

PCA-P1 aneurysm dissection (C) and clip occlusion (D) in the left carotid oculomotor triangle (An, Aneurysm; ICA, internal carotid artery; P1, P1 segment; P2, P2 segment).

tralateral side. Head and shoulders are slightly elevated above heart level. A skull clamp is used for head fixation. The skin is marked in a curved, oblique line just behind the hairline, approximately $8-10 \mathrm{~cm}$ long and $3 \mathrm{~cm}$ above the zygoma. The skin incision is made to detach a one-layer skinmuscle flap from the cranium. A left-sided latera supraorbital craniotomy is presented in Figure 9 .

\section{Intracranial Dissection}

With these frontotemporal approaches, the sylvian fissure must be widely opened to obtain enough space for the aneurysm dissection in this deep surgical corridor. Sometimes an anterior or posterior clinoidectomy is necessary to improve binocular visualization [Yonekawa 1997]. For somewhat more distal PCA aneurysms, a selective amygdalohippocampectomy can be necessary for exact visualization of the aneurysm [Yonekawa 2011]. In particular, the transsylvian route is preferable for high-lying proximal PCA aneurysms. Additionally, frontotemporal craniotomies allow access to mos of the aneurysm neck can be more difficult from a frontotemporal view than a subtemporal view as the aneurysms of the $\mathrm{P} 1$ segment and $\mathrm{P} 1 / \mathrm{P} 2$ junction typically project in the cranial or anterior direction. Treatment of PCA-P1/2 junction aneurysms is complicated by the involvement of the P1, P2 and PCoA in the aneurysm's formation and the neipsilateral anterior circulation aneurysms. Exposure cessity to preserve all three vessels. If one of the efferent vessels has to be sacrificed, the other must be preserved. During the microsurgical management of proximal PCA aneurysms, preservation of all perforating branches is crucial (Fig. 10)

\subsubsection{Subtemporal Approach to PCA Aneurysm}

The subtemporal approach is favorable for the treatment of PCA aneurysms in proximity to the tentorium. The approach was initially developed by Drake in 1961 for the treatment of basilar aneurysms and later adopted for PCA aneurysms. Different authors have subsequently contributed to the further development of this approach [Hernesniemi 2005/2005, McLaughlin 2014, Terasaka 2000, Zador 2010].

Positioning

int is placed in the lateral park bench position. To facilitate minimal retraction of the temporal lobe it is necessary to release 50 to $100 \mathrm{ml}$ of cerebrospinal fluid (CSF) by lumbar drainage.

\section{Skin Incision}

A horseshoe-shaped skin incision is made starting

$1 \mathrm{~cm}$ anterior to the tragus, above the zygomatic

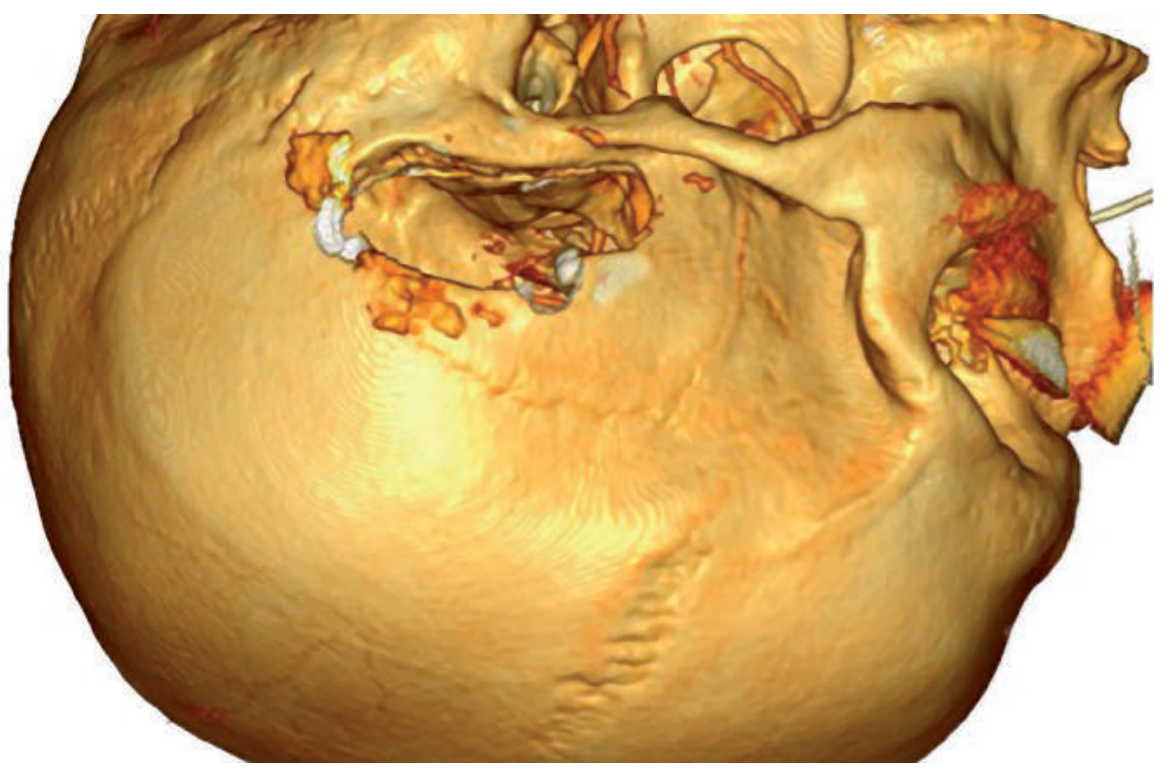

Figure 11. 3D CT of temporal craniotomy for a left subtemporal approach arch, and curving posteriorly around the earlobe until reaching the high-line between the porion and asterion. A one-layer skin-muscle flap is then everted. The Sugita frame provides strong retraction in the basal direction via its spring hooks. The temporal muscle is dissected down to the origin of the zygomatic arch. During dissection, the external auditory canal should be left intact. The skin is typically thin over this region. If performing an external carotid/internal carotid bypass using the STA as a bypass donor, the skin incision can be varied.

\section{Craniotomy}

One burr hole is placed at the cranial border of the planned bone flap. A curved blunt dissector is used to carefully detach the bone from the underlying dura A $3-4 \mathrm{~cm}$ bone flap is detached with a craniotome (Fig. 11). The first cut is made in the anterior direction to the base of the middle fossa; the second cut is made posteriorly towards the floor of the middle fossa. Finally the bone is thinned down along the basal border of the temporal bone and the bone flap is cracked. Holes for tack-up sutures are drilled at the cranial border of the craniotomy. The craniotomy is then widened basally by removing bone in the temporobasal direction using a highspeed drill to expose the floor of the middle fossa 
so that no ridges obstruct the view towards the subtemporal region. The craniotomy must be modified slightly to accommodate the exact aneurysm location.

\section{Intracranial Dissection}

The dura is opened via a curved flap with a cauda base and the dural edges are elevated over the craniotomy dressings. The secret to proper utilization of the subtemporal approach lies in gaining rapid access to the tentorial edge without heavy compression of the temporal lobe. This is where cisterns are opened to release additional CSF, allowing relaxation of the brain. The spinal drain can be closed at this point. The temporal lobe should be elevated close to the temporal pole. The dissection proceeds posteriorly, with great care taken not to excessively stretch the bridging veins. Abrupt retraction or elevation of the middle portion of the temporal lobe risks tearing of the vein of Labbé which would result in swelling of the temporal lobe and venous infarction. Once the temporal lobe is mobilized and elevated with the tentorial edge visible, a retractor is placed to retain space for furthe advancement. We prefer a relatively wide retractor that provides a large surface area without focal pressure points. The elevation of the uncus with the retractor exposes the opening to the interpeduncular cistern and the third nerve [Yasargil 1976] The subtemporal standard view is presented in Figure 12. The third nerve can be mobilized by cutting the arachnoid bands surrounding it, however palsy can develop even with minimal manipulation. By contrast, in some patients even prolonged manipulation of the third nerve does not lead to any signs of postoperative palsy. Even with the uncal retraction, the opening into the interpeduncular cistern remains narrow. It can be widened by placing a straight micro clip at the edge of the tentorium in front of the insertion and the intradural course of the fourth nerve, lifting the tentorial edge upwards [Hernesniemi 2005]. If this procedure does not provide a wide enough corridor, we partially divide the tentorium for better exposure. The cut perpendicular to the tentorial edge and measuring about $10 \mathrm{~mm}$ in length, is made posterior to the

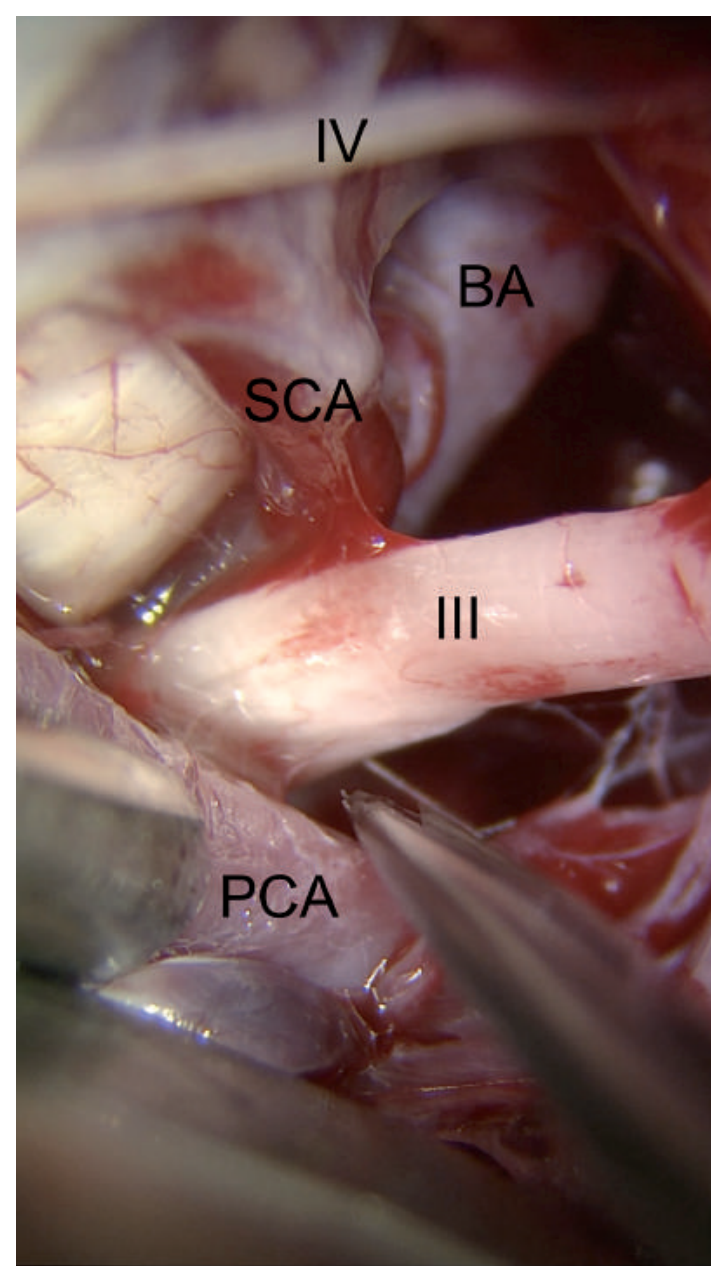

Figure 12. Standard view from a left subtemporal approach (III, oculomotor nerve; IV, trochlear nerve; BA, basilar artery; PCA, posterior cerebral artery; SCA, superio cerebellar artery.

insertion of the fourth nerve. The tentorial flap is then fixed with a small aneurysm clip to allow better exposure of the upper portion of the basilar artery [Hernesniemi 2005]. Venous bleeding after the first tentorium incision can be stopped by the injection of glue into this first small opening.

Vessel and Aneurysm Management

In cases with a low-lying P1 origin at the basilar bifurcation, exposure of the tentorium is absolutely necessary and a more posterior approach with larger bone flap is preferred. The arachnoid is opened via a wide incision beginning above the fourth nerve and the superior cerebellar artery (SCA), below the third nerve and the side of midbrain, and continuing forward to free the carotid and posterior communication arteries. A careful water dissection technique described by Toth et al. in 1987 is useful when entering the narrow arachnoid layers [Nagy 2006, Toth 1987]. Oculomotor nerve paresis is the second most common complication of open microsurgical management of upper posterior circulation aneurysms. This is related to the close proximity of the PCA to the oculomotor nerve. Direct mechanical irritation and disturbance of the vascularization of the oculomotor nuclei and fascicles is possible. The frontotemporal approach allows a slightly better trajectory for the protection of the third nerve compared to the subtemporal approach. The paresis usually regresses after a period of several weeks to a few months. Due to the different surgical trajectory, the trochlear nerve can interfere with the surgical field of the subtemporal approach (Fig. 13). Intraoperative monitoring of the third and fourth nerves can prevent permanent damage [Zhou 2012]

Prior to clipping, perforating arteries must be protected carefully during preparation and exposure of the aneurysm. In cases of SAH, this preparation is hindered by blood clots. Before clipping the aneurysmal neck, the perforating branches must be carefully separated. Often a complete dissection of the aneurysm dome is not advisable. Larger P1P2 junction aneurysms can be challenging in that P1, P2 and posterior communicating arteries may be involved in the aneurysm formation, necessitating cautious clipping to preserve the integrity of all three vessels. The P2 segment is hidden under the parahippocampal gyrus as it winds around the side of the midbrain. As the P2 is followed out from its anterior extremity, it is usually possible to elevate this gyrus gently with the tip of the retractor to locate the P1 branching and the neck of the aneurysm. Occasionally, it is necessary to remove a centimetre or so of the parahippocampal gyrus in order to expose a highly placed or more complex aneurysm lying on the upper midbrain in the choroidal fissure. Temporary clipping is recom-

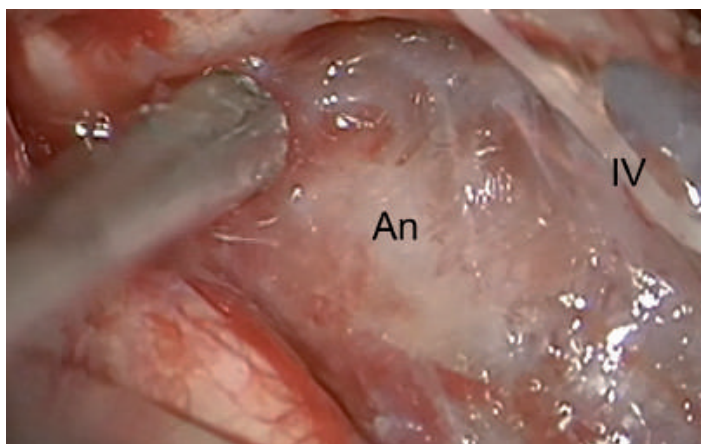

Figure 13. Mobilization and preservation of the right trochlear nerve from the sack of a PCAP1/2 junction aneurysm using a right subtemporal approach (IV, trochlear nerve; $A n$, aneurysm).

mended during dissection around the aneurysm (Fig. 14). The duration of temporary clipping should be short and caution is advised with atherosclerotic vessels. Temporary clips should not interfere with the final clipping procedure. While placing temporary clips, care must be taken to avoid accidentally injuring the perforating arteries.

After the final clip has been placed, the dista temporary clip is removed first to evaluate if there is any bleeding from a potentially incompletely clipped aneurysm. A safe clip replacement is possible whereby the clip is released without actually being removed. While slowly placing the final clip, the perforating arteries should be closely observed to avoid injury. In the case of difficult neck inlay into the clip where temporary clipping is not possible, it can be useful to induce a transient cardiac arrest using a rapid bolus of intravenous adenosine (20-25 mg) [Luostarinen 2009]. After pilot clip placement, the dissection around the aneurysm can be extended if necessary. Aneurysm puncture and down coagulation is used to shrink the aneurysm before placing the final permanent clip. This extends the overall view of the dissection area and helps prevent injuries to perforating arteries and branches. The technique of permanent clip placement is well described [Kamiyama 2010, Lawton 2010]. An example for tandem clipping of a giant PCA-P2 aneurysm is given in Figure 15. 

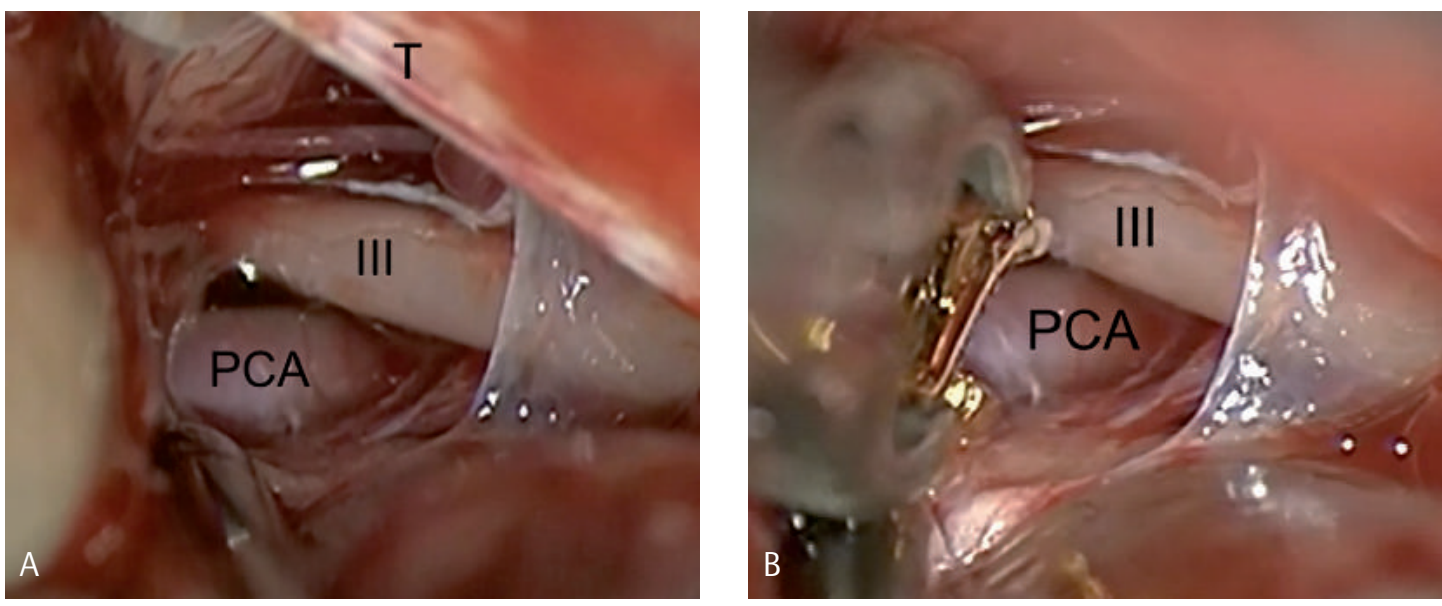

Figure 14. Exposure (A) and temporary proximal occlusion (B) of the anterior P2 segment through a left subtempora approach, in proximity to the oculomotor nerve (III, oculomotor nerve; PCA, posterior cerebral artery; T, tentorium).

For immediate intraoperative control of the aneurysm, use of intraoperative indocyanine green (ICG) videoangiography has been mandatory at our institution since 2006, and allows real-time imaging of the vascular system [Dashti 2010, Raabe 2003/2005]. Care should also be taken that the aneurysm clips do not interfere with the crania nerves.

Closure

The entire closing procedure is performed under microscopic view and completed in layers. However a water-tight closure is necessary. During initia

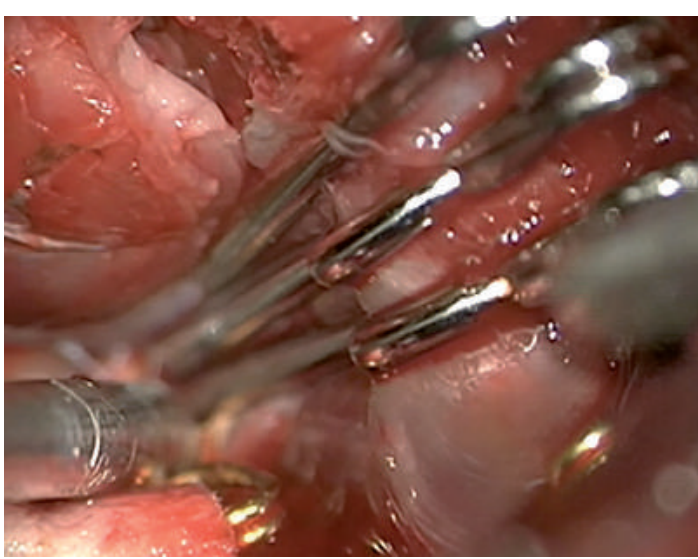

Figure 15. Tandem clipping of a large PCA-P2 aneurysm using a right subtemporal approach. temporobasal drilling, very often some of the air cells of the temporal bone are opened. This necessitates meticulous closure at the end of the surgery to prevent postoperative CSF leak. Utilization of Tachosil ${ }^{\circledR}$ can be helpful in this case [Kivelev 2015] Sealing the air cells with a part of the tempora muscle flap everted over the bony edge and sutured to the dura is one option; other methods include using fat graft, fibrin glue, and bone wax.

2.5.1.3 Posterior Approaches to PCA Aneurysms

Far distal PCA aneurysms on the P3 and P4 segments require different approaches. In 1984 Yasargi described the parasagittal parietal-occipital craniotomy in sitting position for the dissection and clipping of distal PCA aneurysms. Although far distal PCA aneurysms at the P4 segment are extremely rare, they are easily accessible from an occipital interhemispheric approach [lshibashi 1989 Hashimoto 2000, Ito 1998, Orita 1994, Yamahata 2010]. Figure 16 shows a right-sided parasagitta parietooccipital craniotomy. Later Yonekawa et al. in 2011 described the supracerebellar transtentoria approach in sitting position for the microsurgica treatment aneurysms of the PCA-P2P and PCA-P3 segments of the PCA [Yonekawa 2001/2011]. Both approaches allow the application of OA-PCA by-

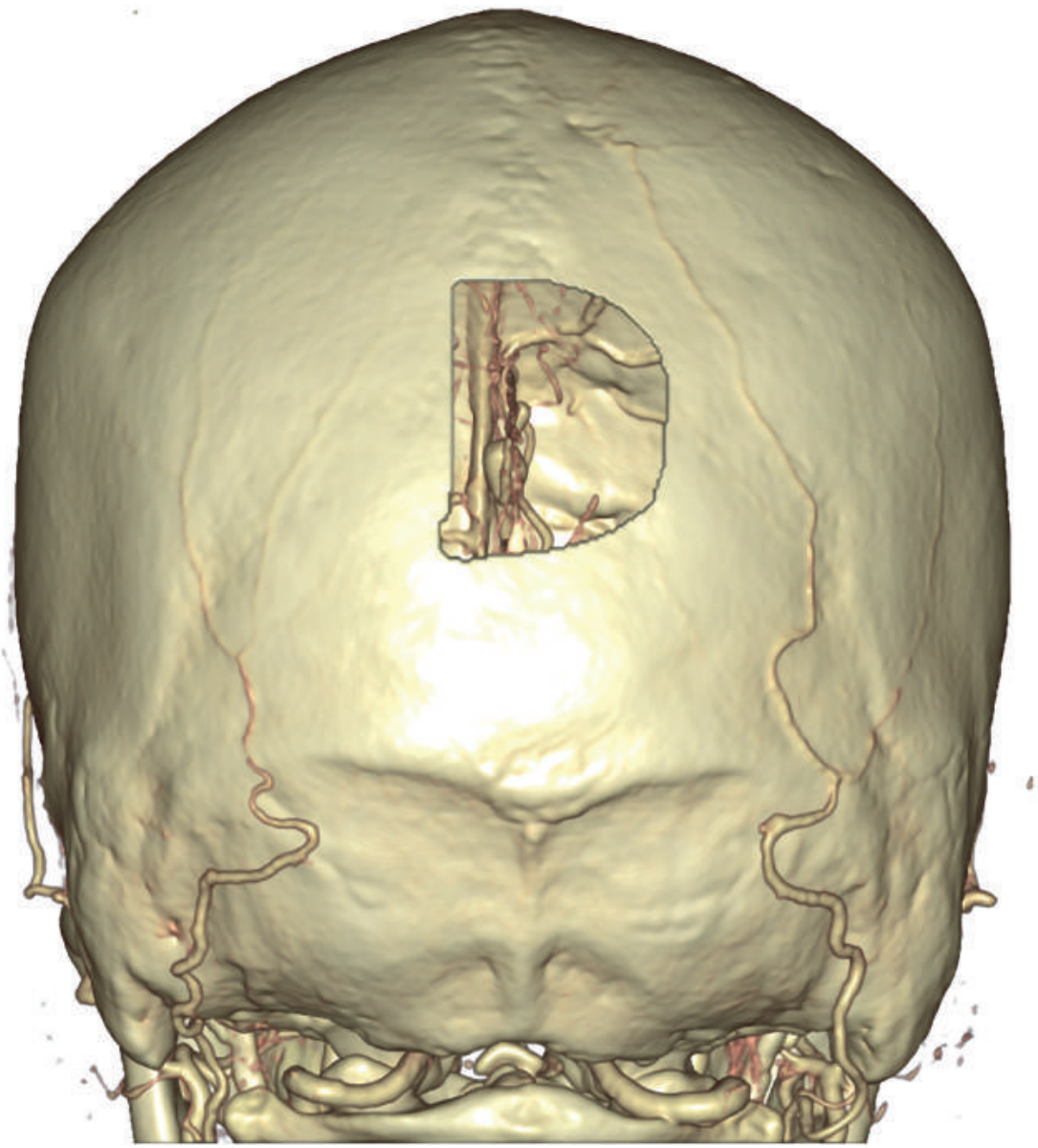

Figure 16. Right sided parasagittal parietooccipital craniotomy.
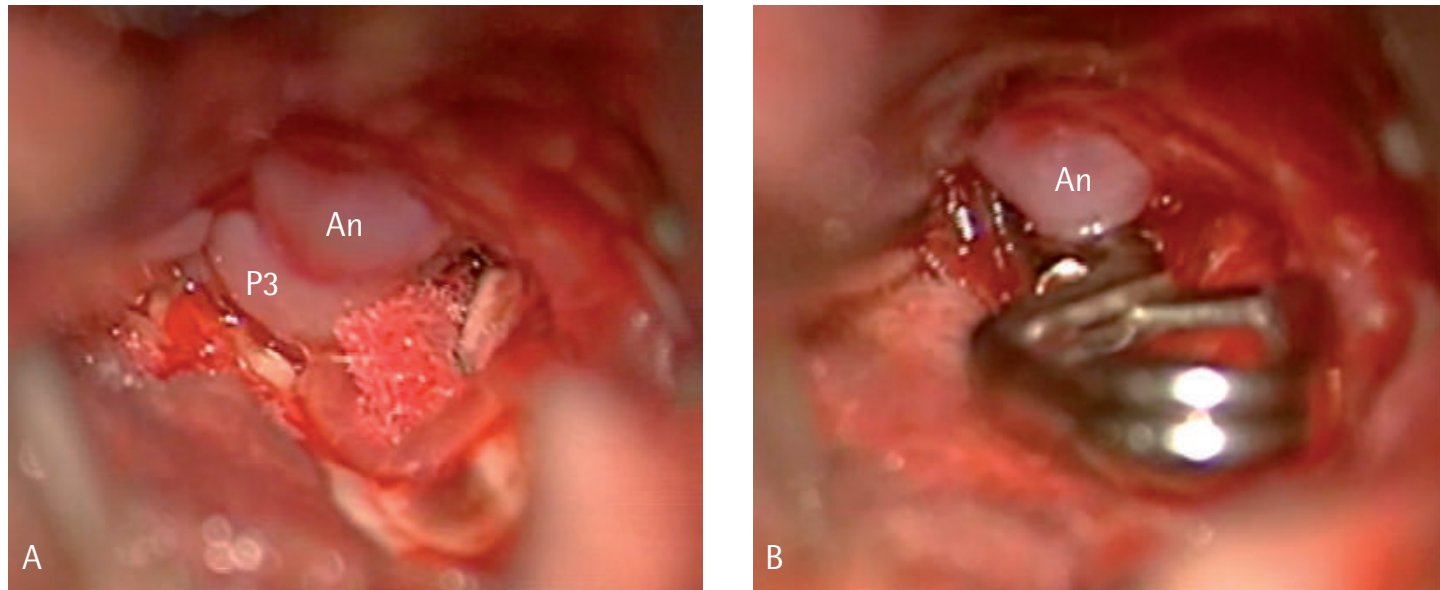

Figure 17. Dissection (A) and clipping (B) of a P3 segment aneurysm (An) using a right posterior interhemispheric approach 

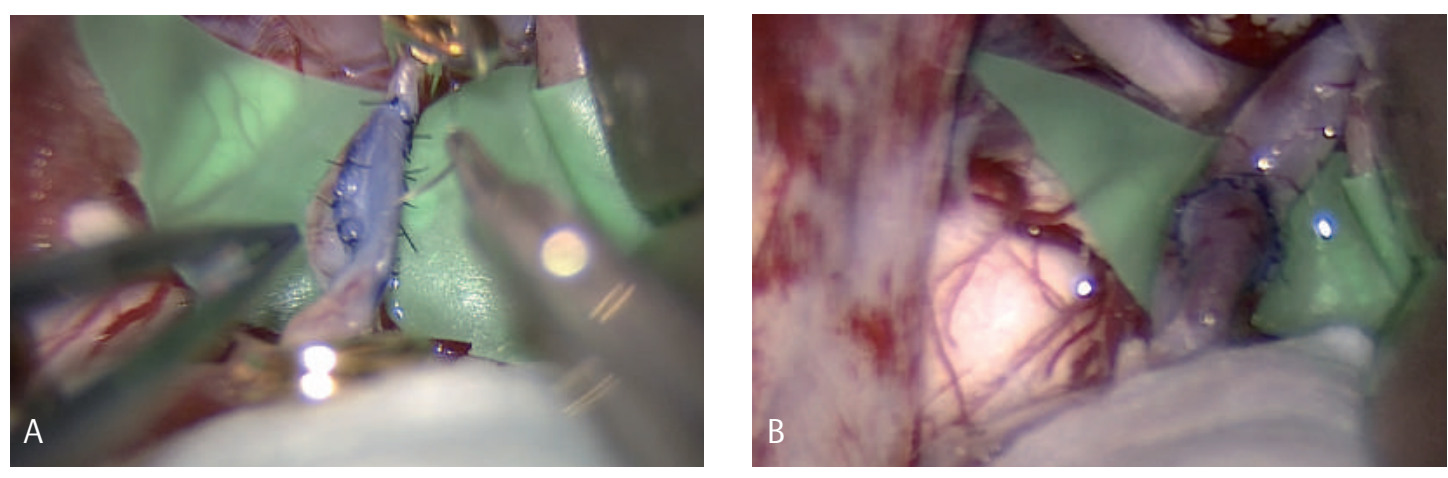

Figure 18. Application of a microanastomosis (A) for a STA-P2 bypass (B) through a left subtemporal approach

passes for the revascularization of distal PCA territory [Vishteh 1998, Yonekawa 2011]. Figure 17 show the microsurgical view from a posterior interhemispheric approach for the clip occlusion of a rightsided P3 segment aneurysm.

\subsubsection{Revascularization Procedures Applied to} PCA Aneurysms

Revascularization procedures of the PCA are considered to be effective for the prevention of cerebra ischemic infarctions, including the distal PCA area [Chang 2010, Goehre 2016, Kalani 2014, Kazumata 2011, Mohit 2007, Saito 2006, Sekhar 2001, Sund 1982, Takeuchi 2015, Touho 1995, Vishteh 1998 Yasargil 1969/1970/1977, Yonekawa 2011, Zado 2010]. Multiple bypass procedures with the PCA as the recipient vessel have been described, such as the OA-PCA [Chang 2010, Kazumata 2011 Touho 1995, Vishteh 1998], STA-PCA (Fig. 18) [Goehre 2016, Hopkins 1982, Takeuchi 2015, Ulku 2010] MMA-PCA [Ustun 2006] and the ECA-RA-PCA or ECA-VA-PCA bypass as high flow bypass procedures [Reyes 1995, Sundt 1982/1986, Sundt III 1987, Sh 2011, Sekhar 1999, Tanikawa 2006]. The visibility of the arterial wall can be improved by the use of pyoctanium blue (Fig. 19) [Kamiyama 1993]. The SCA-PCA anastomoses are described as in situ techniques. A side-to-side technique as well as an endto-side (Fig. 19) technique is possible [Saito 2006 Sundt 1982]
The vessel diameters are shown in Table 1. However, specific complications like bypass failure and intracranial hematomas have also been described [Chang 2010]. The dimensions of the vessel calibers are also summarized in Table 1. Even application of ELANA bypasses is possible [Langer 2005, Tulleken 1993/1998]. The depth of the surgical corridor from a subtemporal approach amounts to $50-65 \mathrm{~mm}$ according to own measurements. In this way, this anastomosis is substantially different from a superficial vascular reconstruction and special training is required [Yonekawa 1999]. The intraoperative assessment of the bypass flow can be tested by indocyanine green videoangiography and ultrasonic perivascular flow probe [Charbel 1998, Raabe 2003/2005, Woitzik 2005].

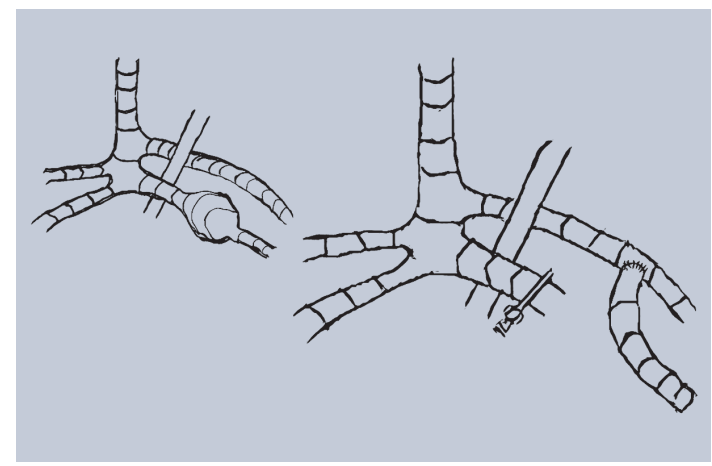

Figure 19. PCA-SCA end-to-side anastomosis after aneu(1982). rysm resection (schematic drawing) according to Sundt, Jt.

Table 1. Vessel diameters for revascularization of the PCA [Kawashima 2005/2011].

\begin{tabular}{|l|l|}
\hline & Vessel Diameter $(\mathrm{mm})$ \\
\hline Posterior cerebral artery (PCA) & \\
\hline Anterior P2 segment & $2.13 \pm 0.38$ \\
\hline Posterior P2 segment & $1.73 \pm 0.33$ \\
\hline P3 segment & $1.67 \pm 0.16$ \\
\hline Superior cerebellar artery (SCA) & \\
\hline Lateral pontomesencephalic segment (single trunk) & $1.51 \pm 0.12$ \\
\hline Occipital artery (OA) & \\
\hline At the digastric groove & $2.05 \pm 0.48$ \\
\hline At the level of the superior nuchal line & $2.01 \pm 0.45$ \\
\hline Superficial temporal artery (STA) & \\
\hline At the level of zygoma & $1.93 \pm 0.48$ \\
\hline External carotid artery (ECA) & \\
\hline Cervical portion & $5.75 \pm 0.94$ \\
\hline
\end{tabular}

2.5.2 Endovascular Treatment of PCA Aneurysms

Endovascular interventions of the PCA are usually done under general anesthesia and systemic heparinization [Ciceri 2001, Hallacq 2002]. Saccular PCA aneurysms of the P1 and P1/2 junction are suitable for the direct GDC coil embolization with parent vessel preservation [Ciceri 2001]. For wide neck PCA aneurysms, a balloon assisted technique or stent assisted coiling can be helpful to avoid encroachment of the coils in the vessel lumen of the parent artery (Fig. 20) [Arat 2002, Ciceri 2001, Huang 2013]. A combined occlusion of the aneurysm and the parent artery is often required for the treatment of PCA aneurysms distal to the P1/2 junction (Fig. 21); this is possible by detachable coils (Fig. 22), histoacryl and detachable balloons [Ciceri 2001, Cotroneo 2007, Eckard 2000, Hallaca 2002, van Rooij 2006]. The authors consider that most patients are able to compensate the parent vessel occlusion by collateral flow, but ischemic complications occur in up to 28\% [Ciceri 2001] 50\% [Cotroneo 2007] or 78\% [Kashiwazaki 2011] of cases. However, the long endovascular route to the terminal segments of the posterior circulation and a tortuous path can aggravate or prevent endovascular access.

2.5.3 Outcome after Posterior Cerebral Artery Aneurysm Treatment

\subsubsection{Radiological Outcome}

Regarding the literature, it appears that the rate of incomplete occlusion of PCA aneurysms is very low [Drake 1996, Hallacq 2002]. The reason for this is that when an aneurysm was considered as difficult for neck clipping or endovascular occlusion, another option such as parent vessel occlusion was used for complete exclusion of the aneurysm formation from the circulatory system [Cotroneo 2007, Drake 1996, Hallacq 2002, Kashiwazaki 2011]. In general, the rate of parent vessel occlusions is with 43-100\% high for PCA aneurysms, which is due to their characteristic features such as a high incidence of fusiform shape [Cotroneo 2007, Drake 1996, Hallacq 2002, Kashiwazaki 2001]. Since the adoption of stent assisted coiling the frequency of parent vessel occlusion has decreased for this type of aneurysm 

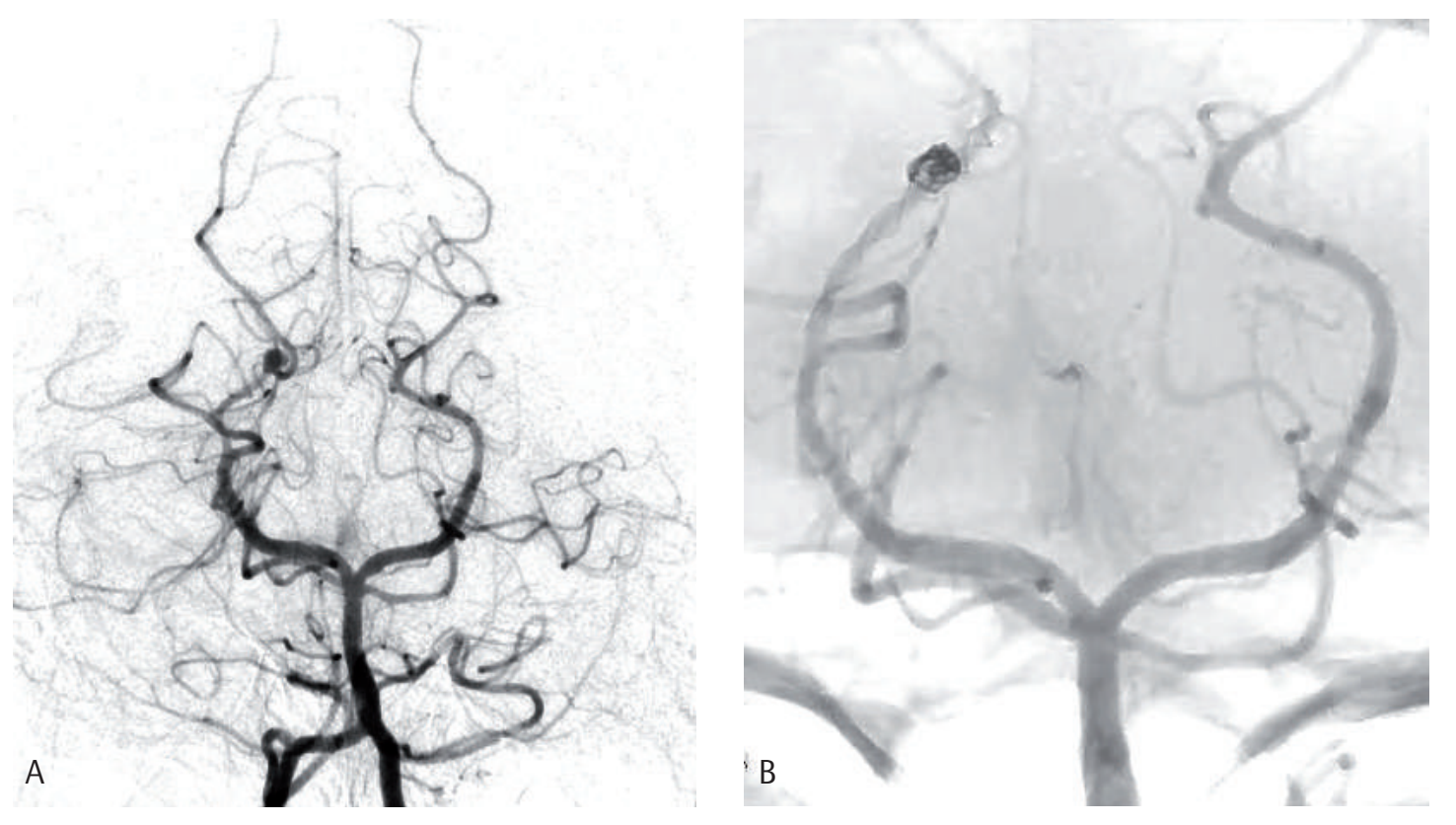

Figure 20. A fusiform PCA-P3 segment aneurysm (A) is occluded with a GDC coil under stent protection of the PCA (B).
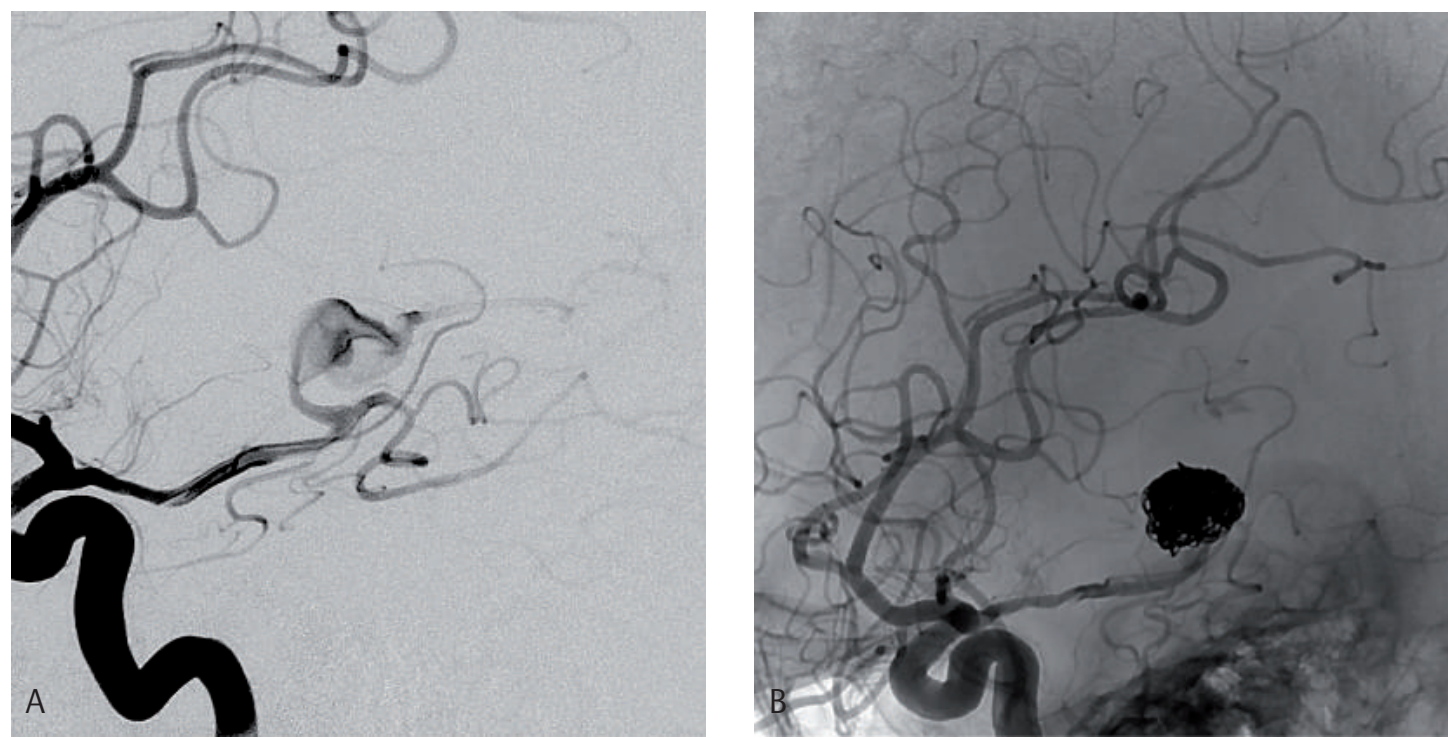

Figure 21. GDC occlusion of a fusiform PCA-P3 segment aneurysm (A) with parent artery occlusion (B) on a fetal left

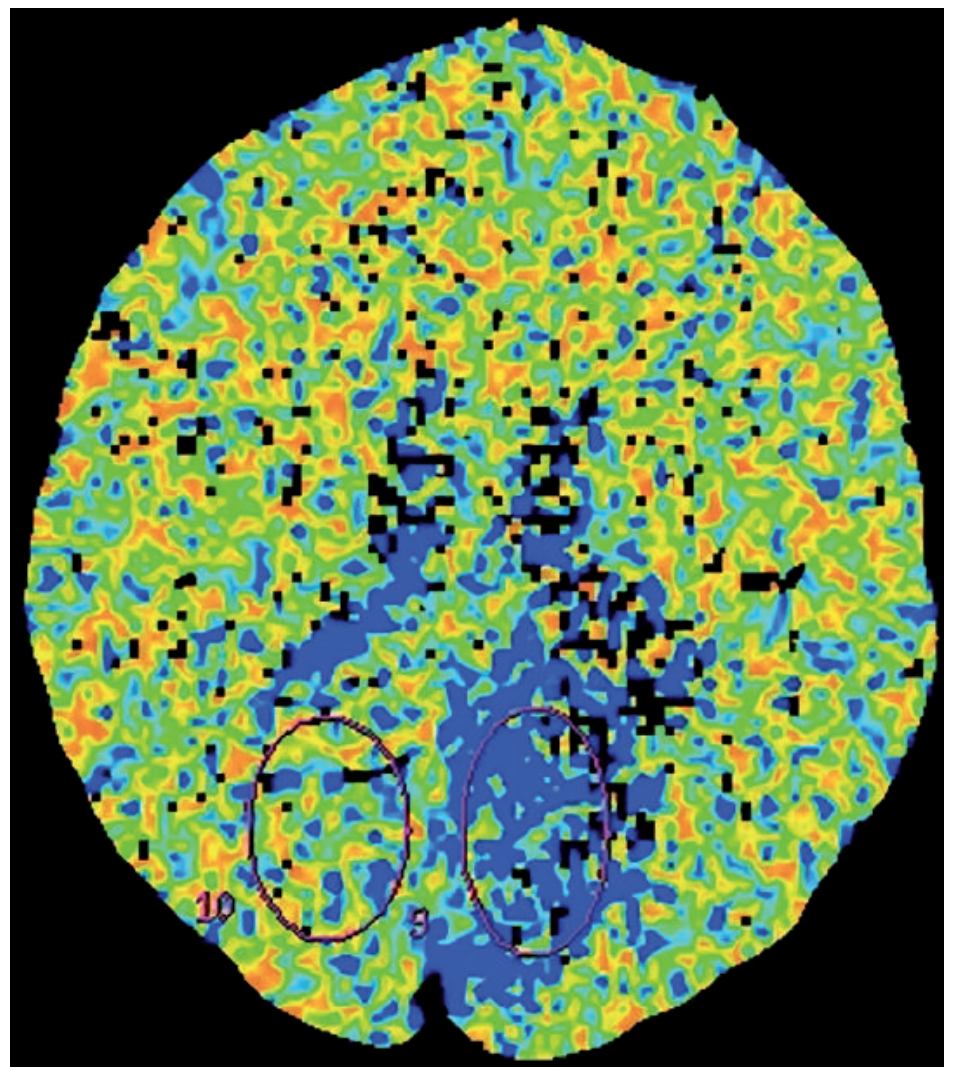

Figure 22. Decreased perfusion (blue; MTT) of the left PCA territory after endovascular parent vessel occlusion.

regarding to endovascular treatment [Huang 2013]. However, incidence of ischemic infarction (Fig. 22) following parent vessel occlusion is high at 50-78\% in all series that included consequent follow up, even when the infarct area was not large [Cotroneo 2007, Kashiwazaki 2011]. However, in case of bypass application MRI imaging with 4D-flow techniques allows for less invasive bypass flow evaluation [Sekine 2015].

\subsubsection{Clinical Outcome}

Early reports on conservative and surgical management of PCA aneurysms show unfavorable but also good treatment outcomes [Bertrams 1968, Drake 1969, Hunt 1967]. As an example, the first results of Drake and Amacher from 1969 were presented: The treatment of 8 patients with PCA aneurysms show that one patient died, one had a poor outcome caused by contralateral hemiplegia and ipsilateral oculomotor palsy, and another patient suffered a monoparesis and a oculomotor paresis. The other five patients had a good or excellent outcome.

It is problematic to give a general overview of the treatment results due to the low incidence of PCA aneurysms; most of the series are small, with fewer than 25 cases and analyzed using different evaluation standards. Table 2 provides a summary of PCA aneurysm series with more than 10 cases. The following is a summary of the treatment results of the five most rigorous reports on PCA aneurysms, each with more than 30 patients. Drake 


\section{Table 2. Series on PCA aneurysms.}

\begin{tabular}{|l|c|c|l|}
\hline Author & Year & Cases & Treatment \\
\hline Drake et al. & 1996 & 125 & surgical \\
\hline Zhitao et al. & 2010 & 42 & surgical \\
\hline Chang et al. & 2010 & 33 & surgical and endovascular \\
\hline Wang et al. & 2015 & 30 & surgical \\
\hline Taylor et al. & 2003 & 30 & surgical and endovascular \\
\hline Sanai et al. & 2008 & 27 & surgical and endovascular \\
\hline Kim et al. & 2013 & 25 & surgical and endovascular \\
\hline van Rooij et al. & 2006 & 22 & endovascular \\
\hline Park et al. & 2015 & 21 & surgical and endovascular \\
\hline Kashiwazaki et al. & 2011 & 21 & endovascular \\
\hline Hamada et al. & 2005 & 21 & surgical, endovascular and conservative \\
\hline Yonekawa et al. & 2011 & 20 & surgical \\
\hline Ciceri et al. & 2001 & 20 & endovascular \\
\hline Li et al. & 2008 & 18 & endovascular \\
\hline Seoane et al. & 1997 & 15 & surgical \\
\hline Gerber et al. & 1992 & 15 & surgical \\
\hline Roh et al. & 2008 & 13 & endovascular \\
\hline Kitazawa et al. & 2001 & 11 & surgical \\
\hline Sakata et al. & 1993 & 11 & surgical \\
\hline Luo et al. & 2012 & 10 & endovascular \\
\hline Coert et al. & 2007 & 10 & surgical and endovascular \\
\hline Honda et al. & 2004 & 10 & surgical and conservative \\
\hline Hallacq et al. & 2002 & 10 & endovascular \\
\hline & & & \\
\hline
\end{tabular}

et al. (1996) report roughly 78\% good or excellent results among their 125 patients ( 75 patients following SAH) [Drake 1996]. Chang et al. (2010) from the Barrow Institute report good or excellent results in 29 of 33 cases (87\%), however 3 cases (9\%) were fatal and 9 patients $(27 \%)$ had an initial SAH [Chang 2010]. Taylor et al. (2003) analyzed $30 \mathrm{pa-}$ tients and reported that 8 of 18 patients (44\%) with unruptured PCA aneurysms and 6 of 12 patients (50\%) with ruptured PCA aneurysms achieved a good outcome after one-year follow-up; howeve one patient died during treatment [Taylor 2003]
In the 30-patient case series of Wang et al. (2015) 26 patients $(87 \%)$ had a good result even though 18 patients (60\%) suffered from an initial aneurysm rupture and 18 of the aneurysms were large or giant [Wang 2015]. There was a single fatal outcome in this study. Zhitao et al. (2010) analyzed a patient collective of 42 patients with PCA-P2 segment aneurysms, 25 of whom after SAH [Zhitao 2010]. Remarkably, 41 patients (97\%) had a good treatment result after a mean follow-up period of 5.8 years.

\section{Aims of the study}

To describe the characteristic features of PCA aneurysms. (Study I)

To analyze the treatment strategies and outcomes of PCA aneurysms. (Study II)

To analyze the treatment of PCA aneurysms via subtemporal approach. (Study III)

To describe the treatment of PCA aneurysms and ipsilateral anterior circulation aneurysms inside the circle of Willis via lateral supraorbital approach.

(Study IV) 


\section{Patients, Materials and Methods}

The study retrospectively reviewed 133 patients (41 men and 92 women) with 147 PCA aneurysms. All patients were treated between 1934 and 2014 at one of two Finnish neurosurgical centers: the Department of Neurosurgery at the University of Eastern Finland, Kuopio and the Department of Neurosurgery at the University of Helsinki. These institutions are the only neurosurgical centers for all of southern and eastern Finland, serving a population of 2.8 million people. Between 1934 and 2014 a total of 15,300 patients with 19,177 intracranial aneurysms were treated at our institutions. Data was collected with the approval of the local university ethics committee (469/E0/04 HUCH). A commercially available software package was used for data analyses (SPSS for Mac, version 21.0 [2012]; SPSS, Inc, Chicago, Illinois).

Study I

"Characteristics of Posterior Cerebral Artery Aneurysms: An Angiographic Analysis of 93 Aneurysms in 81 Patients" analyzed 81 patients with 93 PCA aneurysms.

Study II

"Posterior Cerebral Artery Aneurysms: Treatment and Outcome Analysis in 121 Patients" analyzed 121 patients with 135 PCA aneurysms.

Study III

"Subtemporal Approach to Posterior Cerebral Artery Aneurysms" analyzed 34 patients with 37 PCA aneurysms treated via subtemporal approach.

Study IV

"Lateral supraorbital approach to ipsilateral PCAP1 and ICA-PCoA aneurysms" described the latera supraorbital approach for the treatment of a proximal PCA aneurysm in one patient.
4.1. Publication I - Characteristics of PCA Aneurysms

4.1.1 Patients

The characteristic features of 93 PCA aneurysms in 81 patients were analyzed. These patients were treated between 1980 and 2012 at the neurosurgical centers of the University of Eastern Finland Kuopio and the University of Helsinki. Patients with a subarachnoid hemorrhage had a median age of 51 years (range: $11-86$ years) at diagnosis while patients without had a median age of 45 years (range: $10-88$ years) at diagnosis.

\subsubsection{Imaging}

The PCA aneurysms were diagnosed by conventiona digital subtraction angiography (DSA) in $27 \mathrm{pa}$ tients, by computed tomography angiography (CTA) in 31 patients, and with both methods in $22 \mathrm{pa}-$ tients. One patient was diagnosed by magnetic resonance angiography (MRA) alone. If CTA and DSA were performed, CTA was used for the presented measurements. For DSA analyses a metallic reference was used, as small measurement errors are possible even with localization of pathology close to the central beam.

The following angiographic variables were determined: maximal aneurysm length, width, and shape (fusiform/saccular), neck and parent artery diameter, distance to the basilar bifurcation for $\mathrm{P} 1$ $\mathrm{P} 1 / 2$ junction and $\mathrm{P} 2$ segment aneurysms, dome orientation of saccular aneurysms and any secondary pouches, and the anatomic relationship to the posterior clinoid process.

For calcified or thrombosed aneurysms the measurements were done from outer wall to outer wall. The widest wall-to-wall distance was used fo the calculation of the median aneurysm size. The image analyses were done by two experienced neu- rosurgeons, one of whom has double specialization in neurosurgery and neuroradiology according to European Union regulations.

Publication II - Treatment and Outcome of PCA Aneurysms

4.2.1 Analysis

Hospital records and images were analyzed to identify patients with PCA aneurysms. From these resources the following data were collected: patient age, sex, Hunt and Hess grade on admission, treatment modality, time to treatment, occlusion grade, complications, neurological deficits, and cause of death. The modified Rankin Scale (mRS) was used to measure outcomes, evaluated at one-year follow-up. For presentation and analysis of the data, outcomes were categorized into three groups: (i) good (mRS 0-1), (ii) moderate (mRS 2-4), and (iii) poor ( $m R S 5-6$ ). This represents a more rigorous review than that in "Publication III - Subtemporal Approach to CPA Aneurysms". All patients were examined angiographically for diagnosis via computed tomography angiography (CTA), digital subtraction angiography (DSA), or magnetic resonance angiography (MRA). Radiological images were stored in the hospital's digital archiving system (PACS; AGFA, IMPAX, version 4.5, launched in 1998) while X-ray photographs were housed in the central $X$-ray image archive. The image analyses were completed by two experienced neurosurgeons, one with double specialization in neurosurgery and neuroradiology. The following radiological data were collected: aneurysm height, neck diameter, dome width, previous treatment (coiling or clipping), and the presence of remnant aneurysm parts following treatment.

4.2.2 Patients

A total of 121 consecutive patients ( 36 male, $85 \mathrm{fe}$ male) with 135 PCA aneurysms were identified and further analyzed. Patients were subdivided into nine groups for detailed analyzes: 1) unruptured saccular aneurysms $(n=9), 2$ ) unruptured fusiform aneurysms $(n=10), 3)$ unruptured giant aneurysms $(n=7), 4)$ unruptured PCA aneurysms with associated aneurysms $(n=21), 5)$ ruptured saccular aneurysms $(n=20)$ 6) ruptured fusiform aneurysms $(n=7), 7)$ ruptured PCA aneurysms with associated aneurysms $(n=18)$ 8) SAH from an associated aneurysm rupture $(n=17)$ and 9) SAH from an associated AVM $(n=12)$. In total, 52 patients presented ruptured PCA aneurysms.

4.3 Publication III - Subtemporal Approach to PCA Aneurysms

4.3.1 Patients

Between 1980 and 2012, 34 patients (7 male, 27 female) with 37 PCA aneurysms were operated on via the subtemporal approach. Fourteen of these patients became symptomatic by acute subarachnoid hemorrhage from PCA aneurysm rupture. Eight patients had a HEtH grade of 1-2 and 6 patients a $\mathrm{HCH}$ grade of 3-4. Six patients had acute hydrocephalus. Two patients had an intracerebra hematoma in the temporal lobe and one in the occipital lobe. Additionally, five patients had intraventricular hemorrhage. Another aneurysm ruptured in two patients, both of whom had a H\&tH grade of 2. Eighteen patients had no SAH. Twelve patients were diagnosed incidentally; six patients were symptomatic by hemiparesis from mass effect $(n=2)$, headache $(n=2)$, diplopia $(n=2)$ and embolic syndrome $(n=1)$

4.3.2 Analysis

The clinical data and radiological images were analyzed retrospectively. Clinical variables collected included age, gender, aneurysm rupture state, Hunt and Hess grade, date of surgery, intraoperative procedures, and complications. The complications were divided into approach related complications and aneurysm management related complications. The modified Rankin scale (mRS) was used for the description of the early outcome after 3 months. Good outcome was classified as mRS 0-2, moderate outcome as mRS $3-4$, and poor outcome as mRS 


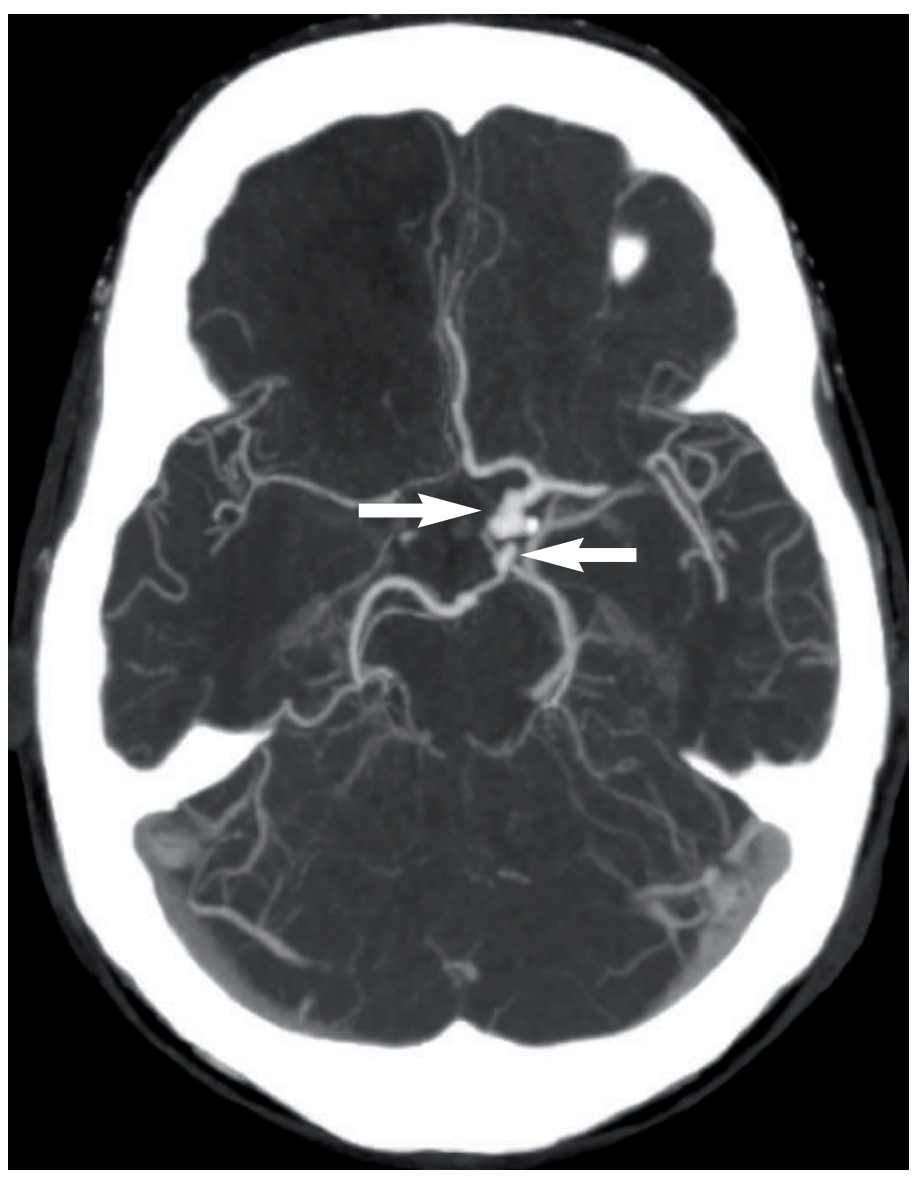

Figure 23. Axial CTA shows a left ICA-PCoA (left arrow) and PCA-P1 aneurysm (right arrow).

5-6. Radiological image analyzes used the preoperative and postoperative computed tomography, computed tomography angiography, and digital subtraction angiography images for determination of the aneurysm location, aneurysm size and shape, Fisher grade, intracerebral hematoma, intraventricular hemorrhage, postoperative parent artery occlusion, and postoperative hematomas and infarcts.

\subsection{Publication IV - Lateral Supraorbital} Approach to PCA Aneurysm

Publication IV was written as a technical note for the presentation of the LSO for the combined treatment of ipsilateral anterior circulation aneurysms.

\section{Results}

\section{Characteristics of PCA Aneurysms}

Location

Proximal PCA aneurysms are more frequent than distal PCA aneurysms. The collected data has the following distribution: P1As ( $n=39), P 1 / P 2 A s(n=25)$, P2As $(n=21)$, and P3As $(n=8)$. The proximal PCA segments (P1 and P1/2 junction) were affected by $69 \%(n=64)$ of all PCA aneurysms and $77 \%$ of these were located above the posterior clinoid level. Additionally, 54\% of all PCA aneurysms were located at the left PCA.

Symptoms of Unruptured PCA Aneurysms

Analysis included 64 unruptured PCA aneurysms in 53 patients. Vascular imaging for ruptured associated aneurysms show 12 associated PCA aneurysms. Eight patients were diagnosed following symptoms of ischemic strokes, three patients presented oculomotor nerve palsy, and ten patients had AVMrelated PCA aneurysms. One patient had a PCA aneurysm and an AVM with feeding arteries from the anterior circulation. Only one patient became symptomatic by mass effect. Eighteen aneurysms were found incidentally.

\section{Anatomic Variations}

An ipsilateral fetal PCA configuration was observed in nine patients and a contralateral feta PCA configuration in six patients. Two patients presented a bilateral fetal CPA configuration. One patient had the entire anterior circulation filling from the contralateral PCoA. One patient with a P1 aneurysm had an ipsilateral middle cerebral artery perfusion from the PCoA. A kinking P1 segment was present in three $\mathrm{P} 1$ segment aneurysms and in one $\mathrm{P} 1 / 2$ junction aneurysm.

\section{Parent PCA Diameter}

The parent artery diameter was larger for unruptured PCA aneurysms $(1.8 \mathrm{~mm})$ than for ruptured
$(1.5 \mathrm{~mm})$. This was still the case even when PCA aneurysms from AVM feeding PCAs were removed from the analysis. There was no difference in the mean parent artery diameters between aneurysms of the proximal (P1 and $P 1 / 2$ junction) and dista (P2 and P3) PCA; the mean diameter was $1.5 \mathrm{~mm}$ in both groups.

\section{Involvement of PCA Branches at the Origin}

An angiographically visible branch originating from the aneurysm or its base was found in 37 aneurysms (59\%), excluding P1/P2 junction aneurysms. In 26 saccular aneurysms these perforating branches originated from the aneurysm base. In fusiform aneurysms, we observed that in seven cases these branches originated immediately proximal or distal from the aneurysm formation. In four cases the perforating branches originated directly from the fusiform aneurysm.

Size and Features of Fusiform PCA Aneurysms A greater proportion of the fusiform aneurysms were either large $(n=1)$ or giant $(n=5)$ compared with saccular aneurysms: $25 \%$ vs $7 \%$. An irregular wall structure was found in four unruptured (25\%) and five ruptured (63\%) fusiform PCA aneurysms. The P2 segment was particularly affected by fusiform PCA aneurysms $(n=9)$. Only two fusiform P3 segment aneurysms were detected, both of which were ruptured. An overview is given in Table 3

Size and Features of Saccular PCA Aneurysms Only $74 \%(n=69)$ of the observed PCA aneurysms were saccular; the remaining $26 \%$ were fusiform (Tab. 4). The rupture rate of saccular and fusiform aneurysms was comparable at $30 \%$ vs. $31 \%$, respectively. The subclassification of unruptured saccular PCA aneurysm $(n=48,52 \%)$ was the larges subgroup. Most of the 21 ruptured saccular PCA aneurysms were of small or medium size; 12 (57\%) 
Table 3. Length and diameter analyzes of 24 fusiform PCA aneurysms.

\begin{tabular}{|l|c|c|c|c|c|}
\hline & $\begin{array}{c}\text { P1 } \\
\text { aneurysms }\end{array}$ & $\begin{array}{c}\text { P1/2 junction } \\
\text { aneurysms }\end{array}$ & $\begin{array}{c}\text { P2 } \\
\text { aneurysms }\end{array}$ & $\begin{array}{c}\text { P3 } \\
\text { aneurysms }\end{array}$ & Total \\
\hline $\begin{array}{l}\text { Fusiform aneurysms } \\
\text { unruptured, no. (\%) }\end{array}$ & $4(10 \%)$ & $5(20 \%)$ & $7(33 \%)$ & 0 & $16(17 \%)$ \\
\hline $\begin{array}{l}\text { Lenght [mm]; } \\
\text { median (range) }\end{array}$ & $5(3-8)$ & $10(2-35)$ & $8(5-40)$ & - & $8(2-40)$ \\
\hline $\begin{array}{l}\text { Diameter [mm]; } \\
\text { median (range) }\end{array}$ & $3(2-14)$ & $10(2-32)$ & $5(5-20)$ & - & $5(2-32)$ \\
\hline $\begin{array}{l}\text { Fusiform aneurysms } \\
\text { ruptured, no. (\%) }\end{array}$ & $4(10 \%)$ & 0 & $2(10 \%)$ & $2(25 \%)$ & $8(9 \%)$ \\
\hline $\begin{array}{l}\text { Length [mm]; } \\
\text { median (range) }\end{array}$ & $8(3-9)$ & - & 7 and 37 & 12 and 13 & $8.5(3-37)$ \\
\hline $\begin{array}{l}\text { Diameter [mm]; } \\
\text { median (range) }\end{array}$ & $4(2-6)$ & & 6 and 33 & 9 and 10 & $6(2-33)$ \\
\hline
\end{tabular}

Table 4. Characteristics of 69 saccular PCA aneurysms.

\begin{tabular}{|l|c|c|c|c|c|}
\hline & $\begin{array}{c}\text { P1 } \\
\text { aneurysms }\end{array}$ & $\begin{array}{c}\text { P1/2 junction } \\
\text { aneurysms }\end{array}$ & $\begin{array}{c}\text { P2 } \\
\text { aneurysms }\end{array}$ & $\begin{array}{c}\text { P3 } \\
\text { aneurysms }\end{array}$ & Total \\
\hline $\begin{array}{l}\text { Saccular aneurysms } \\
\text { unruptured, no. (\%) }\end{array}$ & $26(67 \%)$ & $11(44 \%)$ & $9(43 \%)$ & $2(25 \%)$ & $48(52 \%)$ \\
\hline $\begin{array}{l}\text { Length [mm]; } \\
\text { median (range) }\end{array}$ & $5(1-12)$ & $5(2-21)$ & $4(2-36)$ & 3 and 35 & $3(1-36)$ \\
\hline $\begin{array}{l}\text { Width [mm]; } \\
\text { median (range) }\end{array}$ & $2(2-8)$ & $3(2-18)$ & $4(2-36)$ & 3 and 24 & $3(2-36)$ \\
\hline $\begin{array}{l}\text { Neck [mm]; } \\
\text { median (range) }\end{array}$ & $2(1-10)$ & $2(2-14)$ & $2(2-9)$ & 3 and 8 & $2(1-14)$ \\
\hline $\begin{array}{l}\text { Saccular aneurysms } \\
\text { ruptured, no. (\%) }\end{array}$ & $5(13 \%)$ & $9(36 \%)$ & $3(14 \%)$ & $4(50 \%)$ & $21(23 \%)$ \\
\hline $\begin{array}{l}\text { Lenght [mm]; } \\
\text { median (range) }\end{array}$ & $5(2-9)$ & $6(2-17)$ & $15(11-21)$ & $6(3-9)$ & $6(2-25)$ \\
\hline $\begin{array}{l}\text { Width [mm]; } \\
\text { median (range) }\end{array}$ & $4(2-4)$ & $6(2-14)$ & $9(8-15)$ & $4(3-6)$ & $4(2-15)$ \\
\hline $\begin{array}{l}\text { Neck [mm]; median } \\
\text { (range) }\end{array}$ & $3(2-3)$ & $4(3-10)$ & $6(4-8)$ & $3(3-4)$ & $3(2-10)$ \\
\hline
\end{tabular}

Table 5. Dome orientation of saccular PCA aneurysms.

\begin{tabular}{|l|l|}
\hline PCA Segment & Typical Aneurysm Dome Orientation (\%) \\
\hline P1 aneurysms & upward (67\%) \\
\hline P1/2 junction aneurysms & anterior or upward (80\%) \\
\hline P2 aneurysms & lateral (67\%) \\
\hline P3 aneurysms & posterior (50\%) \\
\hline
\end{tabular}

of them were smaller than $7 \mathrm{~mm}$. An irregular wall structure with secondary pouches was found in 15 $(22 \%)$ of the saccular PCA aneurysms, $10(66 \%)$ of which were ruptured. Saccular PCA aneurysms had a typical dome projection for each segment, as presented in Table 5.

\section{P1 Segment Aneurysms}

Most PCA aneurysms were located at the P1 segment $(n=39,42 \%)$. Most of these were saccular $(n=31,79 \%)$ and unruptured $(n=30,77 \%)$. There was no statistically significant size difference between ruptured and unruptured saccular $\mathrm{P} 1$ aneurysms $(\mathrm{P}=.38)$. The dominant dome projection for saccular aneurysms was upward $(n=21,67 \%)$, in continuation of the blood flow from the basilar artery. Half of the eight fusiform P1 segment aneurysms were ruptured and the remainder were unruptured. The four ruptured aneurysms had a somewhat larger average size: $8 \mathrm{~mm}$ vs $5 \mathrm{~mm}$.

\section{P1/2 junction Aneurysms}

The P1/P2 junction was the second most frequent location for PCA aneurysms, with 25 aneurysms $(27 \%)$. Most of these were unruptured $(n=16,64 \%)$ and saccular ( $n=20,80 \%)$. The saccular P1/P2 junction aneurysms projected mainly in either an anterior $(n=10,50 \%)$ or upward $(n=6,30 \%)$ direction. There was only a minor average size difference between the ruptured $(n=9)$ and unruptured $(n=11)$ saccular P1/P2 junction aneurysms: $6 \mathrm{~mm}$ vs. $5 \mathrm{~mm}$. All five fusiform $\mathrm{P} 1 / \mathrm{P} 2$ junction aneurysms were unruptured. The P1/P2 junction aneurysms had the most complex angioarchitecture of PCA aneurysms in general. In five cases the PCoA originated just proximal to the aneurysm base and in four cases just distal to the aneurysm base. In eight cases the PCoA was completely involved in the aneurysm formation.

\section{P2 Segment Aneurysm}

There were $21 \mathrm{P} 2$ segment aneurysms (24\%), most of which were unruptured $(n=16,76 \%)$. Although saccular aneurysms were more common than fusiform, the proportion of fusiform aneurysms was larger at the P2 segment than the P1 segment or P1/P2 junction ( $40 \%$ vs. $21 \%$ and $20 \%$, respectively). Therefore, the P2 segment was the most common location for fusiform aneurysms $(n=9)$ in our series. There was an average size difference between the ruptured $(n=3)$ and unruptured $(n=9)$ saccular P2 segment aneurysms (15 mm vs. $4 \mathrm{~mm}$ $\mathrm{P}=.22$ ). Fusiform $\mathrm{P} 2$ segment aneurysms affected a longer portion of the parent artery than fusiform aneurysms at other PCA segments. In general, diagnosed P2 segment aneurysms were larger than aneurysms at the other PCA segments. The saccular P2 segment aneurysms mainly projected in the lateral direction $(n=8,67 \%)$

\section{P3 Segment Aneurysms}

The P3 segment was the least frequent location for PCA aneurysms, representing only eight aneurysms (9\%). Six (75\%) of these were ruptured which represents the highest rupture rate of all PCA segments. Unlike at the P2 segment, the proportion of fusiform aneurysms (25\%) at the $\mathrm{P3}$ segment was similar to that of the proximal PCA aneurysms. Both of the fusiform P3 segment aneurysms were ruptured. There was one giant unruptured saccular P3 segment aneurysm. The four ruptured saccular P3 segment aneurysms had a median length of $6 \mathrm{~mm}$, similar to the ruptured saccular P1 segment or P1/P2 junction aneurysms. Three of the six saccular P3 segment aneurysms $(50 \%)$ projected in the posterior direction.

\section{Associated Aneurysms}

Altogether 49 of 81 patients had a total of 98 associated aneurysms. Interestingly, 36 of these 49 patients became symptomatic by an associated aneurysm rupture. The vessel distribution of associated aneurysms is given in Table 6 .

PCA Aneurysms in Association with AVM

In ten patients the PCA aneurysm was found on an AVM feeding PCA. In two patients, multiple PCA aneurysms were found. The average age of patients with AVM related PCA aneurysms was less than the average study population ( 40 vs. 50 years), but this difference was not statistically significant $(p=.72)$. Most of the AVM related aneurysms were located 
Table 6. Distribution of 98 associated aneurysms.

\begin{tabular}{|l|c|}
\hline Affected Vessel & Quantity of Aneurysms \\
\hline Middle cerebral artery & 21 \\
\hline Internal carotid artery & 19 \\
\hline Posterior cerebral artery & 12 \\
\hline Posterior communicating artery & 13 \\
\hline Anterior communicating artery & 11 \\
\hline Distal anterior cerebral artery & 9 \\
\hline Basilar artery & 7 \\
\hline Superior cerebellar artery & 4 \\
\hline Vertebral artery & 2 \\
\hline
\end{tabular}

on the proximal PCA in close relation to the basilar artery; the mean distance to the basilar artery was $6 \mathrm{~mm}$. The aneurysm distribution along the PCA segments was as follows: P1 ( $n=9), P 1 / 2$ junction $(n=2)$, and P2 $(n=3)$. The aneurysms had a saccular configuration with a median width of $4 \mathrm{~mm}$. The median parent vessel diameter on AVM related PCA aneurysm was larger than in non-AVM related PCA aneurysms: 2.5 vs. $1.5 \mathrm{~mm}$.

\subsection{Outcome after PCA Aneurysm Treatment}

5.2.1 Historical Series (1954-1979)

To provide an overview of conservative treatments, we analyzed historical records. There were 12 patients with 12 PCA aneurysms treated before 1980. O these 12 aneurysms, nine (75\%) were ruptured. The distribution of the aneurysms along the PCA segments was: $P 1 A s(n=2 ; 17 \%), P 1 / 2 A s(n=8 ; 66 \%)$, P2As $(n=1 ; 8 \%)$, P3As $(n=1 ; 8 \%)$. Three PCA aneurysms were found in autopsy, nine with conventional angiography. These patients (5 male, $7 \mathrm{fe}-$ male) had a mean age of 43 years (range 23-63 years). All patients were treated conservatively. The follow-up period ranged from 3 months to 34 years in initial survivors. One patient re-bled after 24 years of conservative treatment and the aneurysm was treated by microsurgical clip occlusion.
5.2.2 Distribution of 135 PCA Aneurysms

The P1 segment was the most affected segment with 53 aneurysms (39\%), followed by the $\mathrm{P} 1 / 2$ junction ( $n=39 ; 29 \%)$, P2 segment $(n=28 ; 21 \%)$ and P3 segment $(n=15 ; 11 \%)$. The highest rupture rate was in P3 aneurysms (60\%), particularly fusiform P3 segment aneurysms (75\%). However, the P2 segment was most often affected by fusiform aneurysms $(n=10)$.

\subsubsection{Clinical Presentation}

SAH was the most common symptom ( $n=62)$. An additional IVH was present in 21 patients, ICH in 3 patients, and a SDH in 1 patient. In 17 patients the SAH was caused by associated aneurysm rupture. Twelve patients (10\%) had an AVM-related PCA aneurysm. Oculomotor nerve affection was found in seven patients $(6 \%)$. Six patients $(5 \%)$ had symptoms of ischemia following embolism. Two patients became symptomatic from mass effect.

\subsubsection{Microsurgical Treatment}

Sixty-three aneurysms were treated microsurgically two aneurysms had previously been incompletely occluded by coiling. Aneurysms affected the $P 1$ segment $(n=18), P 1 / 2$ junction $(n=22), P 2$ segment $(n=15)$, and P3 segment $(n=8)$. Forty-four aneurysms were saccular and nineteen aneurysms fusiform. The following approaches were used: subtemporal approach, pterional approach, lateral supraorbital approach, and posterior interhemispheric approach for distal aneurysms. Modified temporal approaches were used for two bypass procedures. The following procedures were applied: neck clipping $(n=45)$, failed clipping $(n=1)$, neck clipping after failed endovascular occlusion $(n=2)$, aneurysmorrhaphy $(n=1)$, trapping $(n=2$, one after failed clipping), proximal occlusion $(n=7)$, parent vessel occlusion after bypass ( $\mathrm{n}=4$, two ELANA procedures), and wrapping ( $n=1)$. In 23 procedures, associated aneurysms were addressed from the same approach. Incomplete aneurysm occlusion occurred in six cases after neck clipping and in after aneurysm trapping. Oculomotor nerve palsy was observed in nine patients and trochlear nerve palsy in one patient.

\subsubsection{Endovascular Treatment}

Endovascular treatment was applied for 19 aneurysms affecting the $P 1$ segment $(n=8), P 1 / 2$ junction $(n=4)$, P2 segment $(n=3)$ and P3 segment $(n=4)$. Only four of these aneurysms were fusiform. Direct coiling $(n=15)$, stent assisted coiling $(n=1)$ and sole stenting $(n=2)$ were the techniques applied. In one case the parent vessel was occluded to occlude three PCA aneurysms. Parent vessel occlusion was used in a second case, where the patient developed an asymptomatic PCA infarction. Five aneurysms were incompletely occluded, two of which were subsequently surgically treated and three followed up. Two patients developed permanent oculomotor nerve palsy.

\subsubsection{Conservative Treatment}

Consideration for conservative treatment was mainly based on the patient's poor clinical condition (i. e. H\&H grade $V, n=10$ ). Twenty-nine PCA aneurysms with a size under $4 \mathrm{~mm}$ were treated conservatively. Most AVM related aneurysms were also treated indirect or conservatively following AVM treatment. One patient died following an ia- trogenic injury during diagnostic DSA. One patient was treated conservatively due to advanced age.

\subsubsection{One-Year Outcome}

Patients with Unruptured Saccular PCA Aneurysms $(n=9)$

Six of nine patients were treated conservatively (Tab.7). One patient with oculomotor palsy and older age (88 years) was treated conservatively (mRS was 1 after one year with persistent oculomotor palsy). During the first year of follow-up, one patient died following a cardiac infarction. The other patients had aneurysms below $4 \mathrm{~mm}$ in size and al of them had favorable outcomes (mRS 0). Three patients were treated microsurgically (Tab. 7). Two patients, including one who underwent bypass bridging, had a good outcome. One patient had a moderate outcome caused by PCA infarction after parent vessel occlusion.

Patients with Unruptured Fusiform PCA Aneurysms $(n=10)$

Nine patients were diagnosed incidentally. One patient became symptomatic with embolic symptoms. Only one patient with a small aneurysm $(<3 \mathrm{~mm})$ was treated conservatively and had a good outcome. All other patients were treated by microsurgical means. Three patients were treated by proximal occlusion and two of them developed a PCA infarction after proximal occlusion. One aneurysm was clipped following failed coiling and one clipped aneurysm required re-operation to trap the aneurysm. Four aneurysms were directly clipped. Three patients developed permanent oculomotor nerve palsy following direct clipping. One aneurysm was trapped after bypass bridging. The overall outcome was good in five cases and moderate in five cases (Table 7).

Patients with Ruptured Saccular PCA Aneurysms $(n=20)$

All of these patients suffered from SAH. One patient had an additional oculomotor palsy. Four patients were treated conservatively due to poor clinical condition on admission ( $H E t H V, n=3$ ) or advanced 
Table 7. One-year outcome of 46 patients with PCA aneurysms.

\begin{tabular}{|c|c|c|c|c|}
\hline & $\begin{array}{c}\text { Unruptured } \\
\text { Saccular PCA } \\
\text { Aneurysms }(n=9)\end{array}$ & $\begin{array}{c}\text { Unruptured } \\
\text { Fusifrom PCA } \\
\text { Aneurysms }(n=10)\end{array}$ & $\begin{array}{c}\text { Ruptured } \\
\text { Saccular PCA } \\
\text { Aneurysms }(n=20)\end{array}$ & $\begin{array}{c}\text { Ruptured } \\
\text { Fusiform PCA } \\
\text { Aneurysms }(n=7)\end{array}$ \\
\hline \multicolumn{5}{|l|}{ Treatment, no. } \\
\hline Microsurgical treatment & 3 & 9 & 13 & 2 \\
\hline Endovascuar treatment & 0 & 0 & 3 & 2 \\
\hline Conservative & 6 & 1 & 4 & 3 \\
\hline \multicolumn{5}{|l|}{ Outcome, no. } \\
\hline mRS 0-1 (good) & 7 & 5 & 8 & 2 \\
\hline mRS 2-4 (moderate) & 1 & 5 & 6 & 3 \\
\hline mRS 5-6 (poor) & 1 & 0 & 6 & 2 \\
\hline
\end{tabular}

age and sever cardiac dysfunction ( $n=1)$ (Tab. 7). Two patients were treated by direct coiling and one by a stent/coil technique (Tab. 7). Two patients had a good outcome. The other patient developed an anterior circulation infarction and recovered with a mRS of 4 after one year. Microsurgical treatment with direct clip application was applied to 13 patients (Tab. 7). The parent vessel was occluded in five cases. One patient had a poor outcome that later proved fatal after intraoperative aneurysm rupture during clipping from a pterional approach. One aneurysm was incompletely occluded by clipping and the patient died following re-rupture (confirmed in autopsy). The one-year outcome was good in six cases and moderate in four cases.

Patients with Ruptured Fusiform PCA Aneurysms $(n=7)$

All patients in this subgroup suffered from SAH. Three were in poor clinical condition and treated conservatively. Only one patient survived during the first year. Two were treated successfully by endovascular techniques. In one case, a patient developed a PCA infarction following extended temporary clipping while managing an intraoperative rupture. One patient was treated successfully by proximal occlusion. The outcomes are summarized in Table 7.
Patients with Unruptured Giant PCA Aneurysm (diameter $\geq 25 \mathrm{~mm} ; n=7$ )

Three patients became symptomatic via rupture, two via mass lesion, one via thromboembolism, and one was an incidental finding. Six aneurysms were located at the P2 or P3 segment and four presented a fusiform shape. The following treatment methods were applied: proximal occlusion via subtempora approach $(n=3)$, coil embolization with parent vesse occlusion $(n=1)$, thrombectomy and PCA reconstruction $(n=1)$, complex ELANA bypass $(n=1)$. One patient was treated conservatively following iatrogenic injury during DSA. A ventriculoperitonea shunt was required in one case. One patient had one a fatal outcome (Tab. 8).

Patients with Unruptured PCA Aneurysms with As sociated Unruptured Aneurysms ( $n=21$ )

Twenty-one patients had multiple aneurysms and unruptured PCA aneurysms (Tab. 8). Thirteen patients had a good outcome and seven a moderate outcome. The remaining patient died following complication from a diagnostic DSA procedure. Microsurgery was applied to ten patients. In three cases a pterional or lateral supraorbital approach was used to occlude the PCA aneurysm in the same procedure with associated aneurysms. In five patients a two-step strategy was chosen. In two cases good outcome, five had moderate outcomes, and

Table 8. One-year outcomes of 75 patients with complex vascular lesions and PCA aneurysms.

\begin{tabular}{|c|c|c|c|c|c|}
\hline & $\begin{array}{c}\text { Patients with } \\
\text { Unruptured } \\
\text { Giant PCA } \\
\text { Aneurysms } \\
(n=7)\end{array}$ & $\begin{array}{c}\text { Patients with } \\
\text { Unruptured } \\
\text { PCA Aneurysms } \\
\text { with Associated } \\
\text { Unruptured } \\
\text { Aneurysms }(n=21)\end{array}$ & $\begin{array}{l}\text { Patients with } \\
\text { Unruptured } \\
\text { PCA Aneurysm } \\
\text { and Ruptured } \\
\text { Associated } \\
\text { Aneurysm }(n=17)\end{array}$ & \begin{tabular}{|c|} 
Patients with \\
Ruptured \\
PCA Aneurysms \\
with Associated \\
Unruptured \\
Aneurysms ( $n=18)$
\end{tabular} & $\begin{array}{l}\text { Patients with } \\
\text { an Associated } \\
\text { AVM }(n=12)\end{array}$ \\
\hline \multicolumn{6}{|l|}{ Treatment, no. } \\
\hline $\begin{array}{l}\text { Microsurgical } \\
\text { treatment }\end{array}$ & 5 & 10 & 4 & 10 & 2 \\
\hline $\begin{array}{l}\text { Endovascuar } \\
\text { treatment }\end{array}$ & 1 & 3 & 3 & 5 & 0 \\
\hline Conservative & 1 & 8 & 10 & 3 & 10 \\
\hline \multicolumn{6}{|l|}{ Outcome, no. } \\
\hline mRS 0-1 (good) & 1 & 13 & 7 & 5 & 3 \\
\hline mRS 2-4 (moderate) & 5 & 7 & 4 & 9 & 8 \\
\hline mRS 5-6 (poor) & 1 & 1 & 6 & 4 & 1 \\
\hline
\end{tabular}

an additional posterior interhemispheric approach was used to occlude a distal PCA aneurysm (P3 segment). Flow modulation by a complex bypass procedure was used in one case for the treatment of multiple posterior circulation aneurysms. In three cases, all aneurysms were occluded by endovascular techniques in one interventional session. Proximal occlusion was used in one case to occlude a total of three PCA aneurysms. In eight patients the PCA aneurysm was treated conservatively due to small aneurysm size or poor clinical conditions.

Patients with Unruptured PCA Aneurysms with Associated Ruptured Aneurysms ( $n=17$ )

Seventeen patients suffered from associated aneurysm rupture, exhibiting the following Hunt and Hess grade distribution: HEtH I $(n=3), H E t H ~$ $(n=7), H E H$ III $(n=1), H E t H ~ I V ~(n=2)$, and HEtH V $(n=4)$. The following intracranial vessels were affected by ruptured aneurysms: MCA $(n=5), B A$ $(n=4)$, ICA $(n=3), A C o A(n=3)$, and VA $(n=2)$. For three patients, endovascular approaches were used to treat all affecting aneurysms. A multi-stage procedure with a microsurgical approach for the PCA aneurysm was used in four cases. Ten patients with an unruptured PCA aneurysm were treated conservatively after the treatment of the ruptured aneurysm. Following this treatment, one patient was in such poor condition that the cerebral aneurysms could not be treated. A secondary hydrocephalus was treated by EVD in five cases (29\%). A permanent shunt was not needed for any of these patients. Seven patients had a good outcome, three patients a moderate outcome, and six a fatal outcome (Tab. 8).

Patients with Ruptured PCA Aneurysms with Associated Unruptured Aneurysms ( $n=18$ ) Eighteen patients with ruptured PCA aneurysms and associated aneurysms were treated (Tab. 8). Poor clinical condition (HEtH grade V) led to conservative treatment in three cases, with all outcomes being fatal. One suffered from a cardiac infarction following SAH. Microsurgery was applied to ten patients. Ruptured PCA aneurysms were addressed directly in six cases and all reachable aneurysms were occluded from the same approach. Additional surgeries were necessary in four cases. The following outcome results were achieved: good $(n=3)$, moderate $(n=6)$, and fatal $(n=1)$. Five patients 
were treated endovascularly. In four cases associated anterior circulation aneurysms were treated by clip occlusion. Two patients recovered with a good outcome and three a moderate outcome.

Patients with an Associated AVM ( $n=12$

There were 12 patients with associated AVMs; in eight of these cases the aneurysm was located on an AVM-feeding PCA. Direct microsurgical occlusion was considered necessary in only two cases; in one case a ruptured saccular P2 aneurysm was clipped and in the other case a P3 aneurysm was clipped together with a flow-related basilar bifurcation aneurysm. Both cases utilized via subtemporal approach. In six cases the aneurysms were treated in directly by AVM occlusion. A conservative treatment was chosen for four patients. One patient was in poor clinical condition after AVM rupture. The outcome was good in three cases, moderate in eight cases, and poor in one case. The outcome deficit was primarily related to the AVM and its treatment Only one patient suffered from a flow-related PCA aneurysm rupture. The outcomes are summarized in Table 8.

\subsubsection{Complications and Poor Outcome Analyses}

Of the 121 patients with PCA aneurysms (52\% ruptured vs. $48 \%$ unruptured, but 33\% SAH form associated aneurysm rupture), 21 died during the first year and two remained vegetative. Thirteen of these patients arrived under poor clinical conditions (HEtH grade $\mathrm{V}$ ) and were primarily treated conservatively. Five patients had a moderate SAH (HCH III-IV): one died by cardiac infarction, one bled in an infarct area after proximal PCA occlusion, and three died following severe vasospasm and multiple infarctions. Two patients without SAH died following DSA complications and one by a cardiac infarction. Two other patients entered a vegetative state; one of these cases was associated with a ruptured AVM. Six of eleven patients with parent vessel occlusion had a symptomatic PCA infarction. Incomplete aneurysm occlusion occurred in six cases after neck clipping and aneurysm trapping. Nine patients de- veloped oculomotor nerve palsy following microsurgical treatment and two after endovascular treatment. One developed trochlear nerve palsy after microsurgical treatment

\subsection{Subtemporal Approach to PCA} Aneurysms

Characteristics of 37 PCA Aneurysms Treated from a Subtemporal Approach

Thirty-seven PCA aneurysms were treated from a subtemporal route. In particular, the P2 segment was easily approachable in 16 cases, followed by the $P 1 / 2$ junction $(n=10)$, the $p 1$ segment $(n=6)$ and the P3 segment $(n=5)$. The aneurysm configuration is listed in Table 9 .

Aneurysm Management

The specific treatment modalities for saccular and fusiform PCA aneurysms are shown relative to the rupture status in Tables 10 and 11.

Outcome after 3 Months

Of the patients with SAH from PCA aneurysm rupture, ten achieved a good outcome (mRS 0-2), two achieved a moderate outcome (mRS 3-4), and two had a poor outcome (mRS 5-6). One patient died due to hemorrhagic infarction of the PCA territory 17 days after the proximal occlusion of a $P 3$ aneurysm. The other patient with a poor outcome had an initial Hunt and Hess grade of $\mathrm{V}$ on admission and remained in a vegetative state.

There were two patients suffering from $\mathrm{SAH}$ and unruptured PCA aneurysms. The treatment of the associated PCA aneurysms was uneventful. One patient achieved a good outcome and the other a moderate outcome in regards to the treatment of the primary ruptured aneurysms.

Of the 18 patients without PCA aneurysm rupture, 14 achieved a good outcome (mRS 0-2) and 4 a moderate outcome (mRS 3-4). Two of these patients developed symptoms of a PCA infarction after accidental parent vessel occlusion subsequen to direct clipping of a medium $(10 \mathrm{~mm})$ and large $(21 \mathrm{~mm})$ PCA aneurysm. One patient with a gian
Table 9. Shape and size of 37 PCA aneurysms operated via a subtemporal approach

\begin{tabular}{|l|c|c|}
\hline & $\begin{array}{c}\text { Ruptured } \\
\text { Aneurysms }\end{array}$ & $\begin{array}{c}\text { Unruptured } \\
\text { Aneurysms }\end{array}$ \\
\hline Saccular aneurysms, no. & 9 & 12 \\
\hline $\begin{array}{l}\text { Length (mm); } \\
\text { median (range) }\end{array}$ & $9(5-25)$ & $4(2-35)$ \\
\hline $\begin{array}{l}\text { Neck (mm); } \\
\text { median (range) }\end{array}$ & $4(2-8)$ & $2(2-14)$ \\
\hline Fusiform aneurysms, no. & 5 & 11 \\
\hline $\begin{array}{l}\text { Length (mm); } \\
\text { median (range) }\end{array}$ & $13(9-37)$ & $8(5-40)$ \\
\hline $\begin{array}{l}\text { Diameter (mm); } \\
\text { median (range) }\end{array}$ & $11(5-33)$ & $6(5-32)$ \\
\hline
\end{tabular}

Table 10. Treatment strategies for 23 unruptured PCA aneurysms.

\begin{tabular}{|l|c|c|}
\hline Treatment Modality & $\begin{array}{c}\text { Unruptured } \\
\text { saccular PCA } \\
\text { Aneurysm } \\
(\mathbf{n}=12)\end{array}$ & $\begin{array}{c}\text { Unruptured } \\
\text { fusiform PCA } \\
\text { Aneurysm } \\
(\mathbf{n}=11)\end{array}$ \\
\hline Clipping & 10 & 4 \\
\hline Wrapping & 1 & \\
\hline Proximal occlusion & - & 4 \\
\hline Trapping & - & 1 \\
\hline Trapping after bypass & - & 1 \\
\hline $\begin{array}{l}\text { Proximal occlusion } \\
\text { after ELANA bypass }\end{array}$ & - & 1 \\
\hline Aneurysmorrhaphy & 1 & - \\
\hline
\end{tabular}
paresis after proximal occlusion and another patient with a giant $(40 \mathrm{~mm})$ fusiform PCA aneurysm developed a thalamic infarction by a thromboembolism after an ELANA high flow bypass procedure.

Aneurysm Management Related Complications The most common complication after PCA aneurysm treatment was the occurrence of postoperative infarctions in the PCA supply area. Our series had four such infarctions after direct neck clipping, six after proximal occlusion, one after aneurysm trapping, and one after a complex ELANA procedure. Small neck remnants were found in three aneurysms after direct neck clipping. One of these patients was retreated by aneurysm trapping using the same approach.

The distribution of complications for each treatment option in total numbers; saccular vs. fusiform is shown in parentheses $(n / n)$.

Approach Related Complications

Two patients with a ruptured PCA aneurysm suffered from postoperative temporal lobe contusions caused by temporal lobe retraction. Cranial nerve palsy was observed in six patients; five of these patients exhibited oculomotor nerve palsy, four of whom recovered well during the first 3 months, and one patient suffered from trochlear nerve palsy. Wound infection, dehiscence, and postoperative CSF leakage were not observed in our series.

\begin{tabular}{|l|c|c|}
\hline Treatment Modality & $\begin{array}{c}\text { Ruptured } \\
\text { saccular PCA } \\
\text { Aneurysm } \\
(\mathrm{n}=9)\end{array}$ & $\begin{array}{c}\text { Ruptured } \\
\text { fusiform PCA } \\
\text { Aneurysm } \\
(\mathrm{n}=5)\end{array}$ \\
\hline Clipping & $\mathbf{8}$ & 2 \\
\hline Proximal occlusion & - & 3 \\
\hline Trapping & 1 & - \\
\hline
\end{tabular}




\section{Discussion}

\begin{tabular}{|l|c|c|c|c|c|}
\hline Complication & $\begin{array}{c}\text { Clipping } \\
(\mathbf{n}=25)\end{array}$ & $\begin{array}{c}\text { Proximal occlusion } \\
(\mathbf{n}=\mathbf{7})\end{array}$ & $\begin{array}{c}\text { Trapping } \\
(\mathbf{n}=2)\end{array}$ & $\begin{array}{c}\text { ELANA } \\
(\mathbf{n}=1)\end{array}$ & Total \\
\hline PCA infarction & $4(2 / 2)$ & $6(0 / 6)$ & $1(0 / 1)$ & $1(0 / 1)$ & $12(2 / 10)$ \\
\hline Temporal lobe contusion & $2(2 / 0)$ & - & - & & $2(2 / 0)$ \\
\hline Neck remnant & $3(1 / 2)$ & - & - & & $3(1 / 2)$ \\
\hline Intraoperative rupture & $1(1 / 0)$ & - & - & & \\
\hline Oculomotor nerve palsy & $4(3 / 1)$ & - & - & $1(0 / 1)$ & $5(3 / 2)$ \\
\hline Trochlear nerve palsy & - & - & $1(1 / 0)$ & & $1(1 / 0)$ \\
\hline
\end{tabular}

\subsection{Lateral Supraorbital Approach to PCA} Aneurysms

Using the lateral supraorbital approach we were able to occlude ipsilateral aneurysms of the ICAPCoA segment and the PCA-P1 segment by clipocclusion in 55 minutes operation time, skin to skin. The postoperative computed tomography angiography shows a patent posterior cerebral artery. The patient was discharged six days after the surgery with the same neurological state demonstrated preoperatively (mRS of 2), caused by a preexisting right cerebral infarction secondary to an idiopathic right carotid artery dissection.

\subsection{Characteristics of PCA Aneurysms}

\section{Aneurysm Distribution}

Our analysis confirms the findings of previously published series that saccular proximal PCA aneurysms are more common than distal PCA aneurysms [Ciceri 2001, Drake 1996] as only 32\% of PCA aneurysms were found distal to the P1/2 junction. The most affected location in particular was the P1 segment. Similar distribution patterns are described for the anterior cerebral artery (ACA) and the middle cerebral artery (MCA) [Dashti 2007, Lehecka 2008]. In contrast, fusiform PCA aneurysms present a more uniform distribution pattern. Unequal hemodynamic conditions across the different portions of the arteries may play a role in the formation of these saccular aneurysms.

\section{Ruptured PCA Aneurysms}

It appears that although distal PCA aneurysms are less frequent, they are also more dangerous as evinced by $\mathrm{P} 3$ segment aneurysm rupture rates of up to $75 \%$ compared to $38 \%$ for proximal PCA aneurysms. However, the mechanism is difficult to explain, as distal aneurysms are located in segments with lower flow. Further structural and transcriptomic investigations are necessary to analyze the wall structure and the degeneration processes in these aneurysms [Frösen 2004, Kurki 2011]. Saccular

P1/2 junction aneurysms represent the second largest group among ruptured PCA aneurysms. Turbulent blood flow resulting from two inflow zones and only one outflow may play a role for the formation of these aneurysms, as flow separation and rupture rates are comparable to ACoA and MCAbif aneurysms [Dashti 2007, Hernesniemi 2008].

\section{Size of PCA Aneurysms}

Most PCA aneurysms $(n=77,75 \%)$ were smaller than $7 \mathrm{~mm}$ even when ruptured. Ruptured aneurysms were only slightly larger on average than those unruptured. In our series, we saw only nine large and seven giant aneurysms, representing 12\% of all the PCA aneurysms studied. PCA aneurysms are generally no larger than intracranial aneurysms at other locations [Dashti 2007, Drake 1996 Lehecka 2008, Taylor 2003, Yasargil 1984, Yonekawa 2011]. In our opinion, a different admission policy led to an overrepresentation of large and complex cases compared to previous series.

\section{Fusiform PCA Aneurysms}

The proportion of fusiform PCA aneurysms in our series is high at 24\%, but falls inside the 19-40\% range previously reported [Ciceri 2001, Drake 1996 Hallacq 2002, Taylor 2003]. However, the occurrence rate is very high compared to fusiform anterior circulation aneurysms, where only around 1\% of aneurysms had a fusiform shape [Dashti 2007, de Sousa 1999, Lehecka 2008, Pritz 2011, Steven 2007]. The low-flow distal PCA segment in particular shows more fusiform aneurysms than saccular compared to segments with higher blood flow. In general, blood flow velocity in the PCA is much lower than in the anterior circulation [Hennerici 1987]. One could speculate that the anatomical proximity of the PCA to skull structures imparts a predisposition for fusiform aneurysm formation following a skull injury. The P2 segment in particular, which is in close relation to the tentorial edge, was the segment most often affected with fusiform aneurysms.

Anatomical Relationships of PCA Aneurysms

Saccular PCA aneurysms present a characteristic dome orientation at each PCA segment. Their orientation is often in line with the vascular flow or in the direction of the originating branches. Therefore, PCA aneurysms often exhibit a dome orientation toward the surgical view. Additionally, the location of proximal PCA aneurysms is typically relatively high, above the posterior clinoid level. The typical dome projections and positioning with 
respect to the skull base are important factors for consideration when planning microneurosurgical approaches and treatment strategies for these rare lesions.

AVM and Multiple Aneurysm Association Our findings confirm previous reports, which suggest that PCA aneurysms are often associated with arterio-venous malformations (10\%) and multiple intracranial aneurysms (55\%). This association is particularly influential when planning occlusive therapy. Usually, patients are clinically symptomatic by the AVM. In the case of AVM associated aneurysms, the relevant literature reports shrinkage or disappearance of flow-related aneurysms after complete AVM obliteration [Meisel 2000, Redekop 1998]. Another interesting finding is that all of the AVM related aneurysms, located at dilated and higher flow feeders of AVMs, were saccular.

Historical Aspects

Our own historical series reviewed 12 patients treated between 1954 and 1980. These patients al received conservative treatment and demonstrated a high rate of unfavorable outcomes $(50 \%)$. A case report given by Bertrams in 1968 regarding a patient with a fatal outcome following a giant dista PCA aneurysm rupture reflects our impression of the historic patient records [Bertrams 1968]. Around that point in time the treatment of PCA aneurysms changed from conservative measures to a mostly active microsurgical treatment [Drake 1969, Hun 1967]. In addition, endovascular techniques hav evolved rapidly during the last three decades. As result, PCA aneurysms closely related to the brainstem are now treated by endovascular techniques at many institutions [Ciceri 2001, Hallacq 2002, van Rooij 2006].

\section{Clinical Presentation}

With regard to SAH severity, the overall HEtH grade was similar for proximal PCA aneurysms and distal PCA aneurysms. However, five of the nine ruptured
P3 aneurysms led to an IVH or ICH, highlighting the danger of distal PCA aneurysms. Our series showed a lower frequency of cranial nerve disturbances compared to Drake's series on PCA aneurysms (6\% vs. $21 \%)$. One possible explanation for this difference is the lower rate of large and giant aneurysms in our study (12\% vs. 21\%) [Drake 1996].

Treatment Strategies for Saccular PCA Aneurysm Microsurgery and interventional techniques allow for easy access to proximal saccular PCA aneurysms. We have treated 15 patients presenting 15 saccular PCA aneurysms with endovascular techniques, but the primary aneurysm occlusion rate was low at $73 \%$, compared to $89 \%$ in the microsurgical group. The relevant literature reports that a complete closure of the aneurysm by endovascular technique often requires a parent vessel occlusion [Ciceri 2001 Cotroneo 2007, Hallaca 2002]. Most cases of the actual series were treated by microsurgical means, which allows for direct visual control of the important perforating branches and the occlusion of the aneurysm neck. However, the most frequent complications were more dependent on the chosen strategy rather than the treatment approach. In general, quick aneurysm treatment following SAH is recommended [Fogelholm 1993, Peerless 1994]

Treatment Strategies for Fusiform PCA Aneurysms A fusiform shape is common for PCA aneurysms. The direct microsurgical and endovascular treatment of these aneurysms is aggravated by the origination of perforating branches and the aneurysm shape itself. Direct clip occlusion was possible in only 7 of the 29 fusiform aneurysms (29\%), and 2 of these were only partially occluded. Proxima occlusion must be done with great care to prevent devastating PCA infarction. This treatment strategy can only be recommended as an "ultima ratio". In our opinion reconstructive procedures should be discussed for these cases. Despite the risks, a balloon occlusion test can provide helpful information [Chang 2010, Jayakumar 2004, Lawton 1996, Mathis 1995, Originato 1994]
Need for Revascularization

According to the 125 PCA aneurysm series of Drake et al. (1996), it seems that parent vessel occlusion is a safe treatment option for aneurysms distal to the thalamoperforating branches thanks to the collateral supply potential from the anterior circulation by the anterior/posterior choroidal artery and the pericallosal arteries [Drake 1996]. However, we must be more critical of this assumption based on the results of the present series. The most compromising factor on patient outcome was the appearance of PCA infarctions, particularly when proximal occlusion or trapping was the chosen treatment strategy. While causation is not entirely clear, the main difference between our series and Drake's is that we treated mostly non-giant and non-thrombosed PCA aneurysms where collateral circulation had not yet developed prior to treatment.

Revascularization procedures may often be required for successful treatment of non-saccular or complex aneurysms that cannot be treated by direct clipping. Chang et al. from the Barrow Institute recommended a practical treatment algorithm in 2010 following a series of 33 patients with distal PCA aneurysms. In Chang's study bypass procedures were considered helpful in 14 cases but also observed to be associated with specific complications like bypass failure and epidural hematomas.

Microsurgical Approaches to PCA Aneurysms

When choosing the microsurgical approach for intracranial aneurysm surgery the aneurysm configuration, parent vessel course, and exact location in relation to skull base structures and basal cisterns are particularly important [Seoane 1997, Terasaka 2000]. Frontotemporal and subtemporal routes are the most common approaches for PCA aneurysms [Drake 1996, Seoane 1997, Taylor 2003, Terasaka 2000, Yonekawa 2011]. Regardless of the selected approach, the main challenges are:

- avoidance of brain tissue injury from retraction,

prevention of injury to the venous system (Sylvian veins, the vein of Labbé)
- prevention of brainstem perforator injury, securing sufficient perfusion of the PCA territory with prevention of PCA infarction.

Frontolateral Approaches

Segmental allocation is especially important when selecting the surgical approach [Seoane 1997]. To gain microsurgical access to proximal PCA aneurysms (P1 and P2), the following frontolateral approaches are well described: orbitozygomatic approach, anterior temporal approach, pterional and subtemporal approaches [Drake 1996, Gerber 1993 Türe 2003, Yasargil 1984, Yonekawa 2011]. Using these approaches, the proximal sylvian fissure must be opened to obtain enough space for the aneurysm dissection. However, the surgical corridor is deep narrow, and in close proximity to very sensitive neurovascular structures. Sometimes a selective amygdalohippocampectomy is necessary to obtain enough space [Yonekawa 2011]. The removal of anterior or posterior clinoid can be required to improve the area of binocular vision [Yonekawa 1997/2011]. To approach high-lying P1 segment aneurysms, the transsylvian route is effective. The exposure of the aneurysm neck can be somewhat more difficult from a pterional view point compared with the subtemporal view as aneurysms of the P1 segment and $\mathrm{P} 1 / 2$ junction mainly project in the cranial or anterior direction.

Subtemporal Approach

Drake introduced the subtemporal approach in 1961 for the treatment of basilar aneurysms. This method was later adopted for PCA aneurysms and represents the most direct and efficient route to the PCA [Drake 1961/1996]. The subtemporal approach is relatively simple and fast, avoids extensive bone removal, and therefore belongs in the scope of standard neurosurgical approaches. It also offers good visualization of the interpeduncular and ambient cistern. PCA aneurysms in proximity to the tentorium are well-approachable from a subtemporal route [Hernesniemi 2005, McLaughlin 2014 Terasaka 2000, Uygur 2007, Zador 2010]. The course of the P2 segment, parallel to the tentorium, allows for proximal and distal parent vessel control. How- 
ever, far distal PCA aneurysms and aneurysms high above the posterior clinoid process $(>3 \mathrm{~mm}$ ) canno be reached [Drake 1996, Seoane 1997, Yonekawa 2011].

The main drawback of the subtemporal approach is the required elevation of the temporal lobe and potential problems associated with this movement. This risk is unavoidable, as execution of this method without temporal lobe retraction is not possible To keep the retraction as minimal as possible, prio release of CSF via spinal drain should provide sufficient room for reaching the tentorial edge and the interpeduncular cistern safely for additional CSF release. A severe brain edema or intracerebral hematoma can make the application of the subtemporal impossible. We have observed related complications in our own series; fortunately only two patients suffered from a temporal lobe contusion, but both also had acute SAH.

After sufficient CSF release the subtempora approach provides sufficient working space, even for complex microsurgical treatments such as bypass-bridging techniques, trapping, aneurysmorrhaphy, and in situ anastomoses between the SCA and PCA [Sundt 1982, Terasaka 2000, Zador 2010] Additional aneurysms lying on the ipsilateral proximal SCA, PCoA, or the tip of the basilar artery can be treated in the same session using the subtemporal approach.

Posterior Approaches

It is usually not possible to directly approach fa distal PCA aneurysms (P3 and P4) using the frontolateral or subtemporal approach. Only when proximal occlusion is deemed necessary are these approaches are feasible; the direct treatment of $P 3$ and $\mathrm{P} 4$ aneurysms require different approaches. According to Yasargil (1984) the posterior interhemispheric approach is suitable to reach the terminal PCA (P4). To approach deeper locations around the posterior surface of the midbrain Yonekawa et al. reports that the supracerebellar transtentorial approach in the sitting position is applicable [Touho 1995, Yasargil 1984, Yonekawa 2011].
Using these strategies, we were able to manag 54 patients with multiple intracranial aneurysms. Fortunately, frontotemporal craniotomies are favorable for the management of most ipsilateral anterior circulation aneurysms and endovascular techniques allow the occlusion of several aneurysms during a single intervention [Shen 2014, Yasargi 1984].

Treatment Strategies for PCA Aneurysms in Association with AVM

We addressed only three aneurysms of AVM feeding vessels by direct microsurgical treatment. In the case of AVM associated aneurysms, the literature reports shrinkage or disappearance of flow-related aneurysms after complete AVM obliteration [Meise 2000, Redekop 1998]. The low rupture rate during follow-up supports this decision history. However longer follow-up periods are necessary. The decision-making process for each of these individua cases is very complex in general.

\subsection{Complications}

Parent Vessel Occlusion

The occurrence of ischemic infarctions following parent vessel occlusion is one of the most serious and outcome-affecting complications following PCA aneurysm treatment. Contrary to general opinion and results of comparable studies [Drake 1997, Hallacq 2002], parent artery occlusion is not a safe treatment option for distal PCA aneurysms and can only be recommended as an "ultima ratio" especially in the case of fetal-type PCA [Xu 2015].

Perforator Infarction

The main objective of the treatment of PCA aneurysms is preventing injury to the brainstem and midbrain infarctions. Open microsurgery has the advantage of direct visual control compared to endovascular treatment. ICG videoangiography, as a new intraoperative technique introduced to micro-neurosurgery in 2003, provides real-time images of arterial and venous blood flow and allows an immediate evaluation of the perforating branches. We found only one patient with a thalamic infarction and one patient with a partial temporal lobe infarction.

angle. Using a subtemporal approach, the $4^{\text {th }}$ nerve runs directly across the surgical field in a nearly horizontal fashion and is much thinner and more sensitive than the $3^{\text {rd }}$ nerve. It is possible to accidentally injure the $4^{\text {th }}$ nerve with an instrument shaft, especially during dissection under very high magnification when the $4^{\text {th }}$ nerve is out of focus or surgical view. Protection of the $4^{\text {th }}$ nerve during surgery is only possible by being aware of its exact position during all steps, especially in the case of SAH. traoperative monitoring of the $3^{\text {rd }}$ and $4^{\text {th }}$ nerves can prevent permanent damage [Zhou 2012].

\subsection{Future Aspects of PCA Aneurysm} Treatment

Modern vascular imaging will allow for less invasive methods and provide more detailed information about the aneurysm, wall configuration, vascular reserve, and collateral supply. This information will

$3^{\text {rd }}$ and $4^{\text {th }}$ Nerves

The proximity of the $3^{\text {rd }}$ and $4^{\text {th }}$ nerves to the surgical field is a frequent cause of problems. Oculomotor nerve irritation is the second most common microsurgical complication in treatment of upper posterior circulation aneurysms, irrespective to the chosen approach [Drake 1996, Horikoshi 1999]. The paresis can be caused by direct mechanical irritation as well as vascular impairment of the occulomotor nuclei or fascicle. A temporary paresis can occur even after only minimal manipulation during dissection. Frontotemporal approaches allow a trajectory that is perhaps slightly more favorable for the protection of the $3^{\text {rd }}$ nerve than the subtemporal approach, but oculomotor paresis is possible in this case as well. The paresis usually regresses after a short period (a few weeks to a few months). Clip application is another situation where oculomotor nerve injury is possible; careful clip verification is of paramount importance.

Trochlear nerve injury is uncommon but possible. The risk of such injury is much higher when using the subtemporal approach compared to the pterional approach, due to the different surgical make it easier to decide on the need for revascularization and plan the treatment strategy as a whole. With the progressive development of materials science, new endovascular devices are being made available to our endovascular units. In particular, well-configured saccular aneurysms will be treated mostly by endovascular means. Microsurgical revascularization will gain importance in the treatment of complex lesions. Hybrid procedures, with proximal endovascular occlusion and dista microsurgical flow augmentation, will also be increasingly applied. Clip occlusion will always be available for definitive microsurgical treatment of saccular aneurysms.
Direct visual control in combination with in- 


\section{Conclusion}

PCA aneurysms are rare lesions that are often associated with other vascular pathologies such as multiple aneurysms and AVM. Most PCA aneurysms are smaller than $10 \mathrm{~mm}$, even when ruptured. Dista PCA aneurysms are more often ruptured than proximal PCA aneurysms. The incidence of fusiform PCA aneurysms is high at $26 \%$ and the $P 2$ is the segment most often affected by fusiform PCA aneurysms. Saccular PCA aneurysms typically have a dome orientation in relation to the originating PCA segment.

Aneurysms of the PCA are infrequent and often associated with other vascular pathologies. As a result, individual treatment strategies are required. Both microsurgery and endovascular treatment are effective options for the occlusion of PCA aneurysms. Despite commonly adequate vessel collateralization of the distal PCA territory, preservation or reconstruction of the parent vessel is crucia

\section{Acknowledgement}

for favorable treatment outcomes. The rate of intraoperative third nerve injuries shows that solely visual control is insufficient and intraoperative monitoring is recommended.

III

The subtemporal approach allows access to the proximal PCA segments as well as the P2 and anterior P3 segment. In these cases, CSF release is necessary to prevent temporal lobe injuries. Additionally, the subtemporal approach can provide enough space for revascularization procedures. The most frequently observed complications were not related to the approach method.

\section{IV}

The lateral supraorbital approach is less invasive than a frontotemporal approach and is suitable for the simultaneous microsurgical treatment of proximal anterior circulation and ipsilateral proxima PCA aneurysms.
This study was carried out at the Department of Neurosurgery of Helsinki Central University Hospital from 2012 to 2015 in collaboration with the Department of Neurosurgery of Kuopio University Hospital. I wish to express my gratitude to my teachers, co-workers, friends and family for their support during this time.

Juha Hernesniemi, my supervisor, teacher and friend. Dear Juha, thank you for the opportunity to work closely with you on so many critically ill patients. Thinking back, it was such a great and fascinating time.

Martin Lehecka, for his excellent work as my supervisor. Dear Martin, I am very grateful for your critical comments during all steps of my work on PCA aneurysms.

Behnam Rezai Jahromi, my friend and closest coworker, for his enormous support and friendship during all stages of this project.

Hanna Lehto, for her friendship, her enormous support of this thesis and meticulous work on the aneurysm database.

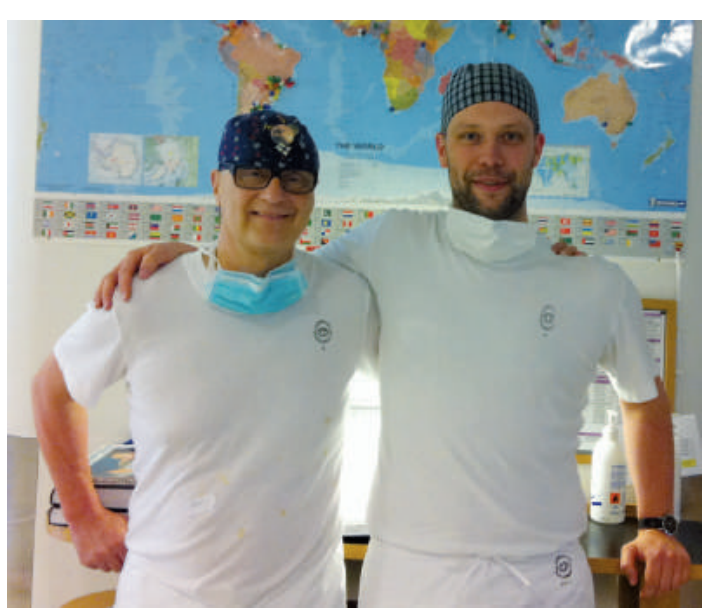

Juha Hernesniemi and Felix Göhre in Summer 2012.
Juha Jääskeläinen and Mikael von und zu Fraunberg, for their fantastic collaboration and hospitality in Kuopio. Dear Juha and Mikael, I am so grateful for your very fast and helpful comments during the final steps of manuscript preparation.

Hugo Andrade, Ferzat Hijazy, Ahmed Elsharkawy and Francisco Munoz, for their friendship, supp and critical advice regarding surgeries, science and life. And also for the wonderful time we had together during our fellowship.

My co-workers, Riku Kivisaari, Tarik Ibrahim, Tetsuaki Sugimoto, Masaki Morishige, Katariina Helin, Lamia Nayeb, Timo Koivisto and Oleg Shekhtman for their continuous support.

Richard Gonzalo Párraga, for providing the anatomical images.

Stefan Schwan, Thomas Mendel, Eckart Stolle and Christopher Ludtka, for their friendship and invaluable help from home (Halle an der Saale).

Hans-Jörg Meisel, my chairman at the Bergmannstrost Hospital in Halle (Saale), for his enormous administrative support.

Wieland Otto and Lutz Lindemann-Sperfeld for their support at the begining of my academic carrier.

Peter Vajkoczy and Rokuya Tanikawa who influenced my work and academic carrier significantly.

Sakari Savolainen and Sami Tetri for their excellent review of the thesis.

Hans-Jürgen Paasch and Janos Stekovics for their 
My parents, Reinhilde and Gerd Göhre, for their love and everlasting encouragement during my childhood, school and study times.

Louis, who has changed my worldview.

Conny and Hugo, my little family, for their love and everlasting support despite the time consuming projects.

Helsinki, April 2016

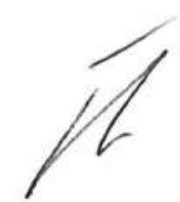

\section{References}

Adamczyk P, Mack WJ: The artery of percheron and etiologies of bilateral thalamic stroke. World Neurosurg. 81(1):80-82, 2014.

Anderson C, Anderson N, Bonita R, for the ACROSS investigators: Epidemiology of aneurysmal subarachnoid hemorrhage in Australia and New Zealand: incidence and case fatality from the Australasian Cooperative Research on Subarachnoid Hemorrhage Study (ACROSS). Stroke. 31(8): 1843-1850, 2000.

Anson JA, Lawton MT, Spetzler RF: Characteristics and surgical treatment of dolichoectatic and fusiform aneurysms. J Neurosurg. 84(2):185-193, 1996.

Arat A, Islak C, Saatci I, Kocer N, Cekirge S: Endovascular parent artery occlusion in large-giant or fusiform distal posterior cerebral artery aneurysms. Neuroradiology. 44(8):700-705, 2002.

Ausman JI, Lee MC, Klassen AC, Seljeskog EL, Chou SN: Stroke: what's new? Cerebral revascularization. Min Med. 59: 223-227, 1976.

Ausman JI, Diaz FG, de los Reyes RA, Pak H, Patel S Boulos R: Anastomosis of occipital artery to anterio inferior cerebellar artery for vertebrobasilar junction stenosis. Surg Neurol. 16:99-102, 1981.

Ausman JI, Diaz FG, de los Reyes RA, Pak H, Patel S, Boulos R: Superficial temporal to proximal superior cerebellar artery anastomosis for basilar artery stenosis. Neurosurgery. 9:56-60, 1981.

Bäck M, Ketelhuth DF, Agewall S: Matrix metalloproteinases in atherothrombosis. Prog Cardiovasc Dis. 52(5):410-428, 2010.

Backes D, Rinkel GJE, Kemperman H, Linn FHH, Vergouwen MDI: Time dependent test characteristics of head computed tomography in patients suspected of nontraumatic subarachnoid hemorrhage. Stroke. 43(8):2115-2119, 2012.

Bertrams J: Das periphere Aneurysma der A. cerebri posterior. Deutsche Zeitschrift für Nervenheilkunde. 194:243-251, (German) 1968.

Bilguvar K, Yasuno K, Niemelä M, Ruigrok YM, von Und Zu Fraunberg $M$, van Duijn $C M$, van den Berg $\mathrm{LH}_{\text {, }}$ Mane S, Mason CE Choi M, Gaál E Bayri Y Kolb
Arlier Z Ravuri S, Ronkainen A, Tajima A, Laakso A, Hata A, Kasuya H, Koivisto T, Rinne J, Ohman J, Breteler MM, Wijmenga C, State MW, Rinkel GJ, Hernesniemi J, Jääskeläinen JE, Palotie $A$, Inoue I,

Lifton RP, Günel M: Susceptibility loci for intracranial aneurysm in European and Japanese populations. Nat Genet. 40(12):1472-1477, 2008.

Bonita R: Cigarette smoking, hypertension and the risk of subarachnoid hemorrhage: a population-based casecontrol study. Stroke. 17(5):831-835, 1986.

Bruno G, Todor R, Lewis I, Chyatte D: Vascular extracellular matrix remodeling in cerebral aneurysms. J Neurosurg. 89(3):431-440, 1998.

Chang SW, Abla AA, Kakarla UK, Sauvageau E, Dashti SR, Nakaji P, Zabramski JM, Albuquerque FC, McDougall CG, Spetzler RF: Treatment of distal posterior cerebral artery aneurysms: a critical appraisal of the occipital artery-to-posterior cerebral artery bypass. Neurosurgery. 67(1):16-25, 2010

Chapman AB, Rubinstein D, Hughes R, Stears JC, Earnest MP, Johnson AM, Gabow PA, Kaehny WD: Intracranial aneurysms in autosomal dominant polycystic kidney disease. N Engl J Med. 327(13):916-920, 1992.

Charbel FT, Hoffman WE, Misra M, Ostergren L: Ultrasonic perivascular flow probe: technique and application in neurosurgery. Neurol Res. 20(5):439-442, 1998

Chen W, Wang J, Xing W, Xu Q, Qiu J, Huang Q, Sun Y, Yu S, Peng Y: Accuracy of 16-row multislice computerized tomography angiography for assessment of intracranial aneurysms. Surg Neurol. 71(1):32-42, 2009

Chou MY, Hartvigsen K, Hansen LF, Fogelstrand L, Shaw PX, Boullier A, Binder CJ, Witztum JL: Oxidationspecific epitopes are important targets of innate specific epitopes are important targets of innate
immunity J Intern Med. 263(5):479-488, 2008.

Chyatte D, Bruno G, Desai S, Todor DR: Inflammation and intracranial aneurysms. Neurosurgery. 45(5):11371146, 1999.

Ciceri EF, Klucznik RP, Grossman RG, Rose JE, Mawad ME: Aneurysms of the posterior cerebral artery: Classification and endovascular treatment. Am 」 Neuroradiol. 22:27-34, 2001. 
Coert BA, Chang SD, Do HM, Marks MP, Steinberg GK: Surgical and endovascular management of symptomatic posterior circulation fusiform aneurysms. J Neurosurg. 106:855-65, 2007.

Connolly HM, Huston J 3rd, Brown RD Jr, Warnes CA Ammash NM, Tajik AJ: Intracranial aneurysms in patients with coarctation of the aorta: a prospective magnetic resonance angiographic study of 100 patients. Mayo Clin Proc. 78(12):1491-1499, 2003.

Cotroneo E, Gigli R, Guglielmi G: Endovascular Occlusion of the Posterior Cerebral Artery in the Treatment of $P 2$ Ruptured Aneurysms. Interv Neuroradiol. 13:127-132, 2007.

Crompton MR: Mechanism of growth and rupture in cerebral berry aneurysms. BMJ. 1(5496):1138-1142, 1966.

Dashti R, Hernesniemi J, Niemelä M, Rinne J, Lehecka M Shen $\mathrm{H}$, Lehto H, Albayrak BS, Ronkainen A, Koivisto $\mathrm{T}$ Jääskeläinen JE: Microneurosurgical management of distal middle cerebral artery aneurysms. Surg Neurol. 67(6):553-563, 2007

Dashti R, Laakso A, Niemelä M, Porras M, Celik O, Navratil O, Romani R, Hernesniemi J: Application of microscope integrated indocyanine green videoangiography during microneurosurgical treatment of intracranial aneurysms: a review. Acta Neurochir. 107(Suppl):107-109, 2010.

Debette S, Germain DP: Neurologic manifestations of inherited disorders of connective tissue. Handb Clin Neurol. 119:565-576, 2014

de Oliveira JG, Beck J, Setzer M, Gerlach R, Vatter H, Seifert V, Raabe A: Risk of shunt-dependent hydrocephalus after occlusion of ruptured intracrain aneurysms by surgical clipping or intracranial aneunsms by surgical clipping or endovascular coiling: a single-institution series and meta-analysis. Neurosurgery. 61(5):924-933, 2007.

DesSaussure RL, Hunter SE, Robertson JT: Saccular aneurysms of the posterior fossa. I Neurosurg. 15(4):385-391, 1958

de Sousa A, Dantas FLR, de Cardoso G, Costa B: Distal Anterior Cerebral Aneurysms. Surg Neurol. 52:128-136, 1999.

Dorhout Mees SM, Rinkel GJ, Feigin VL, Algra A, van den Bergh WM, Vermeulen M, van Gijn J. Calcium antagonists for aneurysmal subarachnoid haemorrhage. Cochrane Database Syst Rev. Jul 18:(3):CD000277, 2007.
Drake CG: Bleeding aneurysms of the basilar artery. Direct surgical management in four cases. J Neurosurg. 18:230-238, 1961

Drake CG, Amacher AL: Aneurysms of the Posterior Cerebral Artery. J Neurosurg. 30:468-474, 1969

Drake CG: The treatment of aneurysms of the posterio circulation. Clin Neurosurg. 26:96-144, 1979.

Drake CG: Sydney John Peerless. Surg Neurol. 30(1):1-2, 1988.

Drake CG, Peerless SJ, Hernesniemi JA: Surgery of Vertebrobasilar Aneurysms. London, Ontario Experience on 1767 Patients. Wien, Austria: SpringerVerlag: 1-329, 1996

Eckard DA, O'Boynick PL, McPherson CM, Eckard VR, Han P, Arnold P, Batnitzky S: Coil occlusion of the parent artery for treatment of symptomatic peripheral intracranial aneurysms. AJNR Am J Neuroradiol $21(1): 137-142,2000$

Erdem A, Ya argil G, Roth P: Microsurgical anatomy of the hippocampal arteries. J Neurosurg 79(2):256-265, 1993

Erixon HO, Sorteberg A, Sorteberg W, Eide PK: Predictors of shunt dependency after aneurysmal subarachnoid hemorrhage: results of a single-center clinical trial. Acta Neurochir. 156(11):2059-2069, 2014.

Feigin VL, Rinkel GJ, Lawes CM, Algra A, Bennett DA, van Gijn J, Anderson CS: Risk factors for subarachnoid hemorrhage: an updated systematic review of epidemiological studies. Stroke. 36(12):2773-2780 2005.

Fisher CM, Kistler JP, Davis JM: Relation of cerebral vasospasm to subarachnoid hemorrhage visualized by computerized tomographic scanning. Neurosurgery. 6(1):1-9, 1980

Flemming KD, Wiebers DO, Brown RD Jr, Link MJ, Nakatomi H, Huston J 3rd, McClelland R, Christianson TJ: Prospective risk of hemorrhage in patients with vertebrobasilar nonsaccular intracranial aneurysm. J Neurosurg. 101(1):82-87, 2004.

Fogelholm R, Hernesniemi J, Vapalahti M: Impact of early surgery on outcome after aneurysmal subarachnoid hemorrhage. A population-based study. Stroke. 24(11): 1649-54, 1993.

Frösen J, Piippo A, Paetau A, Kangasniemi M, Niemelä M, Hernesniemi J, Jääskeläinen J: Remodeling of saccular cerebral artery aneurysm wall is associated with rupture: histological analysis of 24 unruptured and 42 ruptured cases. Stroke. 35(10):2287-2293, 2004

Frösen J, Tulamo R, Paetau A, Laaksamo E, Korja M, Laakso A, Niemelä M, Hernesniemi J: Saccular intracranial aneurysm: pathology and mechanisms. Acta Neuropathol. 123(6):773-786, 2012.

Gerber CJ, Neil-Dwyer G, Evans BT: An alternative surgical approach to aneurysms of the posterior cerebral artery. Neurosurgery. 32(6):928-931, 1993

Goehre F, Kamiyama H, Kosaka A, Tsuboi T, Miyata S, Noda K, Jahromi BR, Ota N, Tokuda S, Hernesniemi J, Tanikawa R. The anterior temporal approach for microsurgical thromboembolectomy of an acute proximal posterior cerebral artery occlusion. Neurosurgery. 10(Suppl 2):174-178, 2014.

Goehre F, Kamiyama H, Noda K, Ota N, Tsuboi T, Miyata S, Matsumoto T, Yanagisawa T, Tokuda S, Tanikawa R: Technical Description of the Medial and Lateral Anterior Temporal Approach for the Treatment of Complex Proximal Posterior Cerebral Artery Aneurysms. World Neurosurg. 86:490-496, 2016.

Guo F, Li Z, Song L, Han T, Feng Q, Guo Y, Xu J, He M, You $\mathrm{C}$ : Increased apoptosis and cysteinyl aspartate specific protease-3 gene expression in human intracranial aneurysm. J Clin Neurosci. 14(6):550-555, 2007.

Hakuba A, Liu S, Nishimura S: The orbitozygomatic infratemporal approach: a new surgical technique. Surg Neurol. 26(3):271-276, 1986

Haley EC Jr, Kassell NF, Torner JC: The International Cooperative Study on the Timing of Aneurysm Surgery. The North American experience Stroke. 23(2):205-214, 1992

Hallacq P, Piotin M, Morert J: Endovascular occlusion of the posterior cerebral artery for the treatment of P2 segment aneurysm: retrospective review of a 10-years series. Am J Neuroradiol. 23:1128-1136, 2002.

Hamada J, Morioka M, Yano S, Todaka T, Kai Y, Kuratsu J: Clinical features of aneurysms of the posterior cerebral artery: a 15-year experience with 21 cases. Neurosurgery. 56(4):662-670, 2005.

Hashimoto Y, Takayama K, Inoue M, Fujishige M, Yamamura A, Nakagawa T: A case of distal posterior cerebral artery aneurysm associated with occlusion of the internal carotid artery. No Shinkei Geka. 28(8):725-729, (Japanese) 2000.
Hausepian EM, Pool JL: A systematic analysis of intracranial aneurysms from the autopsy file of Presbyterian Hospital. J Neuropathol Exp Neurol. 17:409-423, 1958

Helgadottir A, Thorleifsson G, Magnusson KP, Grétarsdottir S, Steinthorsdottir V, Manolescu A, Jones GT, Rinkel GJ, Blankensteijn JD, Ronkainen A, Jääskeläinen JE, Kyo Y, Lenk GM, Sakalihasan $N_{\text {, }}$ Kostulas K, Gottsäter A, Flex A, Stefansson H, Hansen T, Andersen G, Weinsheimer S, BorchJohnsen $\mathrm{K}$, Jorgensen $\mathrm{T}$, Shah $\mathrm{SH}$, Ouyvumi AA, Granger $C B$, Reilly MP, Austin $H$, Levey Al, Vaccarino V Palsdottir E, Walters GB, Jonsdottir T, Snorradottir S, Magnusdottir D, Gudmundsson G, Ferrell RE, Sveinbjornsdottir $S$, Hernesniemi J, Niemelä M, Limet R, Andersen K, Sigurdsson G, Benediktsson R, Verhoeven EL, Teijink JA, Grobbee DE, Rader DJ, Collier DA, Pedersen O, Pola R, Hillert J, Lindblad B, Valdimarsson EM, Magnadottir HB, Wijmenga $C_{\text {, }}$ Tromp G, Baas AF, Ruigrok YM, van Rij AM, Kuivaniemi H, Powell JT, Matthiasson SE, Gulcher JR, Thorgeirsson G, Kong A, Thorsteinsdottir U, Stefansson K: The same sequence variant on 9p21 associates with myocardial infarction, abdominal aortic aneurysm and intracranial aneurysm. Nat Genet. 40(2):217-224, 2008.

Hennerici M, Rautenberg W, Sitzer G, Schwartz A: Transcranial Doppler ultrasound for the assessment of intracranial arterial flow velocity-Part Examination technique and normal values. Surg Neurol. 27:439-448, 1987.

Hernesniemi J, Ishii K, Niemelä M, Smrcka M, Kivipelto L. Fujiki M, Shen $\mathrm{H}$ : Lateral supraorbital approach as an alternative to the classical pterional approach. Acta Neurochir. 94(Suppl):17-21, 2005

Hernesniemi J, Ishii K, Karatas A, Kivipelto L, Niemelä M Nagy L, Shen H: Surgical technique to retract the tentorial edge during subtemporal approach:
technical note. Neurosurgery. 57(4 Suppl):E408, 2005.

Hernesniemi J, Ishii K, Niemelä M, Kivipelto L, Fujiki M, Shen H: Subtemporal approach to basilar bifurcation aneurysms: advanced technique and clinical experience. Acta Neurochir. 94(Suppl):31-38, 2005.

Hernesniemi J, Dashti R, Lehecka M, Niemelä M, Rinne J, Lehto $H$, Ronkainen A, Koivisto $T$, Jääskelainen JE: Microsurgical management of anterior communicationg artery aneurysms. Surg Neurol. 70:8-29, 2008. 
Honda M, Tsutsumi $K_{\text {, Yokoyama }}$, Yonekura M, Nagata I: Aneurysms of the posterior cerebral artery: retrospective review of surgical treatment. Neurol Med Chir. 44:164-168, 2004.

Horikoshi T, Nukui H, Yagishita T, Nishigaya K, Fukasawa I, Sasaki H: Oculomotor nerve palsy after surgery for upper basilar artery aneurysms. Neurosurgery. 44:705-710, 1999.

Huang J, van Gelder JM: The probability of sudden death from rupture of intracranial aneurysms: a metaanalysis. Neurosurgery. 51(5):1101-1105, 2002.

Huang Q, Liu J, Zhao R, Hong B, Xu Y, Zhao W, Yang P, Li $W$ : The safety and efficacy of stenting in the treatment of complex posterior cerebral artery aneurysms: a seven-case report and literature review. Clin Neuroradiol. 23(3):175-87, 2013.

Hunt WE, Hess RM: Aneurysm of the posterior cerebral artery with unexpected postoperative neurological deficit. Case report. J Neurosurg. 26(6):633-635, 1967.

Inagawa T, Kamiya K, Ogasawara H, Yano T: Rebleeding of ruptured intracranial aneurysms in the acute stage. Surg Neurol. 28(2):93-99, 1987.

Inagawa T, Hirano A: Ruptured intracranial aneurysms: an autopsy study of 133 patients. Surg Neurol. 33(2):117-123, 1990.

Inagawa T, Hirano A: Autopsy study of unruptured incidental intracranial aneurysms. Surg Neurol. 34(6):361-365, 1990.

Inagawa T: Trends in incidence and case fatality rates of aneurysmal subarachnoid hemorrhage in Izumo City, Japan, between 1980-1989 and 1990-1998. Stroke. 32(7):1499-1507, 2001.

Ishibashi Y, Onuma T: Peripheral branch (P4 segment) aneurysm of the posterior cerebral artery: a case report. No Shinkei Geka. 17(7):659-662, (Japanese) 1989.

Ito N, Shiokawa Y, Ide K, Takahashi H, Yamakawa K, Saito I: A case of ruptured P4 segment aneurysm of the posteior cerebral artery: therapeutic pitfalls encountered when dealing with the multiple intracranial aneurysms. No Shinkei Geka. 26(7):639-643, (Japanese) 1998.

Jayakumar PN, Desai S, Srikanth SG, Ravishankar S, Kovoor JM: Relevance of occlusion test in endovascular coiling of posterior cerebral artery (p2 segment) aneurysms. Interv Neuroradiol. 10(3):235-248, 2004

Jellinger K: Pathology and aetiology of intracranial aneurysms. In: Pia HW, Langmaid C, Zierski J (eds): Cerebral Anerurysms: Advances in Diagnostic and Therapy. New York, NY, Springer-Verlag, 5-19, 1979.

Johnston SC, Selvin S, Gress DR: The burden, trends, and demographics of mortality from subarachnoid hemorrhage. Neurology. 50(5):1413-1418, 1998.

Juvela S: Rebleeding from ruptured intracranial aneurysms. Surg Neurol. 1989 Nov;32(5):323-326,
1989.

Juvela S, Hillbom M, Numminen H, Koskinen P: Cigarette smoking and alcohol consumption as risk factors for aneurysmal subarachnoid hemorrhage. Stroke. 24(5):639-646, 1993

Juvela S, Porras M, Poussa K: Natural history of unruptured intracranial aneurysms: probability of and risk factors for aneurysm rupture. J Neurosurg. 93(3):379-387, 2000.

Juvela S, Poussa K, Porras M: Factors affecting formation and growth of intracranial aneurysms: a long-term follow-up study. Stroke. 32(2):485-491, 2001.

Juvela S: Prehemorrhage risk factors for fatal intracranial aneurysm rupture. Stroke. 34(8):1852-1857, 2003

Juvela S, Poussa K, Lehto H, Porras M: Natural History of Unruptured Intracranial Aneurysms: A Long-term Follow-up Study. Stroke. 44(9):2414-2421, 2013.

Kalani MY, Hu YC, Spetzler RF: A double-barrel superficial temporal artery-to-superior cerebellar artery (STASCA) and STA-to-posterior cerebral artery (STA-PCA) bypass for revascularization of the basilar apex. J Clin Neurosci. 20(6):887-889, 2013.

Kamiyama H, Takahashi A, Houkin K, Mabuchi S, Abe H: Visualization of the ostium of an arteriotomy in bypass surgery. Neurosurgery. 33(6):1109-1110, 1993.

Kamiyama H, Houkin K: Microsurgery of Cerebral Aneurysms. Tokyo, Japan: Nankodo, Inc.; 1-23, 2010.

Kashiwazaki D, Ushikoshi S, Asano T, Osanai T, Kuroda S, Houkin K: Endovascular treatment for aneurysms of the posterior cerebral artery: 12 years' experience with 21 cases. Acta Neurochir. 153:2151-2158, 2011.

Kassell NF, Torner JC: Aneurysmal rebleeding: $a$ preliminary report from the Cooperative Aneurysm Study. Neurosurgery. 13(5):479-481, 1983.
Kassell NF, Sasaki T, Colohan AR, Nazar G: Cerebral vasospasm following aneurysmal subarachnoid hemorrhage. Stroke. 16(4):562-572, 1985.

Kassell NF: Charles George Drake, M.D. 1920-1998. J Neurosurg. 90(4):797-801, 1999.

Kataoka K, Taneda M, Asai T, Kinoshita A, Ito M, Kuroda R: Structural fragility and inflammatory response of ruptured cerebral aneurysms. A comparative study between ruptured and unruptured cerebral aneurysms. Stroke. 30(7):1396-1401, 1999

Kawashima M, Rhoton AL Jr, Tanriover N, UIm AJ, Yasuda A, Fujii K: Microsurgical anatomy of cerebra revascularization. Part II: posterior circulation. J Neurosurg. 102(1):132-147, 2005.

Kawashima M, Rhoton AL Jr: Surgical anatomy of EC-IC bypass procedures. In: Abdulrauf SI (ed): Cerebral Revascularization: Techniques in Extracranial-toIntracranial Bypass Surgery. Philadelphia, PA: Elsevier Saunders; 65-92, 2011.

Kazumata K, Yokoyama Y, Sugiyama T, Asaoka K: Occipital-posterior cerebral artery bypass via the occipital interhemispheric approach. Surg Neurol Int 4:90, 2013.

Kelly PJ: Thoralf M. Sundt, Jr. Surg Neurol. 31(3):169-171, 1989.

Kitazawa K, Tanaka Y, Muraoka S, Okudera H, Orz Y, Kyoshima K, Kobayashi S: Specific characteristics and management strategies of posterior cerebral artery aneurysms: report of eleven cases. J Clin Neurosci. 8:23-26, 2001.

Kim YB, Lee JW, Huh SK, Kim BM, Kim DJ: Outcomes of multidisciplinary treatment for posterior cerebral artery aneurysms. Clin Neurol Neurosurg. 115(10):2062-2068, 2013.

Knekt P, Reunanen A, Aho K, Heliövaara M, Rissanen A, Aromaa A, Impivaara 0: Risk factors for subarachnoid hemorrhage in a longitudinal population study. I Clin Epidemiol. 44(9):933-939, 1991.

Kocaeli H, Yilmazlar S, Kuytu T, Korfali E: The artery of Percheron revisited: a cadaveric anatomical study. Acta Neurochir (Wien). 155(3):533-539, 2013.

Korja M, Silventoinen $\mathrm{K}$, McCarron P, Zdravkovic S, Skytthe A, Haapanen A, de Faire U, Pedersen NL, Christensen K, Koskenvuo M, Kaprio J; GenomEUtwin Project: Genetic epidemiology of spontaneous subarachnoid hemorrhage: Nordic Twin Study. Stroke. 41(11):2458-2462, 2010.
Korja M, Lehto H, Juvela S. Lifelong Rupture Risk of Intracranial Aneurysms Depends on Risk Factors: A Prospective Finnish Cohort Study. Stroke. 45(7):1958 - 1963, 2014.

Kosierkiewicz TA, Factor SM, Dickson DW: Immunocytochemical studies of atherosclerotic lesions of cerebral berry aneurysms. I Neuropathol Exp Neurol. 53(4):399-406, 1994.

Kurki MI, Häkkinen SK, Frösen J, Tulamo R, von und zu Fraunberg M, Wong G, Tromp G, Niemelä M, Hernesniemi J, Jääskeläinen JE, Ylä-Herttuala S: Upregulated signaling pathways in ruptured human saccular intracranial aneurysm wall: an emerging regulative role of Toll-like receptor signaling and nuclear factor- $B$, hypoxia-inducible factor-1A, and ETS transcription factors. Neurosurgery. 68:1667-1675, 2011.

Laaksamo E, Tulamo R, Baumann M, Dashti R, Hernesniemi J, Juvela S, Niemelä M, Laakso A: Involvement of mitogen-activated protein kinase signaling in growth and rupture of human intracranial aneurysms. Stroke. 39(3):886-892, 2008.

Langer DJ, Vajkoczy P: ELANA: Excimer Laser-Assisted Nonocclusive Anastomosis for extracranial-tointracranial and intracranial-to-intracranial bypass: a review. Skull Base. 15(3):191-205, 2005.

Lavine SD, Meyers PM: Application of new techniques and technologies: Stenting for cerebral aneurysm. Clinical Neurosurgery. 54:64-69, 2007.

Lawton MT, Hamilton MG, Morcos JJ, Spetzler RF: Revascularization and aneurysm surgery: current techniques, indications, and outcome. Neurosurgery. 38(1):83-92, 1996

Lawton M: Seven Aneurysms. Tenets and Techniques for Clipping. New York, NY: Thieme Medical publishers, Inc.; 6-20, 2010.

Lee KH, Lukovits T, Friedman JA: Triple-H" therapy for cerebral vasospasm following subarachnoid hemorrhage. Neurocrit Care. 4(1):68-76, 2006.

Lehecka M, Porras M, Dashti R, Niemelä M, Hernesniemi JA. Anatomic features of distal anterior cerebral artery aneurysms: a detailed angiographic analysis of 101 patients. Neurosurgery. 63:219-228, 2008.

Li Y, Lv X, Jiang C, Liu A, Wu Z: Endovascular treatment of posterior cerebral artery aneurysms. Neuroradiol J. 21(1):128-136, 2008. 
Lindekleiv H, Sandvei MS, Romundstad PR, Wilsgaard T Njølstad I, Ingebrigtsen T, Vik A, Mathiesen EB: Joint effect of modifiable risk factors on the risk of aneurysmal subarachnoid hemorrhage: a cohort study. Stroke. 43(7):1885-1889, 2012.

Linn FH, Rinkel GJ, Algra A, van Gijn J: Incidence of subarachnoid hemorrhage: role of region, year, and rate of computed tomography: a meta-analysis. Stroke. 27(4):625-629, 1996.

Locksley H: Report on the cooperative study of intracranial aneurysms and subarachnoid hemorrhage. Section 5, part 1. Natural history of subarachnoid hemorrhage, intracranial aneurysms and arteriovenous malformations. Based on 6368 cases in the operative Study. J Neurosurg. 1966;25:219-239, 1966.

Longstreth WT Jr, Nelson LM, Koepsell TD, van Belle G: Clinical course of spontaneous subarachnoid hemorrhage: a population-based study in King County, Washington. Neurology. 43(4):712-718, County,

Lonjon M, Pennes F, Sedat J, Bataille B: Epidemiology, genetic, natural history and clinical presentation of giant cerebral aneurysms. Neurochirurgie. 61(6):361-365, 2015

Luo 0, Wang $H_{1}, X_{\text {K }}$, Yu J: Endovascular treatments for distal posterior cerebral artery aneurysms. Turk Neurosurg. 22(2):141-147, 2012

Luostarinen T, Takala RS, Niemi T, Katila AJ, Niemelä M, Hernesniemi J, Randell T: Adenosine-induced cardiac arrest during intraoperative cerebral aneurysm rupture. World Neurosurg. 73:79-83, 2010.

Margolis MT, Hoffman HB, Newton TH: Choroidal arteries in the diagnosis of thalamic tumors. J Neurosurg. 36:287-298, 1972

Mathis JM, Barr JD, Jungreis CA, Yonas H, Sekhar LN, Vincent D, Pentheny SL, Horton JA: Temporary balloon test occlusion of the internal carotid artery: experience in 500 cases. AJNR Am J Neuroradiol. 16(4):749-754, 1995

McLaughlin N, Martin NA: Extended subtemporal transtentorial approach to the anterior incisura space and upper clival region: experience with posterior circulation aneurysms. Neurosurgery. 10(Supp 11):15-23, 2014.

Meisel HJ, Mansmann U, Alvarez H, Rodesch G, Brock M Lasjaunias P: Cerebral arteriovenous malformations and associated aneurysms: analysis of 305 cases from a series of 662 patients. Neurosurgery. 46:793-800, 2000

Mignatti P, Rifkin DB: Biology and biochemistry of proteinases in tumor invasion. Physiol Rev. 3(1):161-195, 1993

Milisavljevi M, Marinkovi S, Marinkovi Z, Malobabi S: Anatomic basis for surgical approach to the distal segment of the posterior cerebral artery. Surg Radiol Anat. 10:259-266, 1988

Miller YI, Choi SH, Wiesner P, Fang L, Harkewicz R, Hartvigsen K, Boullier A, Gonen A, Diehl CJ, Que X, Montano E, Shaw PX, Tsimikas S, Binder CJ, Witztum $\mathrm{JL}$ Oxidation-specific epitopes are danger-associated molecular patterns recognized by pattern recognition receptors of innate immunity. Circ Res. 108(2):235-248, 2011.

Mohit AA, Sekhar LN, Natarajan SK, Britz GW, Ghodke B: High-flow bypass grafts in the management of complex intracranial aneurysms. Neurosurgery. 60(2Supp|1):0NS105-122, 2007.

Molyneux A, Kerr R, Stratton I, Sandercock P, Clarke M, Shrimpton J, Holman R; International Subarachnoid Aneurysm Trial (ISAT) Collaborative Group: International Subarachnoid Aneurysm Trial (ISAT) of neurosurgical clipping versus endovascular coiling in 2143 patients with ruptured intracranial aneurysm in a randomised tial. Lancet. 360(9342):1267-1274, a random

Moniz E, Alves A: L'importance diagnostique de I'angiographie de la fossa post'erieure. Rev Neurol. 2:91-96. (French) 1933.

Nagy L, Ishii K, Karatas A, Shen H, Vajda J, Niemelä M, Jääskeläinen J, Hernesniemi J, Toth S: Water dissection technique of Toth for opening

neurosurgical cleavage planes. Surg Neurol. 65:38-41 2006.

Nakatomi H, Segawa H, Kurata A, Shiokawa Y, Nagata K, Kamiyama H, Ueki K, Kirino T: Clinicopathological study of intracranial fusiform and dolichoectatic aneurysms : insight on the mechanism of growth. Stroke. 31(4):896-900, 2000.

Newby AC, Zaltsman AB: Molecular mechanisms in intimal hyperplasia. J Pathol. 190(3):300-309, 2009.

Nieuwkamp DJ, Setz LE, Algra A, Linn FH, de Rooij NK, Rinkel GJ: Changes in case fatality of aneurysmal subarachnoid haemorrhage over time, according to age, sex, and region: a meta-analysis. Lancet Neurol. 8(7):635-642, 2009.
Ohkuma H, Fujita S, Suzuki S: Incidence of aneurysmal subarachnoid hemorrhage in Shimokita, Japan, from 1989 to 1998. Stroke. 33(1): 195-199, 2002.

Origitano TC, Al-Mefty 0, Leonetti JP, DeMonte F, Reichman $\mathrm{OH}$ : Vascular considerations and complications in cranial base surgery. Neurosurgery. 35:351-363, 1994.

Orita T, Tsurutani T, Izumihara A, Kajiwara K: Distal posterior cerebral artery aneurysms-three case reports. Neurol Med Chir. 34(10):692-696, 1994.

Padget DH: The development of the cranial arteries in the human embryo. Contrib Embryol. 32:205-262, 1948.

Pakarinen S: Incidence, aetiology, and prognosis of primary subarachnoid haemorrhage. A study based on 589 cases diagnosed in a defined urban population during a defined period. Acta Neurol Scand. 43(Suppl29):1-28, 1967.

Papke K, Kuhl CK, Fruth M, Haupt C, Schlunz-Hendann M Sauner D, Fiebich M, Bani A, Brassel F: Intracranial aneurysms: role of multidetector CT angiography in diagnosis and endovascular therapy planning. Radiology. 244(2):532-540, 2007.

Park W, Kwon do H, Ahn JS, Lee SH, Park JC, Kwun BD: Treatment strategies for dissecting aneurysms of the posterior cerebral artery. Acta Neurochir. 157(10):1633-1643, 2015.

Párraga RG, Ribas GC, Andrade SE, Oliveira E: Microsurgical anatomy of the posterior cerebral artery in three-dimensional images. World Neurosurg. 75:233-257, 2011.

Peerless SJ, Hernesniemi JA, Gutman FB, Drake CG: Early surgery for ruptured vertebrobasilar aneurysms. J Neurosurg. 80(4):643-649, 1994.

Percheron G: The anatomy of the arterial supply of the human thalamus and its use for the interpretation of the thalamic vascular pathology. Z Neurol. 205:1-13, 1973.

Perry JJ, Stiell IG, Sivilotti ML, Bullard MJ, Emond M, Symington C, Sutherland J, Worster A, Hohl C, Lee JS, Eisenhauer MA, Mortensen M, Mackey D, Pauls M, Lesiuk H, Wells GA: Sensitivity of computed tomography performed within six hours of onset of headache for diagnosis of subarachnoid haemorrhage: prospective cohort study BM!. 343:d4277, 2011.
Pobereskin LH: Incidence and outcome of subarachnoid haemorrhage: a retrospective population based study. J Neurol Neurosurg Psychiatry. 70(3):340-343, 2001.

Pritz MB: Cerebral Aneurysm Classification Based on Angioarchitecture. J Stroke Cerebrovasc Dis. 20:162-167, 2011

Raabe A, Beck J, Gerlach R, Zimmermann M, Seifert V: Near-infrared indocyanine green video angiography: a new method for intraoperative assessment of vascular flow. Neurosurgery. 52:132-139, 2003.

Raabe A, Nakaji P, Beck J, Kim ப, Hsu FP, Kamerman JD, Seifert V, Spetzler RF: Prospective evaluation of surgical microscope-integrated intraoperative nearinfrared indocyanine green videoangiography during aneurysm surgery. J Neurosurg. 103:982-989, 2005.

Raaymakers TW, Rinkel GJ, Limburg M, Algra A: Mortality and morbidity of surgery for unruptured intracranial aneurysms: a meta-analysis. Stroke. 29(8):1531-1538, 1998.

Redekop G, Terbrugge K, Montanera W, Willinsky R: Arterial aneurysms associated with cerebral arteriovenous malformations: classification, incidence, and risk of hemorrhage. J Neurosurg. 89:539-546, 1998.

Reyes AT, Frame R, Brodman RF: Technique for harvesting the radial artery as a coronary artery bypass graft. Ann Thorac Surg. 59(1):118-126, 1995.

Rinkel GJ, Djibuti M, Algra A, van Gijn J: Prevalence and risk of rupture of intracranial aneurysms: a systematic review. Stroke. 29(1):251-256, 1998

Rivero-Arias 0, Wolstenholme J, Gray A, Molyneux AJ, Kerr RS, Yarnold JA, Sneade M: The costs and prognostic characteristics of ischaemic neurological deficit due to subarachnoid haemorrhage in the United Kingdom. Evidence from the MRC International Subarachnoid Aneurysm Trial. J Neurol. 256(3):364-373, 2009.

Roh HG, Kim SS, Han H, Kang HS, Moon WJ, Byun HS: Endovascular treatment of posterior cerebral artery aneurysms using detachable coils. Neuroradiology. 50(3):237-242, 2008

Ronkainen A, Hernesniemi J: Subarachnoid haemorrhage of unknown aetiology. Acta Neurochir. 119(1-4):29-34, 1992

Ronkainen A, Hernesniemi J, Ryynänen M: Familial subarachnoid hemorrhage in east Finland 1977-1990. Neurosurgery. 33(5):787-796, 1993 
Ronkainen A, Niskanen M, Piironen R, Hernesniemi J: Familial subarachnoid hemorrhage. Outcome study. Stroke. 30(5):1099-102, 1999.

Saeki N, Rhoton A L: Microsurgical anatomy of the upper basilar artery and the posterior circle of Willis. J Neurosurg. 46:563-578, 1997.

Saito H, Ogasawara K, Kubo Y, Tomitsuka N, Ogawa A: Treatment of ruptured fusiform aneurysm in the posterior cerebral artery with posterior cerebral artery-superior cerebellar artery anastomosis combined with parent artery occlusion: case report. Surg Neurol. 65:621-624, 2006.

Sakaki T, Kohmura E, Kishiguchi T, Yuguchi T, Yamashita T Hayakawa T: Loss and apoptosis of smooth muscle cells in intracranial aneurysms. Studies with in situ DNA end labeling and antibody against singlestranded DNA. Acta Neurochir. 139(5):469-474, 1997.

Sakata S, Fujii K, Matsushima T, Fujiwara S, Fukui M, Matsubara T, Nagatomi H, Kuromatsu C, Kamikaseda K: Aneurysm of the posterior cerebral artery: report of eleven cases-surgical approaches and procedures. Neurosurgery. 32:163-167, 1993.

Sanai N, Tarapore P, Lee AC, Lawton MT: The current role of microsurgery for posterior circulation aneurysms: $a$ selective approach in the endovascular era. Neurosurgery. 62(6):1236-1249, 2008.

Sawabe M: Vascular aging: from molecular mechanism to clinical significance. Geriatr Gerontol Int.10 (Suppl1):213-20, 2010.

Sawada M, Hashimoto N, Yamamoto S, Tsukahara T: Distal posterior cerebral artery aneurysm associated with multiple aneurysms. Acta Neurol Scand. 98(3):204-208, 1998

Schievink WI: Intracranial aneurysms. N Engl J Med. 336(1):28-40, 1997.

Sekhar LN, Kalavakonda C: Saphenous Vein and Radia Artery Grafts in the Management of Skull Base Tumors and Aneurysms. Operative Techniques in Neurosurgery. 2(3):129-141, 1999.

Sekhar LN, Duff JM, Kalavakonda C, Olding M: Cerebra revascularization using radial artery grafts for the treatment of complex intracranial aneurysms: techniques and outcomes for 17 patients. Neurosurgery. 49(3):646-658; 2001.

Sekine T, Takagi R, Amano Y, Murai Y, Orita E, Matsumura Y, Kumita SI: 4D flow MRI assessment of extracranial-intracranial bypass: qualitative and quantitative evaluation of the hemodynamics. Neuroradiology. Dec 2, [Epub ahead of print] 2015

Seoane E, Tedeschi H, De Oliveira E, Siqueira M, Calderon G, Rhoton A Jr: Management strategies for posterior cerebral artery aneurysms: a proposed new surgical classification. Acta Neurochir. 139:325-331, 1997.

Shen X, XU T, Ding X, Wang W, Liu Z, Qin H: Multiple intracranial aneurysms: endovascular treatment and complications. Interv Neuroradiol. 20(4):442-447, 2014.

Sivenius J, Tuomilehto J, Immonen-Räihä P, Kaarisalo $\mathrm{M}_{\text {, }}$ Sarti C, Torppa J, Kuulasmaa K, Mähönen M, Lehtonen A, Salomaa V, for the FINSTROKE study group: Continuous 15-year decrease in incidence and mortality of stroke in Finland: the FINSTROKE study. Stroke. 35(2): 420-425, 2004

Starke RM, Connolly ES Jr; Participants in the International Multi-Disciplinary Consensus Conference on the Critical Care Management of Subarachnoid Hemorrhage: Rebleeding after aneurysmal subarachnoid hemorrhage. Neurocrit Care. 15(2):241-246, 2011.

Stegmayr B, Eriksson M, Asplund K: Declining mortality from subarachnoid hemorrhage: changes in incidence and case fatality from 1985 through 2000. Stroke 2004; 35(9):2059-2063, 2004

Steven DA, Lownie SP, Ferguson: Aneurysms of the distal anterior cerebral artery. Results in 59 consecutively managed patients. Neurosurgery. 60:227-233, 2007.

Sundt TM Jr, Piepgras DG: Occipital artery to posterior inferior cerebellar artery bypass surgery. J Neurosurg. 48:916-928, 1978.

Sundt TM Jr, Campbell JK, Houser OW: Transpositions and anastomoses between the posterior cerebral and superior cerebellar arteries. Report of two cases. J Neurosurg. 55(6):967-970, 1981.

Sundt TM Jr, Piepgras DG, Houser OW, Campbell JK: Interposition saphenous vein grafts for advanced occlusive disease and large aneurysms in the posterior circulation. I Neurosurg. 56:205-215, 1982.

Sundt TM Jr, Piepgras DG, Marsh WR, Fode NC: Saphenous vein bypass grafts for giant aneurysms and intracranial occlusive disease. J Neurosurg. 65(4):439-450, 1986

Sundt TM Jr: Surgical Techniques for Saccular and Giant Intracranial Aneurysms. Baltimore, MD Williams\&tWilkins; 213-224. 1990.
Sundt TM 3rd, Sundt TM Jr: Principles of preparation o vein bypass grafts to maximize patency. J Neurosurg. 66(2):172-180, 1987

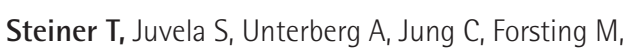
Rinkel G, European Stroke Organization: European Stroke Organization guidelines for the management of intracranial aneurysms and subarachnoid haemorrhage. Cerebrovasc Dis. 35(2):93-112, 2013.

Takeuchi S, Tanikawa R, Tsuboi T, Noda K, Oda J, Miyata S, Ota N, Yoshikane T, Kamiyama H: Superficial temporal artery to proximal posterior cerebral artery bypass through the anterior temporal approach. Surg Neurol Int. 6:95, 2015.

Tanikawa R, Sugimura T, Hino K, Izumi N, Mitsui N, Yamauchi T, Hashimoto M, Hashizume A, Fujita T: Surgical Application of Skull Base Technique for EC-IC Bypass to P2 Segment. Surg Cereb Stroke. 34:440-444, 2006

Taylor CL, Kopitnik TA JR, Samson DS, Purdy PD: Treatment and outcome in 30 patients with posterio cerebral artery aneurysms. J Neurosurg. 99:15-22, 2003.

Taylor CL, Yuan Z, Selman WR, Ratcheson RA, Rimm AA: Cerebral arterial aneurysm formation and rupture in 20,767 elderly patients: hypertension and other risk factors. J Neurosurg. 83(5):812-819, 1995.

Terasaka S, Sawamura Y, Kamiyama H, Fukushima T: Surgical approaches for the treatment of aneurysms on the P2 segment of the posterior cerebral artery. Neurosurgery. 47:359-364, 2000.

Toth S, Vajda J, Pasztor E, Toth Z: Separation of the tumor and brain surface by "water jet" in cases of meningiomas. Journal of Neuro-Oncology. 5:117-124, 1987.

Touho H, Karasawa J, Ohnishi H, Kobitsu K: Anastomosis of occipital artery to posterior cerebral artery with interposition of superficial temporal artery using occipital interhemispheric transtentorial approach: case report. Surg Neurol. 44(3):245-249, 1995.

Tulamo R, Frösen J, Junnikkala S, Paetau A, Pitkäniemi J, Kangasniemi M, Niemelä M, Jääskeläinen ل, Jokitalo Karatas A, Hernesniemi J, Meri S: Complement activation associates with saccular cerebral artery aneurysm wall degeneration and rupture. Neurosurgery. 59(5):1069-1076, 2006.

Tulamo R, Frösen J, Hernesniemi J, Niemelä M: Inflammatory changes in the aneurysm wall: review. J Neurointerv Surg. 2(2):120-130, 2010.
Tulamo R, Frösen J, Junnikkala S, Paetau A, Kangasniem M, Peláez J, Hernesniemi J, Niemelä M, Meri S: Complement system becomes activated by the classical pathway in intracranial aneurysm walls. Lab Invest. 90(2):168-179, 2010

Tulleken CA, Verdaasdonk RM, Berendsen W, Mali WP: Use of the excimer laser in high-flow bypass surgery of the brain. J Neurosurg. 78(3):477-480, 1993.

Tulleken CA, van der Zwan A, van Rooij WJ, Ramos LM: High-flow bypass using nonocclusive excimer laserassisted end-to-side anastomosis of the external carotid artery to the P1 segment of the posterior cerebral artery via the sylvian route. Technical note. J Neurosurg. 88(5):925-927, 1998.

Ulku CH, Ustun ME, Buyukmumcu M: Distal superficial temporal artery to proximal posterior cerebral artery bypass by posterior oblique transzygomatic subtemporal approach. Skull Base. 20(6):415-420, 2010.

Ustun ME, Buyukmumcu M, Ulku CH, Guney 0, Salbacak A: Transzygomatic-Subtemporal Approach for Middle Meningeal-to-P2 Segment of the Posterior Cerebral Artery Bypass: An Anatomical and Technical Study. Skull Base. 16(1):39-44, 2006

Uygur E, Atilla K, Levent G, Deniz B, Mustafa AS, Murad B: Subtemporal approach for a P2-P3 junction aneurysm of the posterior cerebral artery. I Clin Neurosci. 14(5):494-497, 2007.

van Gijn J, Kerr RS, Rinkel GJ: Subarachnoid haemorrhage. Lancet. 369(9558):306-318, 2007.

van Rooij WJ, Sluzewski M, Beute GN: Endovascular Treatment of Posterior Cerebral Artery Aneurysms. Am J Neuroradiol. 27:300-305, 2006.

Vernooij MW, Ikram MA, Tanghe HL, Vincent AJ, Hofman A. Krestin GP, Niessen WJ, Breteler MM, van der Lug A. Incidental findings on brain MRI in the general population. N Engl J Med. 357(18):1821-1828, 2007.

Villablanca JP, Achiriolaie A, Hooshi P, Martin N, Duckwiler G, Jahan R, Frazee J, Gobin P, Sayre J, Viñuela F: Aneurysms of the posterior circulation: detection and treatment planning using volumerendered three-dimensional helical computerized tomography angiography. J Neurosurg. 103(6):1018-1029, 2005

Vishteh AG, Smith KA, McDougall CG, Spetzler RF: Dista posterior cerebral artery revascularization in multimodality management of complex peripheral 
posterior cerebral artery aneurysms: technical case report. Neurosurgery. 43(1):166-170, 1998

Vlak MH, Algra A, Brandenburg R, Rinkel GJ: Prevalence of unruptured intracranial aneurysms, with emphasis on sex, age, comorbidity, country, and time period: a systematic review and meta-analysis. Lancet Neurol. 10(7):626-636, 2011.

Wang H, Li W, He H, Luo L, Chen C, Guo Y: 320-detector row CT angiography for detection and evaluation of intracranial aneurysms: comparison with conventional digital subtraction angiography. Clin Radiol. 68(1):e15-20, 2013.

Wang WX, Xu BN, Wang FY, Wu C, Sun ZH: Microsurgical management of posterior cerebral artery aneurysms: A report of thirty cases in modern era. Br I Neurosurg. 29(3):406-412, 2015.

Weir BKA: Pulmonary edema following fatal aneurysm rupture. J Neurosurg. 49:502-507, 1978.

Wiebers DO, Whisnant JP, Huston J 3rd, Meissner I, Brown RD Jr, Piepgras DG, Forbes GS, Thielen K, Nichols D, O'Fallon WM, Peacock J, Jaeger L, Kassell NF, Kongable-Beckman GL, Torner JC; International Study of Unruptured Intracranial Aneurysms Investigators (ISUIA): Unruptured intracranial aneurysms: natural history, clinical outcome, and risks of surgical and endovascular treatment. Lancet.

Wilson FM, Jaspan T, Holland IM: Multiple cerebral aneurysms - a reappraisal. Neuroradiology. 31(3):232-236, 1989.

Woitzik J, Horn P, Vajkoczy P, Schmiedek P: Intraoperative control of extracranial-intracranial bypass patency by near-infrared indocyanine green videoangiography. J Neurosurg. 102:692-698, 2005.

Xu J, Xu L, Wu Z, Chen X, Yu J, Zhang J: Fetal-type posterior cerebral artery: the pitfall of parent artery occlusion for ruptured $P$ segment and distal aneurysms. J Neurosurg. 123(4):906-914, 2015.

Yamahata H, Tokimura H, Hirabaru M, Hirano H, Arita K: Aneurysm on the cortical branch (P4 segment) of the posterior cerebral artery. Case report. Neurol Med Chir 50(12):1084-1087, 2010.

Yasargil MG: Microsurgery: Applied to Neurosurgery. Stuttgart, Germany: Georg Thieme-Verlag; 1-230, 1969.

Yasargil MG, Antic J, Laciga R, Jain KK, Hodosh RM Smith RD: Microsurgical pterional approach to aneurysms of the basilar bifurcation. Surg Neurol. 6(2):83-91, 1976

Yasargil MG, Yonekawa Y: Results of microsurgical extraintracranial arterial bypass in the treatment of cerebral ischemia. Neurosurgery. 1(1):22-24, 1977.

Yasargil MG: Microneurosurgery: Microsurgical Anatomy of the Basal Cisterns and Vessels of the Brain Diagnostic Studies, General Operative Techniques and Pathological Considerations of the Intracranial Aneurysms (1 Vol). Stuttgart, Germany: Georg Thieme-Verlag; 1-371, 1984.

Yasargil MG: Microneurosurgery: Clinical Considerations, Surgery of the Intracranial Aneurysms and Results (2 Vol). Stuttgart, Germany: Georg Thieme-Verlag; 1-384, 1984.

Yasuno K, Bakırcıo lu M, Low SK, Bilgüvar K, Gaál E, Ruigrok YM, Niemelä M, Hata A, Bijlenga P, Kasuya $H_{1}$

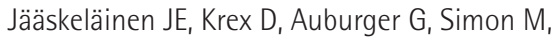
Krischek B, Ozturk AK, Mane S, Rinkel GJ, Steinmetz H, Hernesniemi J, Schaller K, Zembutsu H, Inoue I, Paloti A, Cambien F, Nakamura Y, Lifton RP, Günel M: Common variant near the endothelin receptor type $A$ (EDNRA) gene is associated with intracranial aneurysm risk. Proc Natl Acad Sci USA. 108(49):19707-19712, 2011.

Yonekawa Y, Ogata N, Imhof HG, Olivecrona M, Strommer K, Kwak TE, Roth P, Groscurth P: Selective extradural anterior clinoidectomy for supra- and parasellar processes. Technical note. J Neurosurg. 87(4):636-642, 1997

Yonekawa Y, Imhof HG, Taub E, Curcic M, Kaku Y, Roth P, Wieser HG, Groscurth P: Supracerebellar transtentorial approach to posterior temporomedia structures. J Neurosurg. 94(2):339-345, 2001

Yonekawa Y, Kaku Y, Imhof HG, Kiss M, Curcic M, Taub E, Roth P: Posterior circulation aneurysms. Technical strategies based on angiographic anatomical findings and the results of 60 recent consecutive cases. Acta Neurochir. 72(Suppl):123-140, 1999.

Yonekawa Y, Frick R, Roth P, Taub E, Imhof HG:

Laboratory Training in Microsurgical Techniques and Microvascular Anastomosis. Operative Techniques in Neurosurgery. 2(3):149-158, 1999.

Yonekawa Y, Roth P, Fandino J, Landlot H: Aneurysms of the posterior cerebral artery and approach selection in their microsurgical treatment: Emphasis an their approaches: SAHEA and SCTA. Acta Neurochir. 112(Suppl):85-92, 2011
Zador Z, Lu DC, Arnold CM, Lawton MT: Deep bypasses to the distal posterior circulation: anatomical and clinical comparison of pretemporal and subtemporal approaches. Neurosurgery. 66:92-100, 2010.

Zeal AA, Rhoton AL: Microsurgical anatomy of the posterior cerebral artery. J Neurosurg. 48:534-559, 1978.

Zhitao J, Yibao W, Anhua W, Shaowu O, Yunchao B, Renyi Z, Yunjie W: Microsurgical subtemporal approachtoaneurysms on the $P$ 2segment of theposteriorcerebralartery. Neurol India. 58:242-247, 2010.
Zhou Q, Zhang M, Jiang Y: Intraoperative oculomotor nerve monitoring predicts outcome following clipping of posterior communicating artery aneurysms. J Clin Neurosci. 19:706-711, 2012 
Department of Neurosurgery, Helsinki University Central Hospital, Helsinki, Finland

Department of Neurosurgery, Stroke Center, Bergmannstrost Hospital, Halle, Germany

Department of Neurosurgery, Kuopio University Hospital, Kuopio, Finland

Dr. med. Felix Göhre (corresponding author)

Department of Neurosurgery,

Helsinki University Hospital,

University of Helsinki,

Topeliuksenkatu 5 ,

00260 Helsinki, Finland

Layout, typography and production:

VERLAG JANOS STEKOVICS

Straße des Friedens 10, 06193 Wettin-Löbejün OT Dößel

Telefon: (03 46 07) 21088

Fax: $(034607) 21203$

E-Mail: steko@steko.net

www.steko.net

2016, VERLAG JANOS STEKOVICS

ISBN 978-3-89923-356-8 (gebundene Ausgabe)

ISBN 978-3-89923-357-5 (PDF)

All rights reserved. No part of this Publication may be reproduced or transmitted in any electronic or mechanical manner whatsoever without permission in writing from the Publisher. 